\title{
Geração de referências espaciais em ambientes interativos tridimensionais
}

São Paulo

15 de Julho de 2013 
Diego dos Santos Silva

\section{Geração de referências espaciais em ambientes interativos tridimensionais}

Dissertação apresentada como parte da avaliação do programa de mestrado em Sistemas de Informação EACH - Escola de Artes, Ciências e Humanidades. Mestrado em Ciências.

Orientador: Prof. Dr. Ivandré Paraboni

Versão corrigida

São Paulo

15 de Julho de 2013 
Autorizo a reprodução e divulgação total ou parcial deste trabalho, por qualquer meio convencional ou eletrônico, para fins de estudo e pesquisa, desde que citada à fonte.

\section{CATALOGAÇÃO-NA-PUBLICAÇÃO \\ Biblioteca}

Escola de Artes, Ciências e Humanidades da Universidade de São Paulo

Silva, Diego dos Santos

Geração de referências espaciais em ambientes interativos tridimensionais / Diego dos Santos Silva ; orientador Ivandré Paraboni - São Paulo, 2013.

93 f. : il.

Dissertação (Mestrado em Ciências) - Programa de PósGraduação em Sistemas de Informação, Escola de Artes, Ciências e Humanidades, Universidade de São Paulo, em 2013. Versão corrigida.

1. Inteligência artificial. 2. Relações espaciais. 3. GER. I. Paraboni, Ivandré, orient. II. Título.

CDD 22.ed. - 006.3 
Dissertação sob o título "Geração de referências espaciais em ambientes interativos tridimensionais ", defendida por Diego dos Santos Silva e aprovada em 05 de Setembro de 2013, em São Paulo, Estado de São Paulo, pela banca examinadora constituída pelos doutores:

Prof. Dr. Ivandré Paraboni

Orientador

Prof. Dr. Norton Trevisan Roman

Universidade de São Paulo / EACH

Prof. Dr. Thiago Alexandre Salgueiro

Pardo

Universidade de São Paulo / ICMC 
Dedico e agradeço a minha noiva Aline Buiati que me ajudou durante todos estes anos com paciência, amor e motivação. Dedico também ao meu irmão Darwin pela parceria e amizade, e aos meus pais Marcia e Jair que sempre me apoiaram e acreditaram em mim. 
Agradeço ao meu orientador Ivandré Paraboni por toda paciência e dedicação a este trabalho por todos esses anos, sem ele nada disso seria possível. 
Acredite, corra atrás, a única coisa que existe entre você e o seu sonho é o seu medo.

(Roger Stankewski) 


\section{Resumo}

A geração de expressão de referência $(G E R)$ é um dos principais componentes de aplicações de geração de língua natural a partir de dados não linguísticos. Trabalhos existentes nesta área tendem a se concentrar em domínios bidimensionais e tridimensionais simples. Domínios mais realistas, entretanto, ainda são pouco explorados pela literatura, possivelmente pela dificuldade em produzir modelos computacionais com o grau de complexidade exigido. O recente surgimento de aplicações baseadas em ambientes interativos tridimensionais, todavia, oferece uma ampla gama de oportunidades de pesquisa em GER. Nesse trabalho apresentamos um algoritmo de GER para seleção de atributos espaciais em ambientes interativos tridimensionais do tipo GIVE. A solução proposta é uma extensão de um algoritmo de GER tradicional que utiliza relações espaciais combinado com conhecimento linguístico extraído de corpora e modelos computacionais de referência espacial. Essa solução foi avaliada de forma intrínseca no domínio de instruções em mundos virtuais. 


\section{Abstract}

Referring expressions generation $(R E G)$ is one of the main components in the generation of Natural Language from non-linguistic data. Existing work in the field tends to focus on simple two- or three-dimensional domains. More realistic domains, however, are still little investigated, possibly due to the difficulties in producing computational models with the required degree of complexity. The recent rise of applications based on three-dimensional interactive environments, however, offers a wide range of research opportunities in $R E G$. In this work we present a $R E G$ algorithm for selecting spatial attributes in three-dimensional interactive environments GIVE. The proposed solution is an extension of a traditional REG algorithm that makes use of spatial relations combined with linguistic knowledge extracted from corpora and computational models of spatial reference. The proposal was evaluated intrinsically in the domain of instructions generation in virtual worlds. 


\section{Sumário}

Lista de Figuras $\quad$ x

Lista de Tabelas $\quad$ xi

1 Introdução 1

2 O problema computacional da geração de relações espaciais $\quad 4$

2.1 A abordagem básica de GER: o algoritmo Incremental . . . . . . . . . 4

2.2 O uso de relações espaciais em GER . . . . . . . . . . . . . . . 6

3 Revisão bibliográfica $\quad 11$

3.1 Extensões do algoritmo Incremental . . . . . . . . . . . . . . . . . . 11

3.1 .1 O uso de propriedades relacionais . . . . . . . . . . . . 11

3.1.2 Gerações de expressões de referência sensíveis ao contexto . . . . . . 12

3.1.3 O algoritmo de GER baseado em grafos . . . . . . . . . . . . . 14

3.2 Gerações de referências espaciais em GIVE . . . . . . . . . . . . . 16

3.2.1 Algoritmos de GER desenvolvidos para o ambiente GIVE . . . . . 18

3.3 Gerações de expressões de referência utilizando relações espaciais . . . . . . 22

3.3.1 Relações espaciais em ambientes dinâmicos . . . . . . . . . . . . 22

3.3.2 Relações espaciais em contexto ampliado . . . . . . . . . . . . . . 24

3.3.3 Referência geográfica utilizando relações espaciais para previsões do

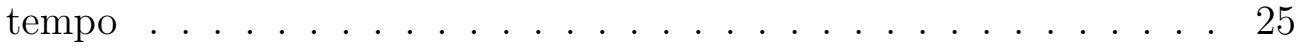

3.3.4 Gerações de expressões de referência com propriedades relacionais e a construção dos corpora GRE3D e GRE3D'7 . . . . . . . . . . . 27 
3.3.5 Padrões de uso de relações espaciais . . . . . . . . . . . . . . . . . . 31

3.3.6 Modelos computacionais de referência espacial . . . . . . . . . . . 32

4 Trabalho realizado $\quad 36$

4.1 Preparação de Dados . . . . . . . . . . . . . . . . . . . . . 36

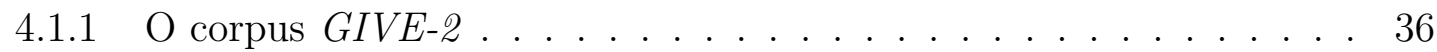

4.1.2 Extração de informações do domínio GIVE . . . . . . . . . . . 38

4.1.3 Extração de expressões de referência . . . . . . . . . . . . . . . 38

4.1.4 Conjuntos de treinamento e teste . . . . . . . . . . . . . . . . . 40

4.2 A solução proposta . . . . . . . . . . . . . . . . . . . . . . . . 42

4.2.1 Extração de propriedades espaciais a partir do domínio . . . . . . . 43

4.2 .2 Classificação de pontos de referência . . . . . . . . . . . . . . . 45

4.2 .3 Seleção da relação espacial preferencial . . . . . . . . . . . . . . . 50

4.2.4 Geração de expressões de referência com uso de relações espaciais 52

5 Avaliação $\quad 54$

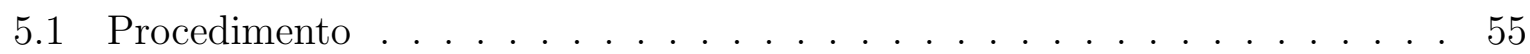

5.2 Resultados . . . . . . . . . . . . . . . . . . . . 58

5.2 .1 Módulos de extração e classificação . . . . . . . . . . . . . . . . . . 58

5.2 .2 Módulos de seleção e GER . . . . . . . . . . . . . . . . . . 59

5.2.3 Comparação entre pares de algoritmos . . . . . . . . . . . . . . 60

5.2.4 Comparação entre grupos de algoritmos . . . . . . . . . . . . . . 61

5.2.5 Comparação com algoritmo sem classificador . . . . . . . . . . . . . 62

5.3 Discussão . . . . . . . . . . . . . . . . . . . . . . . . . 62

5.4 Análise de Erros . . . . . . . . . . . . . . . . . . . . . . 64

6 Conclusões $\quad 66$

6.1 Contribuições . . . . . . . . . . . . . . . . . . . 66 
6.2 Limitações . . . . . . . . . . . . . . . . . . . . . . . . . . . 67

6.3 Trabalhos futuros . . . . . . . . . . . . . . . . . . . . 68

Apêndice A - Exemplo de representação XML do corpus GIVE-2

Apêndice B - Resultado da avaliação intrínseca

Referências 


\section{Lista de Figuras}

1 Exemplo de uma cena do ambiente GIVE (Byron et al., 2007). . . . . . . . 2

2 Exemplo de contexto. . . . . . . . . . . . . . . . . 5

3 Referência a $\mathrm{r}=\mathrm{b} 1$ como "o botão vermelho" . . . . . . . . . . . . . . . 7

4 Referência a $\mathrm{r}=\mathrm{b} 1$ como "o botão vermelho à esquerda do botão azul". . . 8

5 Referência a $\mathrm{r}=\mathrm{b} 3$ como "o botão vermelho à direita do botão vermelho à direita do botão azul". . . . . . . . . . . . . . . . . . . . . 8

6 Referência a r=b3 como "o botão vermelho à direita do botão azul". . . . 9

$7 \quad$ Exemplo de contexto adaptado de Krahmer, Erk e Verleg (2003) . . . . . . 14

8 Grafo rotulado da cena da Figura 7 adaptado de Krahmer, Erk e Verleg

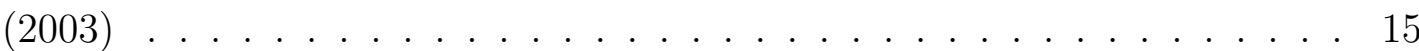

9 Exemplo de uma cena do GIVE extraída de Byron et al. (2007). . . . . . 17

10 Exemplo de uma cena com 3 botões adaptado de Schutte e Dethlefs (2010) 19

11 Exemplo de uma cena com 9 botões adaptado de Schutte e Dethlefs (2010) 19

12 Exemplo adaptado de Schutte e Dethlefs (2010) . . . . . . . . . . . . 20

13 Exemplo de uma cena do ambiente GIVE. Akkersdijk et al. (2011). . . . . 21

14 Exemplo de uma cena utilizada no experimento em Dale e Viethen (2009). 28

15 Cena apresentada no corpus em Viethen e Dale (2011). . . . . . . . . . . . 30

16 Hierarquia de relações espaciais proposta em Kelleher e Costello (2009) . . 33

17 Interface da ferramenta "Replay" em Gargett et al. (2010) . . . . . . . . . . 37

18 Arquitetura proposta . . . . . . . . . . . . . . . . . 42

19 Exemplo de contexto extraído do sistema GIVE. . . . . . . . . . . 45

20 Árvore de decisão induzida. . . . . . . . . . . . . . . . . . . . 48 


\section{Lista de Tabelas}

1 Propriedades do contexto da Figura $3 \ldots \ldots \ldots$. . . . . . . . . . 7

2 Propriedades do contexto da Figura $4 \ldots \ldots \ldots$

3 Propriedades do contexto da Figura $5 \ldots \ldots \ldots$

4 Propriedades do contexto da Figura $6 \ldots \ldots$. . . . . . . . . . . . 9

5 Propriedades atômicas e demais informações extraídas dos três mundos GIVE utilizados na construção do corpus GIVE-2 (Gargett et al., 2010) . 38

6 Propriedades relacionais extraídas das descrições de objetos do tipo 'botão' existentes no corpus GIVE-2 (Gargett et al., 2010) . . . . . . . . . . . 39

7 Uso de relações espaciais no corpus GIVE-2 (Gargett et al., 2010) . . . . . 40

8 Propriedades computadas a partir do contexto da Figura 19 . . . . . . . . 44

$9 \quad$ Atributos de aprendizagem da classe use_relation . . . . . . . . . . . . . 46

10 Matriz de confusão para classe binária use_relation cf. figura 20. . . . . . . 48

11 Resultados da indução do classificador . . . . . . . . . . . . . . . . . . . . 49

12 Instâncias utilizadas no classificador . . . . . . . . . . . . . . . . 50

13 Frequência de atributos observados no conjunto de treinamento. . . . . . . 52

14 Exemplos de descrições para os objetos da figura 19 . . . . . . . . . . . 53

15 Variações consideradas para fins de avaliação . . . . . . . . . . . . . 56

16 Matriz confusão do classificador descrito no algoritmo na seção 4.2 .2 para os dados do conjunto de teste. . . . . . . . . . . . . . . . . . 59

17 Resultados da classificação do conjunto de teste. . . . . . . . . . . . . . . 59

18 Resultados resumidos (10 maiores coeficientes Dice) . . . . . . . . . . . 59

19 Comparação do algoritmo \#23 (seleção proposta, ordenação por frequência, prioridade padrão e papel discriminatório) com suas contrapartidas. . . . . 61 
20 Comparação dos valores médios de Dice a Acurácia por grupo de algoritmos 61

21 Resultado da avaliação sem classificador (algoritmo \#55) . . . . . . . . . . 62

22 Resultados ............................. 71 


\section{Introdução}

Sistemas de Geração de Língua Natural $(G L N)$ convertem informações tipicamente não linguísticas em língua compreensível pelo ser humano (Reiter e Dale, 2000). Sistemas de GLN possuem uma ampla gama de aplicações diretas de geração automática de documentos (Paraboni e Deemter, 1999; Paraboni, 2000; Paraboni e Deemter, 2002b, 2002a), e são potencialmente aplicáveis a várias outras tarefas como simplificação textual (Aluísio et al., 2008), tradução automática (Aziz, Pardo e Paraboni, 2008, 2009), sumarização (Filho e Pardo, 2007) etc.

Um dos componentes centrais de um sistema de $G L N$ é a tarefa computacional da Geração de Expressões de Referência $(G E R)$. Exemplos de expressões de referência incluem o uso de pronomes (e.g., "ele"), descrições definidas (e.g., "o irmão de Maria") nomes próprios (e.g., "Pedro") e outros.

A tarefa de GER consiste em produzir descrições não-ambíguas de objetos do discurso (e.g., pessoas, objetos, eventos etc.) para que estes possam ser corretamente identificados pelo ouvinte. Nesse trabalho, enfocamos o caso específico de primeira menção a entidades utilizando descrições definidas, que em $G L N$ caracteriza o problema de seleção de conteúdo (ou atributos) de expressões de referência (Krahmer e Deemter, 2012). Não será tratada a questão da interpretação destas expressões (Paraboni, 1997; Cuevas e Paraboni, 2008) nem sua realização superficial em uma determinada língua-alvo (Pereira e Paraboni, 2007; Santos, Pereira e Paraboni, 2008; Pereira e Paraboni, 2008; Novais e Paraboni, 2012).

É normalmente esperado que uma expressão de referência seja de fácil compreensão e livre de ambiguidade, de modo que o objeto-alvo (ou referente) possa ser identificado pelo ouvinte sem dificuldades. O problema computacional de GER consiste assim em determinar quais propriedades semânticas do objeto-alvo devem ser selecionadas para constituir a expressão resultante de tal forma que esta expressão descreva apenas o objeto-alvo e nenhum outro objeto do contexto. Além disso, algoritmos de GER geralmente procuram evitar a inclusão de mais atributos do que o estritamente necessário para desambiguação, 
evitando assim falsas considerações lógicas (Grice, 1975).

Muitos dos algoritmos de GER existentes tendem a se concentrar em domínios visuais bidimensionais (Dale e Haddock, 1991; Horacek, 1997; Gardent, 2002; Krahmer e Theune, 2002; Varges, 2004; Krahmer, Erk e Verleg, 2003; Paraboni, Masthoff e Deemter, 2006; Paraboni, Deemter e Masthoff, 2007; Lucena, Pereira e Paraboni, 2010; Paraboni, 2003), ou tridimensionais simplificados (Viethen e Dale, 2008; Dale e Viethen, 2009; Viethen e Dale, 2011; Kelleher e Kruijff, 2006; Zender, Kruijff e Kruijff-Korbayová, 2009). Domínios mais realistas, entretanto, ainda são pouco explorados pela literatura em GER, possivelmente pela dificuldade em se produzir modelos computacionais com o grau de complexidade exigido.

Em anos recentes, entretanto, o surgimento de aplicações baseadas em ambientes interativos tridimensionais (ou "mundos virtuais") passou a oferecer uma ampla gama de novas oportunidades de pesquisa em GER. Domínios deste tipo são significativamente mais complexos do que os tipicamente considerados na pesquisa da área, mas ainda assim com um grau de complexidade reduzida se comparado ao caso de referência no mundo real. O exemplo de domínio interativo tridimensional a ser considerado neste trabalho é o mundo virtual fornecido pelo ambiente GIVE (Byron et al., 2007) ilustrado na figura 1.

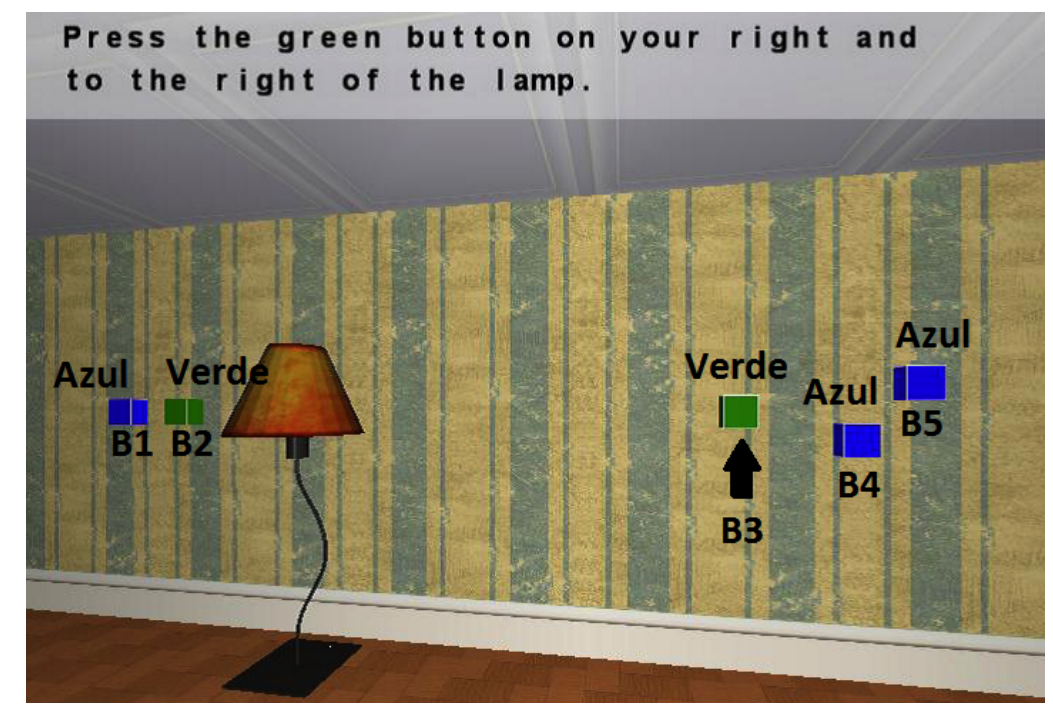

Figura 1 - Exemplo de uma cena do ambiente GIVE (Byron et al., 2007).

O uso de relações espaciais em GER apresenta, no entanto, uma série de desafios computacionais não totalmente tratados pelos algoritmos existentes. O uso de relações espaciais pode simplificar a tarefa de identificação do objeto-alvo, como em "o homem ao lado da porta", mas pode também torná-la mais complexa se, por exemplo, o objeto usado como ponto de referência (no exemplo, a porta) for de difícil identificação (Paraboni 
e Deemter, 2013).

O presente trabalho trata do estudo do problema computacional da geração de expressões de referência contendo relações espaciais para fins de identificação do objeto-alvo, enfocando apenas a tarefa de seleção de conteúdo destas expressões em domínios espaciais do tipo GIVE (Byron et al., 2007). Para este fim, serão consideradas apenas as relações espaciais entre dois objetos do domínio, como em "o botão ao lado da caixa", desconsiderando-se os casos de relação entre um objeto e os participantes do discurso, como em "o botão à sua esquerda". Para um dado objeto-alvo que se deseja descrever com uso de um ponto de referência auxiliar $x$, as relações espaciais consideradas são $\operatorname{acima}(x)$, abaixo(x), à_esquerda_de(x), $\grave{a}_{-} d i r e i t a_{-} d e(x), \grave{a}_{-} f r e n t e(x)$ e atrás $(x)$.

A solução proposta é uma extensão do algoritmo Incremental (Dale e Reiter, 1995) que faz uso de propriedades relacionais e objetiva tomar decisões adequadas (do ponto de vista humano) sobre a seleção de atributos espaciais para uso discriminatório, combinando conhecimento linguístico extraído dos corpora GRE3D (Viethen, 2010) e GIVE-2 (Gargett et al., 2010) e os modelos computacionais em Kelleher e Costello (2009). O resultado final é um algoritmo de GER que faz uso fundamentado de propriedades espaciais e traz uma série de contribuições teóricas para a área, em especial no que diz respeito a quando e como referenciar este tipo de propriedade.

Este trabalho está organizado da seguinte forma: o capítulo 2 apresenta o problema computacional de geração de relações espaciais, apresentando a abordagem básica de GER com o algoritmo Incremental de Dale e Reiter (1995) e o uso de relações espaciais. O capítulo 3 apresenta uma revisão bibliográfica que aborda as variações do algoritmo Incremental (Dale e Reiter, 1995), algoritmos de GER que utilizam relações espaciais, e a geração de expressões de referência no ambiente GIVE (Byron et al., 2007). O capítulo 4 aborda questões de extração de propriedades espaciais a partir de um domínio, a preparação e a utilização do corpus GIVE-2 (Gargett et al., 2010) e o sistema desenvolvido que atende os objetivos e as hipóteses deste trabalho. E por último o capítulo 5 mostra os resultados da pesquisa em detalhes. 


\section{O problema computacional da geração de relações espaciais}

Neste capítulo será apresentada uma visão geral do problema computacional de GER utilizando como base o algoritmo Incremental de Dale e Reiter (1995), bem como a problemática da inclusão de relações espaciais em expressões de referência.

\subsection{A abordagem básica de $G E R$ : o algoritmo Incre- mental}

Nesta seção são definidos conceitos básicos de GER utilizando-se para fins ilustrativos o algoritmo Incremental proposto em Dale e Reiter (1995), que é um dos algoritmos mais conhecidos na área, e que ajudou a definir o próprio problema computacional de GER.

O algoritmo Incremental recebe como entrada um contexto $C$ formado por um grupo de objetos, o objeto-alvo ou referente $r$ que se deseja descrever, e suas propriedades semânticas na forma de pares (atributo, valor), como em (cor, azul).

O objetivo do algoritmo é produzir um conjunto $L$ de propriedades de $r$ tal que $L$ seja capaz de distinguir $r$ de todos os outros objetos em $C$. As propriedades são incluídas em $L$ incrementalmente (de onde provém o nome do algoritmo) segundo uma ordem $P$ predefinida, desde que contribuam para a desambiguação do referente (i.e., excluindo pelo menos um objeto do contexto $C$ ). O algoritmo termina quando um conjunto único (i.e., livre de ambiguidade) de propriedades for produzido (caso em que $L$ poderia ser realizada, por exemplo, como uma descrição definida), ou até que todas as propriedades possíveis em $P$ tenham sido consideradas (caso em que $L$ permaneceria ambígua e poderia ser realizada, por exemplo, como uma descrição indefinida).

Considere-se o exemplo da figura 2, ilustrando um contexto composto por três objetos: dois cachorros (um pequeno e outro grande, tendo o cachorro grande a cor branca e o 
cachorro pequeno a cor preta), e um gato de tamanho pequeno e cor preta.

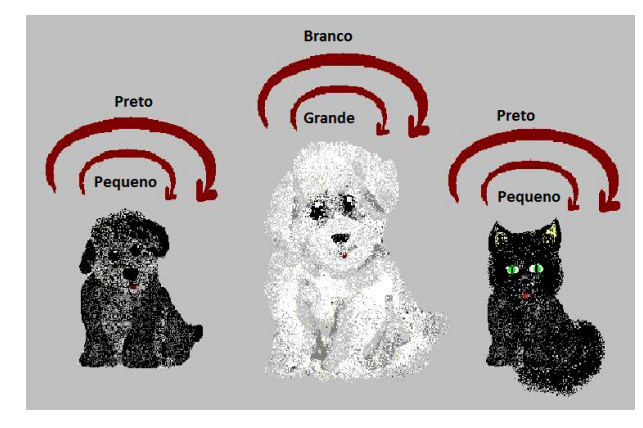

Figura 2-Exemplo de contexto.

Este contexto pode ser representado da seguinte forma.

- Obj1: (tipo, cachorro), (tamanho, pequeno), (cor, preto).

- Obj2: (tipo, cachorro), (tamanho, grande), (cor, branco).

- Obj3: (tipo, gato), (tamanho, pequeno), (cor, preto).

Seja o objeto-alvo $r=$ Obj1, o contexto $C=\{$ Obj2, Obj3\}, e a ordem preferencial de propriedades a serem consideradas $P=\{$ tipo, cor, tamanho $\}$, o algoritmo inicia com uma lista $L$ vazia e percorre $P$ na ordem estabelecida, inserindo em $L$ cada propriedade que exclua pelo menos um objeto em $C$. Neste exemplo, o algoritmo escolhe inicialmente a propriedade (tipo, cachorro) por excluir Obj3, que é tipo gato. A seguir (na ordem em $P$ ), a propriedade (cor, preto) exclui Obj2, que é de cor branca. Como o contexto $C$ não possui mais elementos, o algoritmo retorna a lista $L$, que poderia ser realizada, por exemplo, como "o cachorro preto".

A ordem preferencial de seleção de atributos da lista $P$ tem grande impacto sobre o tipo de expressão produzida pelo algoritmo. Por exemplo, se fosse considerada a ordem $P$ $=\{$ tipo, tamanho, cor $\}$ para o domínio acima, a mesma referência a Obj1 seria "o cachorro pequeno".

Em obediência à máxima de brevidade de Grice (Grice, 1975), algoritmos de GER tendem a favorecer a seleção de atributos discriminatórios. Em anos recentes, no entanto, passaram a ser consideradas também questões como a naturalidade da expressão (ou humanlikeness em Belz e Gatt (2007)), dentre muitos outros objetivos desejáveis. Uma visão geral da área de GER e seus principais desafios é apresentada em Krahmer e Deemter (2012). 
Por razões de complexidade computacional, o algoritmo Incremental (Dale e Reiter, 1995) não realiza backtracking após ter incluído uma propriedade, ou seja, não remove qualquer propriedade que já tenha sido inclusa na expressão $L$ mesmo que outra propriedade incluída posteriormente a tenha tornado redundante. Além disso, o atributo tipo é incluído na expressão $L$ mesmo que não seja discriminatório, já que é realizado tipicamente como núcleo de sintagma nominal (e.g., um substantivo).

Em Dale e Reiter (1995) sugere-se que o algoritmo Incremental esteja próximo do comportamento humano já que humanos também incluem informações redundantes em suas expressões de referência, e que não necessariamente levam a falsas inferências sobre a entidade referida. Em Dale e Reiter (1995) sugere-se que criar um algoritmo que faça a distinção entre as entidades do contexto gerando expressões mínimas talvez seja uma tarefa desnecessária, ou seja, um algoritmo com desempenho próximo ao humano é preferível a um algoritmo que gera uma expressão totalmente livre de redundância.

Na proposta original, o algoritmo Incremental manipula apenas propriedades atômicas, mas com adaptações a serem discutidas na seção 4.2.4, pode também ser aplicado ao caso de propriedades relacionais. Esta modificação é de especial importância para o uso de relações espaciais de que trata este trabalho, como em acima(o), no qual o é um objeto usado como ponto de referência para a descrição de um objeto-alvo $r$.

\subsection{O uso de relações espaciais em $G E R$}

Relações espaciais, assim como quaisquer outras propriedades semânticas, podem ser empregadas para desambiguação de um determinado objeto-alvo em ambientes interativos tridimensionais como GIVE (Byron et al., 2007). Em situações deste tipo, entretanto, é comum haver uma grande variedade de alternativas disponíveis (por exemplo, um objeto pode estar ao lado de outro e acima de um terceiro), e a escolha de qual propriedade referenciar traz consequências importantes para sua interpretação.

O conhecimento sobre como selecionar atributos espaciais de maneira criteriosa, ou sobre como combiná-los na forma de uma expressão de referência adequada do ponto de vista do leitor humano é escasso na literatura em GER. Para ilustrar esta questão, apresentamos a seguir uma série de situações de referência em que a tarefa de seleção de atributos espaciais apresentam desafios desta natureza. Nos exemplos discutidos, tomaremos por base um algoritmo de GER capaz de lidar com propriedades atômicas e relacionais segundo uma ordem de preferência $P$ como segue. Um algoritmo deste tipo 
será proposto na seção 4.2.4.

$P=t i p o$, cor, $\grave{a}_{-} d i r e i t a_{-} d e(x), \grave{a}_{-} e s q u e r d a_{-} d e(x), a_{c i m a} d e(x)$, abaixo_de $(x), \grave{a}_{-} f r e n t e(x)$ e $\operatorname{atrás}(x)$

Considere o exemplo da Figura 3 a seguir, no qual a entidade $b 1$ é o alvo da referência, e suas propriedades atômicas e relacionais na Tabela 1.

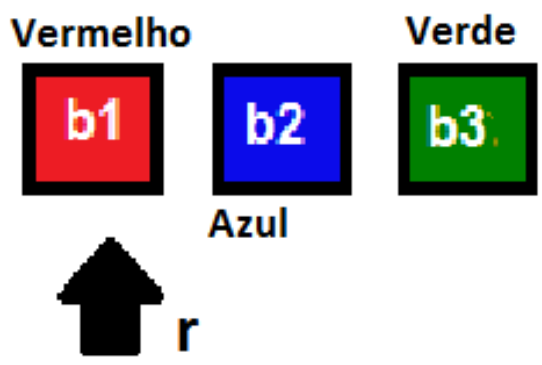

Figura 3 - Referência a r=b1 como "o botão vermelho".

Tabela 1 - Propriedades do contexto da Figura 3

\begin{tabular}{cccl}
\hline Entidade & Tipo & Cor & Propriedades Relacionais \\
\hline b1 & botão & vermelho & à_esquerda_de(b2), à_esquerda_de(b3) \\
b2 & botão & azul & à_direita_de(b1), à_esquerda_de(b3) \\
b3 & botão & verde & à_direita_de(b2), à_direita_de(b1) \\
\hline
\end{tabular}

Devido ao fato de que propriedades atômicas tem precedência sobre propriedades relacionais em $P$, o resultado do algoritmo é uma expressão relativamente simples, como "o botão vermelho". Essa, em princípio, pode ser considerada uma forma adequada de referenciar o objeto b1. Por outro lado, caso a propriedade relacional à_esquerda_de(b2) tivesse prioridade maior, a descrição poderia se tornar desnecessariamente longa, como em "o botão à esquerda do botão à esquerda do botão verde".

Este exemplo parece confirmar pressupostos adotados em trabalhos como Dale e Haddock (1991), segundo os quais propriedades atômicas possuem tratamento prioritário, e propriedades relacionais são consideradas apenas quando o uso de propriedades atômicas não é suficiente para desambiguação. Por outro lado, este mesmo exemplo contradiz os resultados de Viethen e Dale (2011), que sugere que o uso de relações espaciais redundantes é comum mesmo quando o uso da relação não é necessário para desambiguar o referente.

Considere-se agora o exemplo da Figura 4, supondo-se ainda b1 como alvo da referência, e as propriedades na Tabela 2. 


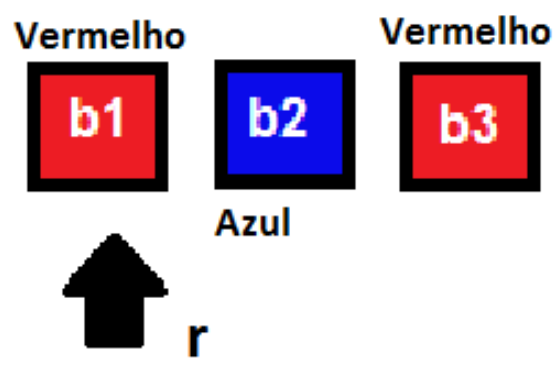

Figura 4 - Referência a r=b1 como "o botão vermelho à esquerda do botão azul".

Tabela 2 - Propriedades do contexto da Figura 4

\begin{tabular}{cccl}
\hline Entidade & Tipo & Cor & Propriedades Relacionais \\
\hline b1 & botão & vermelho & à_esquerda_de(b2), à_esquerda_de(b3) \\
b2 & botão & azul & à_direita_de(b1), à_esquerda_de(b3) \\
b3 & botão & vermelho & à_direita_de(b2), à_direita_de(b1) \\
\hline
\end{tabular}

Neste exemplo, a descrição de $b 1$ seria realizada como "o botão vermelho à esquerda do botão azul". Entretanto, caso as propriedades relacionais como à_esquerda_de(b2) tivessem maior prioridade do que propriedades atômicas como cor, o resultado seria uma expressão ainda mais simples, como "o botão à esquerda do botão azul". A diferença entre estas alternativas é sutil, e não há sugestão de que uma seja necessariamente "melhor" do que a outra (seja qual for o critério adotado para este fim), mas este exemplo - contrário ao anterior - reforça a visão adotada em Dale e Viethen (2009) de que relações espaciais nem sempre são apenas uma estratégia de referência secundária ou menos comum do que o uso de propriedades atômicas.

Considere agora o exemplo da Figura 5 que inclui, além de botões, um objeto maior do tipo lâmpada, tendo como alvo o objeto b3, e as propriedades da Tabela 3.

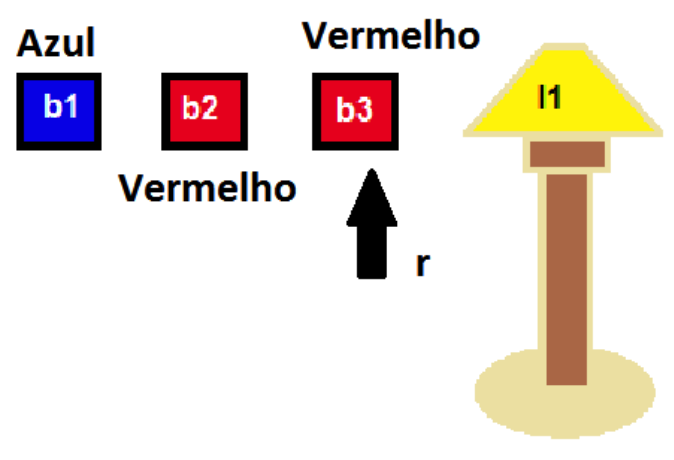

Figura 5 - Referência a $r=b 3$ como "o botão vermelho à direita do botão vermelho à direita do botão azul". 
Tabela 3 - Propriedades do contexto da Figura 5

\begin{tabular}{cccl}
\hline Entidade & Tipo & Cor & Propriedades Relacionais \\
\hline b1 & botão & azul & à_esquerda_de(b2), à_esquerda_de(b3), à_esquerda_de(l1) \\
b2 & botão & vermelho & à_direita_de(b1), à_esquerda_de(b3), à_esquerda_de(11) \\
b3 & botão & vermelho & à_direita_de(b1), à_direita_de(b2), à_esquerda_de(l1) \\
$\mathbf{1 1}$ & lâmpada & & à_direita_de(b1), à_direita_de(b2), à_direita_de(b3) \\
\hline
\end{tabular}

A saída esperada para este exemplo usando-se a lista $P$ na ordem padrão seria uma expressão como "o botão vermelho à direita do botão vermelho à direita do botão azul". Como no exemplo anterior, neste caso a preferência por propriedades relacionais também teria possibilitado uma descrição ligeiramente mais simples, como "o botão à direita do botão vermelho à direita do botão azul". No entanto, priorizando-se a relação à_direita_de(l1), o resultado seria ainda mais simples, como em "o botão à esquerda da lâmpada".

Esse exemplo ilustra que mesmo havendo uma ordem definida para uso de propriedades atômicas e relacionais, ainda resta o problema de como ordenar estas propriedades relacionais na lista de preferências $P$. Em especial, a combinação de objetos menos salientes (e.g., botões) e outros de maior saliência (como a lâmpada no exemplo anterior) apresenta uma série de desafios adicionais. Considere-se o exemplo da Figura 6, tendo como alvo o objeto b3, e as propriedades da Tabela 4.

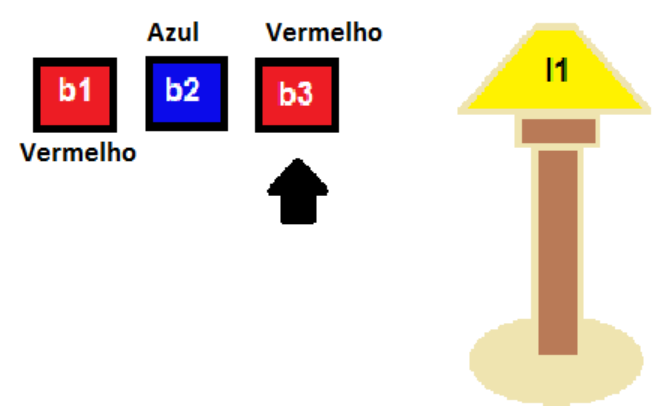

Figura $\boldsymbol{6}$ - Referência a $r=b 3$ como "o botão vermelho à direita do botão azul".

Tabela 4 - Propriedades do contexto da Figura 6

\begin{tabular}{cccl}
\hline Entidade & Tipo & Cor & Propriedades Relacionais \\
\hline b1 & botão & vermelho & à_esquerda_de(b2), à_esquerda_de(b3), à_esquerda_de(l1) \\
b2 & botão & azul & à_direita_de(b1), à_esquerda_de(b3), à_esquerda_de(l1) \\
b3 & botão & vermelho & à_direita_de(b1), à_direita_de(b2), à_esquerda_de(11) \\
11 & lâmpada & - & à_direita_de(b1), à_direita_de(b2), à_direita_de(b3) \\
\hline
\end{tabular}

A expressão de referência para o alvo $b 3$ depende da ordem exata das propriedades 
à_direita_de(b2) e $\grave{a}_{-} e s q u e r d a \_d e(l 1)$ em $P$. E poderia ser por exemplo tanto "o botão vermelho à direita do botão azul" ou "o botão vermelho à esquerda da lâmpada". É possível que neste caso ambas as alternativas sejam igualmente aceitáveis, mas considerando-se que este contexto apresenta um objeto de maior saliência visual (i.e., a lâmpada l1), é plausível que este objeto seja mais adequado como ponto de referência, e que portanto a referência à lâmpada seja preferível. Nota-se ainda que é discutível se a existência de um ponto de referência deste tipo não deveria ter precedência até mesmo sobre a propriedade atômica cor, resultando simplesmente em "o botão à esquerda da lâmpada".

Apesar da aparente vantagem em fazer uso de um ponto de referência como neste exemplo, abordagens de GER existentes não costumam distinguir entre objetos mais ou menos salientes, conhecimento este que provavelmente seria útil à geração destas expressões. Por outro lado, isso não significa que o uso de objetos salientes como pontos de referência deva ser sempre preferível. Por exemplo, caso houvesse uma segunda lâmpada ao lado de $l 1$, o benefício deste tipo de estratégia de referência seria menos evidente, pois o algoritmo usado como exemplo produziria uma expressão como "o botão vermelho à esquerda da lâmpada à esquerda da lâmpada" ${ }^{1}$.

Estes exemplos ilustram apenas alguns dos problemas de seleção de atributos espaciais típicos de um ambiente GIVE ou similar, e que não contam com uma solução algorítmica completa disponível na literatura da área de GER até o presente momento.

\footnotetext{
${ }^{1} \mathrm{O}$ algoritmo em Dale e Haddock (1991) neste caso produziria uma expressão mais breve, como "o botão vermelho à esquerda da lâmpada". Por não se preocupar em desambiguar a referência à lâmpada, no entanto, esta solução pode ser problemática em certos domínios espaciais (Paraboni, Deemter e Masthoff, 2007).
} 


\section{$3 \quad$ Revisão bibliográfica}

GER é uma ativa linha de pesquisa em $G L N$, tendo inclusive sido tema de três competições recentes de algoritmos de seleção de conteúdo tipo (Belz e Gatt, 2007; Gatt, Belz e Kow, 2008, 2009). Como linha de pesquisa, o problema computacional de GER é investigado pelo menos desde os anos 1980 (Appelt, 1985), e consolidou-se como linha de pesquisa especialmente a partir da proposta do algoritmo Incremental (Dale e Reiter, 1995), ainda hoje uma das maiores influências na área.

Este capítulo descreve o estudo inicial de uma série de abordagens para geração de expressões de referência com foco no uso de relações espaciais, com a contextualização das principais técnicas utilizadas e sua possível relação com a presente pesquisa e algumas de suas variações. Na seção 3.1 são descritas algumas extensões do algoritmo Incremental (Dale e Reiter, 1995) discutido no capítulo anterior; a seção 3.2 descreve algoritmos de GER no contexto do sistema GIVE (Byron et al., 2007), e na seção 3.3 são descritas técnicas de geração de expressão de referência utilizando relações espaciais.

\subsection{Extensões do algoritmo Incremental}

Esta seção é dedicada a apresentar alguns dos principais trabalhos relacionados ao algoritmo Incremental (Dale e Reiter, 1995), e propostas de soluções de problemas originalmente não abordados por este.

\subsubsection{O uso de propriedades relacionais}

O foco do trabalho em Dale e Haddock (1991) é a proposta de um algoritmo básico de GER utilizando relações, como em "O copo sobre a mesa". Em especial, o algoritmo em Dale e Haddock (1991) trata dos problemas da recursividade infinita de relações (e.g., "o copo sobre a mesa que sustenta um copo que...") e evita o uso de informação redundante permitindo que uma entidade auxilie na desambiguação de outra (e.g., "o copo sobre a 
mesa" em um contexto com vários copos e mesas, porém apenas uma mesa sustentando um copo).

A solução proposta para estes problemas é a criação uma rede de consistências para determinar quais propriedades já foram referenciadas, e que considera o poder discriminatório global da expressão gerada. Por exemplo, supondo-se um objeto-alvo $x$ do tipo mesa, e entidades $a, b$ e $c$ diretamente relacionados a ela, a lista das propriedades relacionais de $x$ poderia ser representada como $P x=a c i m a \_d e(a), a c i m a \_d e(b)$, abaixo_de(c).

O algoritmo produz a referência do objeto-alvo $x$ da seguinte forma: primeiramente, é escolhida uma propriedade relacional de forma aleatória entre as entidades e o alvo; caso esta propriedade não seja suficiente para gerar uma expressão não ambígua, esta entidade e a relação entre o alvo são inseridas na expressão de referência, e a entidade relacionada é inserida na rede de consistência. Caso contrário, é produzida a expressão atual e o algoritmo finaliza.

A seguir, é escolhida uma nova relação envolvendo outra entidade. Antes de verificar se é possível utilizá-la na expressão de referência, o algoritmo verifica se a entidade já está presente na rede de consistência. Em caso afirmativo, a relação escolhida é descartada. Este procedimento é repetido até que a expressão (completa) representada na rede permita identificar o objeto-alvo de modo não ambíguo, ou até que todas as entidades tenham sido incluídas na rede de consistência. O procedimento para decidir a ordem das relações a ser considerada pelo algoritmo não é descrito em Dale e Haddock (1991).

Do ponto de vista do presente trabalho, o algoritmo de Dale e Haddock (1991) é útil por tratar do problema de recursividade infinita e por fazer uso de propriedades relacionais semelhantes às referências espaciais a serem abordadas.

\subsubsection{Gerações de expressões de referência sensíveis ao contexto}

Em Krahmer e Theune (2002) é acrescentado ao algoritmo Incremental (Dale e Reiter, 1995) o conceito de saliência relativa de entidades. Saliência, neste caso, é uma medida que define quanto um determinado objeto se sobressai em relação aos demais no contexto em que está inserido. Segundo Krahmer e Theune (2002) esta noção de saliência pode ser interpretada tanto em temas visuais (saliência física ou visual) quanto discursivas. Em Krahmer e Theune (2002) argumenta-se que é possível fazer referência a um objeto-alvo com um número reduzido de propriedades sem necessidade de distinguir este objeto de todos os outros no contexto, mas apenas dos objetos com saliência igual ou maior a ele 
próprio.

Suponha-se um cenário com diversas caixas de cores diferentes, e todas inicialmente com a mesma saliência relativa. Neste exemplo, suponha-se que uma caixa é referenciada pela primeira vez pela expressão "A caixa branca", o que incrementa sua saliência relativa neste contexto. Depois disso, se o mesmo objeto é referenciado novamente, então não é necessário distingui-lo de todos os objetos no contexto, mas somente dos objetos com saliência igual ou superior a dele. Como neste caso nenhum outro objeto teve seu peso de saliência elevado (pois nenhum deles foi referenciado ainda), a caixa branca possui maior saliência do que todas as demais caixas, e pode então ser referenciada apenas como "a caixa" ou mesmo "ela".

A escolha do tipo de expressão dependeria do número de objetos que precisam ser levados em conta, ou seja, do número de objetos com saliência igual ou superior a saliência do objeto-alvo. Caso a saliência de todos os objetos do contexto seja a mesma, o algoritmo proposto em Krahmer e Theune (2002) terá o mesmo comportamento do algoritmo Incremental proposto em Dale e Reiter (1995) .

O algoritmo proposto em Krahmer e Theune (2002) cria uma estrutura do tipo árvore na qual as entidades são distribuídas de acordo com seus pesos de saliência. Quanto menor o valor de saliência de uma entidade, menor será sua posição hierárquica na árvore. A cada nova referência a uma entidade, o algoritmo aumenta seu peso de saliência e sua posição hierárquica.

Existem várias formas de definir saliência para fins de referência utilizando-se este algoritmo. A título de exemplo, em Krahmer e Theune (2002) são apresentadas duas interpretações possíveis para o conceito de saliência discursiva baseadas na teoria de Centering (Walker, 1998). Na primeira delas, a saliência das entidades vai sendo decrementada ao longo do discurso, enquanto que na segunda a saliência é reduzida a zero tão logo uma entidade deixe de ser mencionada na expressão seguinte.

Estas interpretações não serão entretanto discutidas no presente trabalho, que não tratará do problema de referência a objetos do discurso, mas sim a objetos em um contexto físico. O conceito de saliência tratada em Krahmer e Theune (2002) é ainda assim potencialmente útil para o presente trabalho dada sua possível analogia com a questão da saliência física. Além disso, o algoritmo em Krahmer e Theune (2002) também gera certos tipos de propriedades relacionais semelhantes às investigadas no presente trabalho. 


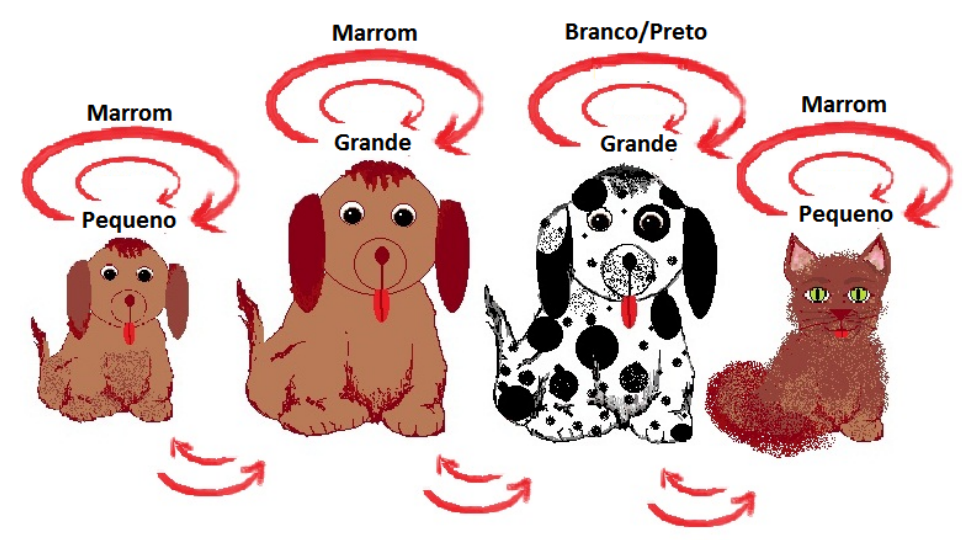

Figura 7 - Exemplo de contexto adaptado de Krahmer, Erk e Verleg (2003)

\subsubsection{O algoritmo de $G E R$ baseado em grafos}

Em Krahmer, Erk e Verleg (2003) é descrita uma implementação alternativa do problema de geração de expressões de referência que modela o contexto como um grafo rotulado e direcionado. Neste modelo, os vértices $V$ são entidades, e as arestas $A$ são propriedades atômicas (laços) e relacionais (arestas ligando vértices distintos).

Dado um grafo $(V, A)$ e um objeto-alvo $r$, o objetivo do algoritmo é criar um subgrafo que defina um conjunto de propriedades distintivas de $r$ (i.e., arestas relacionadas ao objeto-alvo $r$ ) que devem ser incluídas em uma expressão de referência. Isso é obtido com uso de algoritmos tradicionais da Teoria de Grafos conforme Krahmer, Erk e Verleg (2003).

O algoritmo baseado em Grafos implementa a política de seleção de atributos na forma de uma função de custo que direciona o percurso na estrutura. O custo da inclusão de cada propriedade pode assim ser configurado para cada situação com maior flexibilidade do que no caso da lista preferencial $P$ do algoritmo Incremental (Dale e Reiter, 1995), o que possibilita a implementação de abordagens comuns que utilizam regras para a seleção de atributos, incluindo o próprio algoritmo Incremental e outros.

Na figura 7 é apresentado um exemplo de contexto que pode ser representado pelo grafo rotulado da figura 8, no qual os vértices são os animais (no exemplo, três cachorros e um gato) e as arestas são propriedades atômicas (cores, tamanhos etc.) ou relacionais (posição relativa etc.). Cada aresta seria também associada a um custo determinado pela função adjacente (não exibido).

O algoritmo funciona da seguinte forma. Dado um grafo $G$ representando o contexto e 


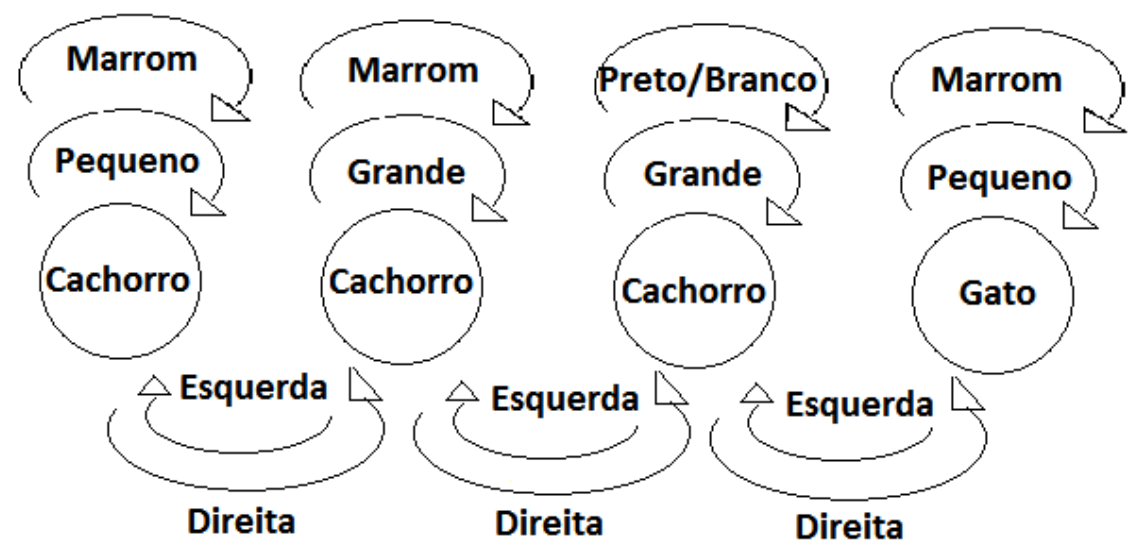

Figura 8 - Grafo rotulado da cena da Figura 7 adaptado de Krahmer, Erk e Verleg (2003)

uma entidade-alvo $r$ a ser identificada, é feita a busca do tipo Branch-and-Bound (Lawler e Wood, 1966) por um subgrafo $H$ que contenha o vértice $r$ e um conjunto de arestas rotuladas que não se aplique a nenhum outro vértice, ou seja, constituindo uma expressão livre de ambiguidade. Esta condição é implementada com uso de um algoritmo de teste de isomorfismo em grafos. Mais especificamente, o subgrafo $H$ inicia com a inclusão do vértice $r$ e expande recursivamente a seleção de arestas de acordo com seu custo (determinado pela função de custo implementada). A cada nova inclusão, seja ela uma propriedade atômica da entidade ou uma propriedade relacional, o algoritmo verifica se não existe nenhum outro grafo isomorfo a $H$ em nenhum outro vértice do grafo principal $G$, ou seja, verifica se $H$ é único.

Considere, por exemplo, a cena da Figura 8 tendo como entidade-alvo o cachorro marrom de tamanho grande, e considere que o custo de inclusão das propriedades tamanho, cor e relação espacial sejam respectivamente 1, 2 e 3. O algoritmo inicia verificando qual a aresta de menor custo de $r$. Esta aresta é selecionada e inserida no subgrafo $H$. É verificado então se existe algum grafo isomorfo a $H$. Se não houver, o algoritmo encerra retornando o subgrafo $H$. Caso contrário, repete-se o procedimento escolhendo outra aresta, até que seja encontrado um subgrafo $H$ não isomorfo a nenhum outro grafo.

No exemplo da Figura 8, a aresta inicial é o tamanho dos animais, e o subgrafo gerado é isomorfo, ou seja, possui outro subgrafo exatamente igual, uma vez que o cachorro preto e branco possui o mesmo valor para esta propriedade. Enquanto o subgrafo $H$ não for único, o algoritmo continua buscando e incluindo novas arestas de acordo com seus pesos, até retornar o subgrafo único com o menor custo para fazer distinção da entidade-alvo. 
Caso não encontre uma solução, o algoritmo retorna um subgrafo nulo.

O custo de cada subgrafo é definido por pesos associados a cada aresta selecionada. As funções de custo servem para orientar o processo de busca e dar preferência a algumas soluções sobre outras. Por exemplo, para reproduzir o comportamento do algoritmo Incremental em (Dale e Reiter, 1995) bastaria atribuir um custo menor às arestas que definem as propriedades mais utilizadas no domínio, como por exemplo, cor, tamanho etc. Segundo a ordem $P$ usada no algoritmo, quanto maior a preferência por um atributo, menor seu custo.

Em Krahmer, Erk e Verleg (2003) é afirmado que uma das vantagens desta implementação é a disponibilidade de muitos algoritmos eficientes para lidar com estruturas de grafos. Além disso, o fato de podermos manipular as funções de custo facilita a reprodução e estudo de diversos algoritmos existentes, mostrando-se um caminho para futuras pesquisas na área.

\subsection{Gerações de referências espaciais em GIVE}

GIVE (Generating Instructions in Virtual Environments) (Byron et al., 2007) é uma plataforma construída para prover uma nova abordagem de avaliação de sistemas de $G L N$, utilizada até o momento em três competições da área (ou shared tasks) da série GIVE Challenge (Byron et al., 2009; Koller et al., 2010; Striegnitz et al., 2011). Nestas competições, participaram sistemas de $G L N$ de várias instituições internacionais de pesquisa, os quais foram disponibilizados on-line através de servidores do projeto, e avaliados por usuários de várias partes do mundo.

A plataforma GIVE oferece aos desenvolvedores de sistemas de GLN um ambiente gráfico 3D interativo, encarregando-se de fazer a comunicação entre este ambiente e o sistema de $G L N$, além de tomar conta de várias outras tarefas de apoio ao teste e avaliação do mesmo. O desenvolvedor de GLN pode assim concentrar-se apenas no seu sistema, e fazer uso da plataforma para desenvolver rapidamente uma aplicação de teste. Uma cena exemplo da plataforma GIVE extraída de Byron et al. (2007) pode ser observada na figura 9.

O usuário final no sistema GIVE é um jogador de uma caça ao tesouro que deve percorrer um labirinto acionando botões que podem prover diversas funções como abrir e fechar portas de acesso ou ativar e desativar alarmes. Além de botões manipuláveis, um ambiente GIVE inclui também objetos maiores como peças de mobília e outros. Estes 


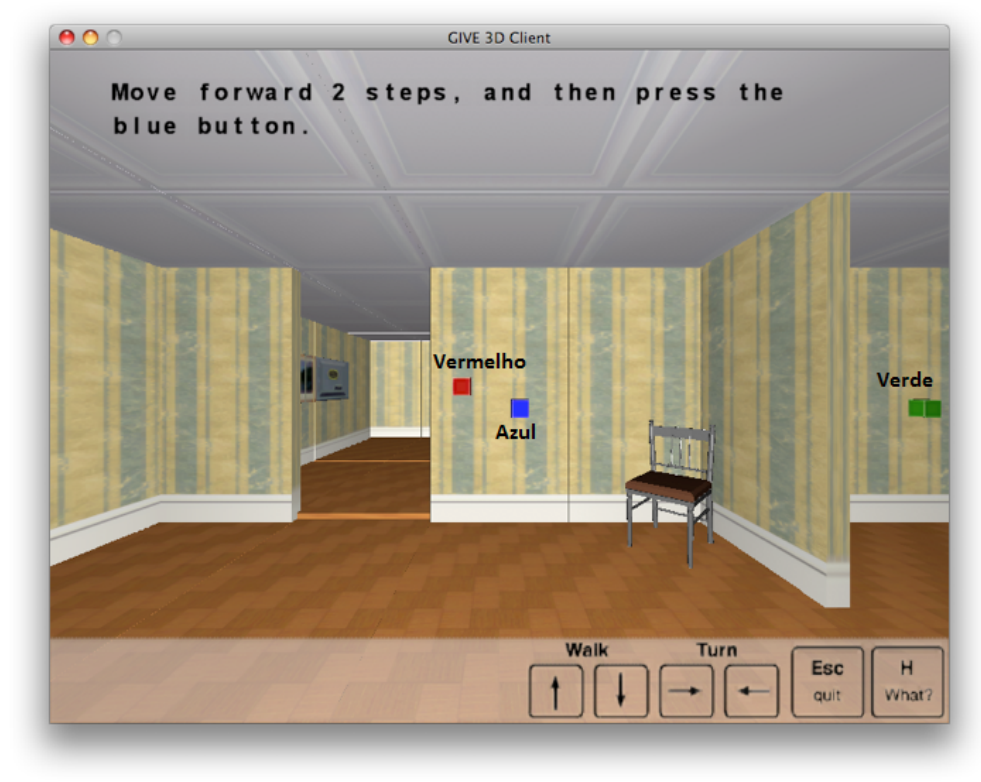

Figura 9 - Exemplo de uma cena do GIVE extraída de Byron et al. (2007).

objetos podem, a critério do desenvolvedor do sistema, ser aproveitados para auxiliar o jogador a cumprir a tarefa. Por exemplo, um sistema poderia implementar um algoritmo de GER que faz uso de pontos de referência como em "o botão vermelho ao lado da porta" para auxiliar a navegação. O uso de pontos de referência não é, entretanto, um recurso nativo do sistema GIVE.

Desenvolvedores podem criar seus próprios sistemas de $G L N$ e deixar a cargo do sistema GIVE o controle dos movimentos do usuário, ações e tempos de execução. A plataforma também fornece ferramentas de manipulação deste ambiente, com as quais o desenvolvedor tem a liberdade de configurar o mundo virtual da maneira que desejar. $\mathrm{O}$ ambiente GIVE utiliza uma ferramenta de planejamento para estipular os passos que o jogador deve executar do início do jogo até o objetivo final, e então retorna este plano para que seja usado pelo sistema de GLN da forma que cada desenvolvedor achar conveniente. O plano consiste de uma série de passos de baixa granularidade como movimentar-se de uma posição para outra, ou acionar botões. Cabe ao sistema de $G L N$ subjacente decidir como agregar estes passos em objetivos mais gerais, e transformá-los em instruções linguísticas a serem apresentadas ao jogador.

O componente de GER na plataforma GIVE é uma implementação do algoritmo proposto em Areces, Figueira e Gorín (2011) que utiliza técnicas de lógica computacional para produzir descrições livres de ambiguidade. Nesta abordagem, não há controle sobre quais atributos serão selecionados, e não há garantia de que a descrição gerada seja mínima 
(i.e., livre de redundância). Os atributos considerados são do tipo atômico como tipo e cor, mas alguns dos algoritmos de GER desenvolvidos para a série GIVE Challenge (Byron et al., 2009; Koller et al., 2010; Striegnitz et al., 2011) apresentam recursos adicionais, como o uso de relações espaciais. Os quatro exemplos de algoritmos deste tipo que são mais relevantes para o presente trabalho são discutidos a seguir.

\subsubsection{Algoritmos de GER desenvolvidos para o ambiente GIVE}

Em Braunias et al. (2010), a geração de expressões de referência inclui a propriedade cor em todas as expressões geradas, mesmo que estas não excluam nenhuma entidade do contexto. Relações espaciais são usadas ao fazer referência a entidades de um mesmo grupo, definido como um conjunto de entidades que possuem o mesmo valor para uma das coordenadas $x, y$ ou $z$, e cuja diferença entre as demais coordenadas seja inferior a um valor constante $d$.

Por exemplo, sejam três botões com as respectivas coordenadas $x, y, z b 1(1,2,3)$, b2 $(1,2.2,2.7)$ e $63(1,1.9,2.9)$. Estes botões fazem parte de um grupo se a constante $d$ for igual a 0,3 , e acima deste valor não são considerados visualmente relacionáveis. Um botão $b 4(1,2,4)$, por exemplo, não pode fazer parte deste grupo, pois não estaria suficientemente próximo para formar uma percepção de conjunto.

Em Braunias et al. (2010), as relações espaciais entre entidades de um mesmo grupo são computadas comparando-se suas coordenadas. As relações consideradas são: acima, esquerda, direita, meio, centro e fundo. Estas relações podem ser utilizadas também em conjunto, dependendo da quantidade de objetos em um mesmo grupo. Por exemplo, se um grupo contém quatro botões em uma mesma linha e na mesma altura, e deseja-se fazer referência ao terceiro botão da esquerda para a direita, pode-se gerar uma expressão como "O botão centralizado, à direta".

Um segundo algoritmo de GER desenvolvido para a plataforma GIVE, e que também produz alguns tipos de referências espaciais é apresentado em Schutte e Dethlefs (2010). Mesmo não detalhado-se o funcionamento deste algoritmo, algumas ideias em Schutte e Dethlefs (2010) são potencialmente úteis para o presente trabalho. Por exemplo, suponha que se deseja descrever o botão $a$ na Figura 10 e o botão $c$ na Figura 11 (ambas adaptadas de Schutte e Dethlefs (2010)). Na primeira situação, o algoritmo geraria uma descrição como "o primeiro botão da esquerda", e na segunda produzirá "o primeiro botão de cima para baixo e o terceiro botão da esquerda para direita". 


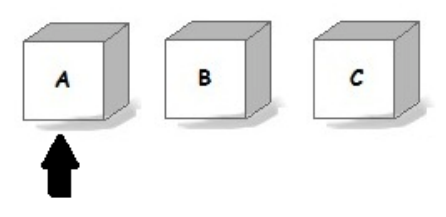

Figura 10 - Exemplo de uma cena com 3 botões adaptado de Schutte e Dethlefs (2010)

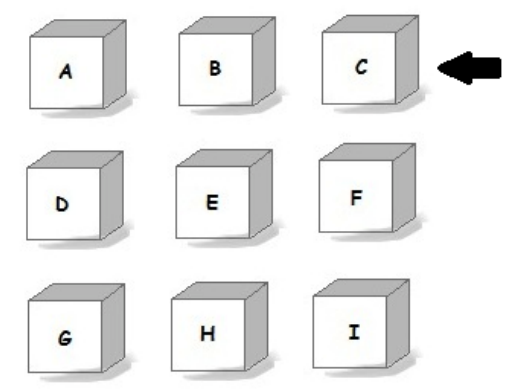

Figura 11 - Exemplo de uma cena com 9 botões adaptado de Schutte e Dethlefs (2010)

Em Schutte e Dethlefs (2010) são propostas duas abordagens para geração de expressões de referência, ambas explorando o modo pelo qual o usuário navega pelo ambiente GIVE. A descrição gerada utiliza uma relação espacial entre entidades caso não seja possível identificar qual ação deve ser tomada de uma maneira mais simples. Por exemplo, caso o usuário tenha que de atravessar uma porta, e no campo de visão dele existam duas portas, o algoritmo não pode gerar uma expressão do tipo "Passe pela porta". Neste caso o algoritmo verifica se existe alguma entidade que possa ser utilizada para servir de referência para a porta correta. Se existir um botão vermelho entre as duas portas, por exemplo, o algoritmo utiliza este botão como referência, produzindo instruções como "atravesse a porta à esquerda do botão vermelho".

Em situações de manipulação de entidades do tipo botão, os algoritmos propostos em Schutte e Dethlefs (2010) seguem duas estratégias distintas, denominadas P1 e P2. A Figura 12, adaptada de Schutte e Dethlefs (2010) será utilizada para demonstrar como os dois algoritmos se comportam nestas situações, dado o objetivo de referenciar o botão azul $B 4$ à direita do botão vermelho $B 3$.

Neste exemplo, a estratégia $P 1$ geraria uma instrução como "pressione o botão à direita do botão vermelho", enquanto que a estratégia $P \mathscr{2}$ geraria uma instrução do tipo "pressione o botão à direita do botão que está à direita do botão verde".

Ambas estratégias propõem uma solução válida, porém $P 1$ inclui entidades que estão mais próximas do alvo, enquanto que $P 2$ utiliza o contexto visual do usuário e faz re- 


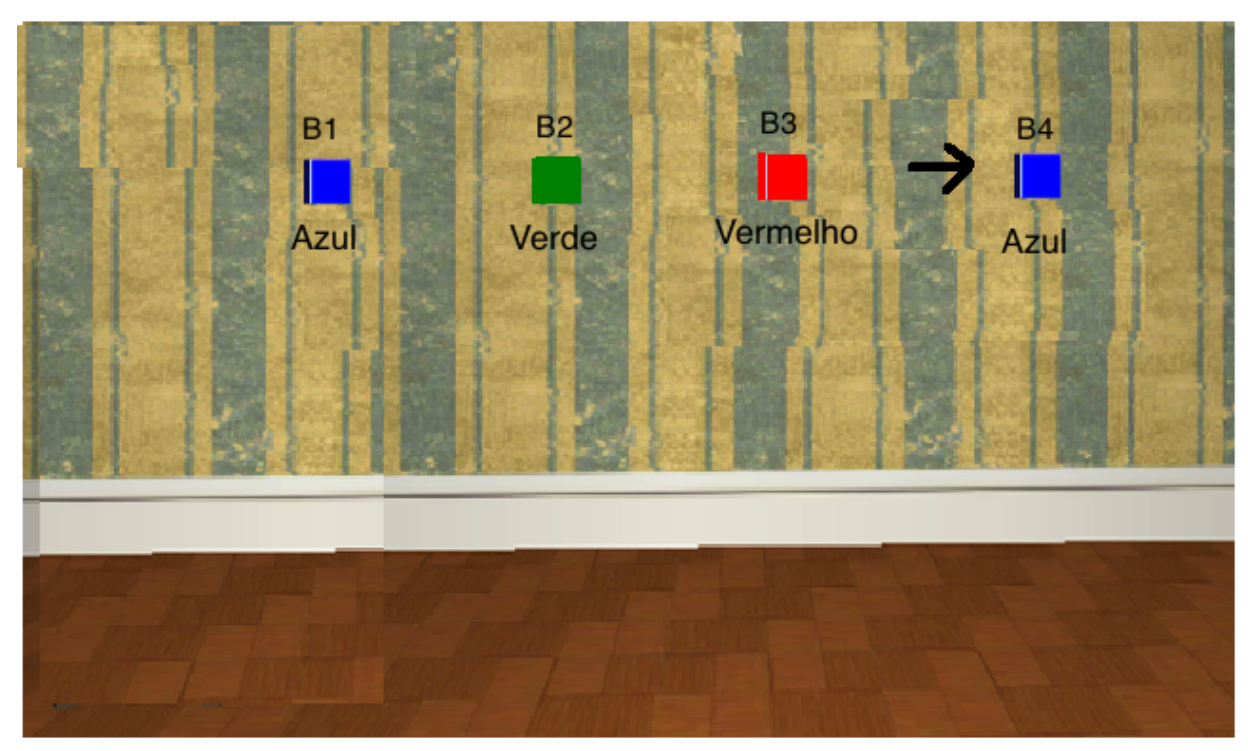

Figura 12 - Exemplo adaptado de Schutte e Dethlefs (2010).

ferência a partir da entidade que está mais próxima dele. Em geral, os resultados em Schutte e Dethlefs (2010) mostraram que a estratégia P1 saiu-se melhor do que P2. De acordo com os próprios usuários, $P 1$ teria gerado instruções mais claras do que $P 2$.

Finalmente, o trabalho em Akkersdijk et al. (2011) propõe uma abordagem de GER na qual as expressões geradas procuram ser as mais breves possíveis. Segundo Akkersdijk et al. (2011), variar muito o número de palavras torna a leitura da instrução mais difícil, aumentando a dificuldade de navegação do usuário GIVE. As instruções para pressionar um botão usam dois métodos distintos, em ambos os casos utilizando a cor do botão mesmo que ela não seja estritamente necessária para a identificação do alvo. Em Akkersdijk et al. (2011) é argumentado que isso previne possíveis confusões e que, além disso, seres humanos normalmente são redundantes em suas descrições.

O primeiro método para gerar expressões de referência é denominado SimpleREG. Este método procura por pontos de referência próximos ao alvo, e nunca inclui mais de um ponto de referência na expressão gerada. Segundo Akkersdijk et al. (2011), estas expressões podem se tornar extensas e potencialmente confusas.

Os pontos de referência são escolhidos de acordo com a proximidade destes em relação ao alvo. Já botões são usados como pontos de referência somente se estes não causarem nenhum tipo de ambiguidade, ou seja, o algoritmo utiliza como ponto de referência uma entidade inequívoca sempre que possível. 
A posição do alvo em relação ao ouvinte também é considerada no momento de gerar as expressões. Como pode ser visto no exemplo da Figura 13, a expressão gerada em Akkersdijk et al. (2011) para o objeto-alvo $r$ foi "o botão verde $B 3$ à sua direita e à direita da lâmpada $L 1 "$.

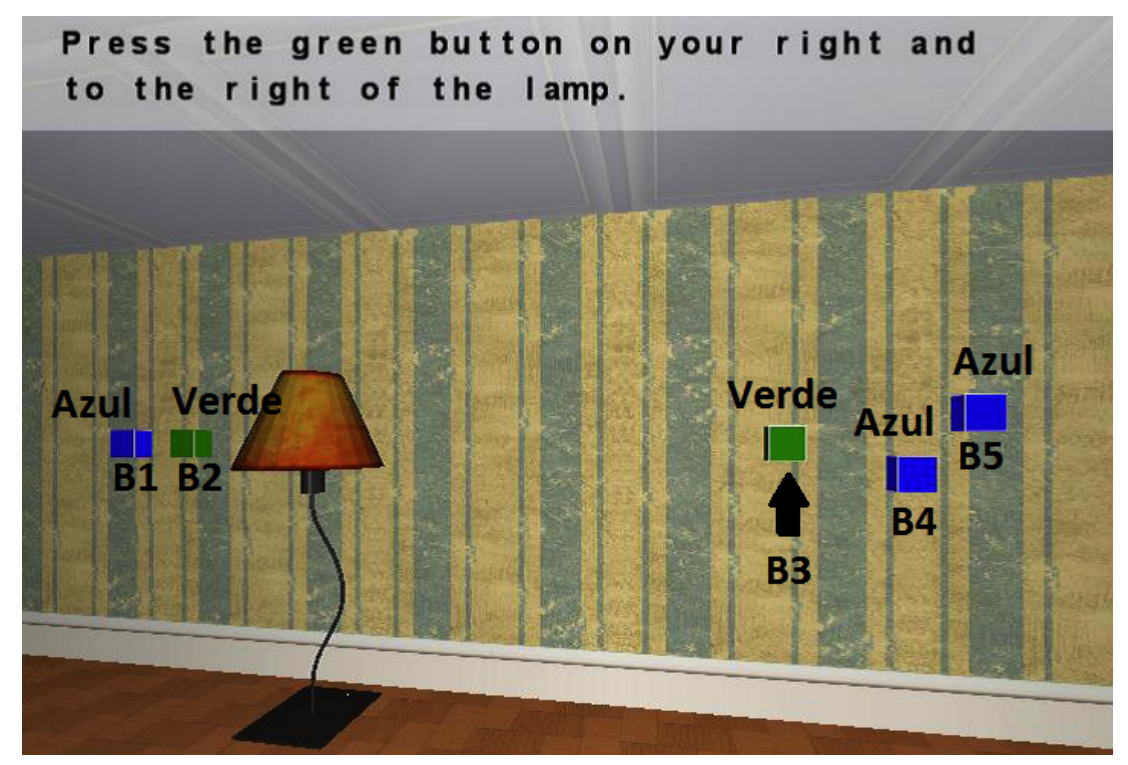

Figura 13 - Exemplo de uma cena do ambiente GIVE. Akkersdijk et al. (2011).

O segundo método para gerar expressões de referência em Akkersdijk et al. (2011) é denominado GridREG. Este algoritmo cria uma matriz de todos os botões do contexto visual, e verifica a quantidade de botões da esquerda para a direita e de cima para baixo. Este algoritmo segue a mesma ideia proposta em Schutte e Dethlefs (2010) para o exemplo da Figura 11.

O critério de qual dos dois algoritmos será utilizado depende do número de botões visíveis que tenham a mesma cor que o botão alvo. O algoritmo SimpleREG é utilizado em situações simples, na qual o alvo tem a mesma cor de apenas um outro botão no campo de visão do usuário. Já o algoritmo GridREG é utilizado em situações na qual existe mais de um botão com a mesma cor que o alvo.

Os trabalhos apresentados até aqui são os algoritmos diretamente mais relevantes para o presente trabalho. Entretanto, como estes sistemas foram avaliados apenas deforma extrínseca (i.e., medindo-se o desempenho global de usuários GIVE na tarefa de navegação) não é possível distinguir o eventual impacto do uso de relações espaciais das outras funcionalidades de cada sistema, as quais incluem, por exemplo, um grande número de melhorias não relacionadas à tarefa de GER. Desta forma, estes estudos permanecem apenas como exemplos de tratamento do problema. 


\subsection{Gerações de expressões de referência utilizando relações espaciais}

A geração de expressões de referência usando relações espaciais é o foco principal deste estudo. No decorrer desta seção serão revisados alguns trabalhos que abordam esta questão de forma mais específica.

\subsubsection{Relações espaciais em ambientes dinâmicos}

O trabalho apresentado em Kelleher e Kruijff (2006) tem o objetivo de modelar o comportamento de um robô capaz de se comunicar com pessoas de uma maneira natural e fluente. Em Kelleher e Kruijff (2006) sugere-se que trabalhos prévios em GER tratam de relações espaciais apenas de forma estática. Segundo Kelleher e Kruijff (2006), algoritmos como (Dale e Haddock, 1991; Horacek, 1997; Gardent, 2002; Krahmer e Theune, 2002; Varges, 2004) não são aplicáveis para o caso de um robô que se locomove em ambientes dinâmicos, onde as relações espaciais passíveis de referência sofrem mudanças constantes.

Gerar expressões de referência em contextos dinâmicos requer grande poder de processamento. A cada nova referência, o algoritmo terá de fazer a comparação de todas as entidades entre si e analisar suas relações novamente. Em Kelleher e Kruijff (2006) são citadas pesquisas da área de psicologia que afirmam que relações espaciais não são simples de serem observadas pelo ouvinte, e que esta percepção requer muita atenção.

O algoritmo proposto em Kelleher e Kruijff (2006) é uma extensão do algoritmo Incremental em Dale e Reiter (1995), com suporte à saliência visual e de discurso. A saliência visual é estimada pelos algoritmos apresentados em Kelleher e Genabith (2004), e a saliência de discurso determinada segundo a teoria em Hajičová (1993). A construção do contexto é determinada pela separação de entidades que podem ou não servir como ponto de referência para relações. No início, todas as entidades possuem o mesmo grau de saliência, e no decorrer da execução determinadas entidades aumentam ou diminuem este valor.

Somente as entidades que podem ser referenciadas utilizando-se relações espaciais são utilizadas no algoritmo. Por exemplo, em um contexto em que tenha uma bola ao lado de um cachorro, ambas entidades podem ser referenciadas utilizando-se uma relação espacial do tipo ao lado de. No entanto, caso exista uma segunda bola mais distante das demais entidades, esta não poderá ser referenciada utilizando-se uma relação espacial, pois não é 
uma relação clara para o ouvinte.

As relações espaciais entre os pontos de referência e o objeto-alvo são incluídas em uma lista ordenada de acordo com critérios derivados de estudos em ciência cognitiva estabelecidos em Bryant, Tversky e Franklin (1992) e Gapp (1995). Estes critérios estabelecem, por exemplo, que as relações acima_de(x) e abaixo_de(x) são mais facilmente perceptíveis do que as relações $a_{-} f r e n t e(x)$ e atrás $(x)$, que por sua vez são mais facilmente perceptíveis do que as relações $\grave{a}_{-} d i r e i t a_{-} d e(x)$ e $\grave{a}_{-} e s q u e r d a_{-} d e(x)$.

Em Kelleher e Kruijff (2006), os pontos de referência considerados podem estar em uma de cinco categorias: o falante, o ouvinte, a cena em questão, uma entidade na cena ou um grupo de entidades na cena. Entretanto, há ainda pouca evidência científica de qual ordem de preferência deva ser considerada em um expressão de referência. Entre as categorias ouvinte e falante seriam intuitivamente mais fáceis de identificar devido ao fato de o ouvinte saber sua própria posição e normalmente também conhecer a posição do falante (Kelleher e Kruijff, 2006).

O algoritmo em Kelleher e Kruijff (2006) inicia utilizando o algoritmo Incremental de Dale e Reiter (1995) para descrever a entidade-alvo. Se não obtiver sucesso, o contexto é então dividido em três partes: entidade-alvo, candidatos a pontos de referência (que são as entidades que podem ser referenciadas utilizando-se relações espaciais com a entidadealvo) e demais entidades do contexto (que não são passíveis de referência por meio de relações espaciais perceptíveis pelo ouvinte). Em seguida, é computada a lista de relações espaciais existentes entre a entidade-alvo e os pontos de referência, e esta lista é ordenada de acordo com as propostas de preferência de relações espaciais em Bryant, Tversky e Franklin (1992).

A seguir, o algoritmo itera sobre a lista de relações espaciais e verifica se a relação do alvo com o ponto de referência é suficiente para gerar uma expressão de referência livre de ambiguidade. Caso não seja suficiente, o algoritmo utiliza o próximo elemento da lista, ou seja, outro ponto de referência. Por exemplo, caso a expressão "o livro sobre a mesa" não seja suficiente para gerar uma expressão não ambígua da entidade-alvo, ou o algoritmo utiliza a relação com outro ponto de referência (e.g., "o livro ao lado direito da caneta azul"), ou utiliza relações entre dois pontos de referência (e.g., "o livro sobre a mesa ao lado do sofá"). Para evitar recursividade infinita de relações entre entidades, o algoritmo limita a quantidade de entidades que podem ser utilizadas na descrição gerada.

Do ponto de vista do presente trabalho, o estudo em Kelleher e Kruijff (2006) é relevante por apresentar uma proposta de como modelar a preferência por propriedades 
espaciais, e por fornecer uma forma alternativa de tratar o problema de recursividade infinita já tratada em Dale e Haddock (1991). Além disso, é abordada também a questão da geração de expressões de referência envolvendo mais de uma entidade. Alguns aspectos desta proposta serão consideradas no algoritmo proposto na seção 4.2.4.

\subsubsection{Relações espaciais em contexto ampliado}

Em Zender, Kruijff e Kruijff-Korbayová (2009) é proposto um algoritmo que segue a mesma abordagem de Kelleher e Kruijff (2006) para geração de expressão de referência em ambientes dinâmicos. O foco do trabalho em Zender, Kruijff e Kruijff-Korbayová (2009), entretanto, é gerar expressões de referência em contextos ampliados, e não apenas no contexto no qual esteja o ouvinte (ou seja, levando-se em consideração todas as entidades do domínio, inclusive as entidades fora do campo de visão do ouvinte). Segundo Zender, Kruijff e Kruijff-Korbayová (2009), isso seria desejável, por exemplo, em aplicações nas quais um robô deve locomover-se em um ambiente mais complexo, necessitando fazer referência a entidades fora do contexto imediato. Da mesma forma que em Kelleher e Kruijff (2006), as propriedades referenciáveis são dinâmicas e computadas em tempo de execução, sofrendo alteração a cada modificação do contexto.

O algoritmo em Zender, Kruijff e Kruijff-Korbayová (2009) inicia fazendo um levantamento das propriedades atômicas e relacionais de todas as entidades existentes no universo no qual o robô irá se locomover. Por exemplo, dado um contexto com dois livros e uma mesa, "o livro vermelho" e "o livro sobre a mesa" são representados da seguinte maneira:

- Entidade1: (tipo, livro), (cor, vermelho), (sobre, Entidade2)

- Entidade2: (tipo, mesa)

No passo seguinte, é criado um modelo dos ambientes nos quais estas entidades estão localizadas. No exemplo dado, se o livro vermelho estiver localizado em uma biblioteca, o modelo seria representado da seguinte maneira:

Contexto: (Biblioteca, $(($ Entidade1), (Entidade2)))

De posse destas informações, é construído um grafo representando a hierarquia dos ambientes existentes no universo pelo qual o robô irá se locomover. Por exemplo, caso seja necessário encontrar uma determinada sala que fica em uma biblioteca, basta navegar por este grafo até que seja possível traçar uma rota até a sala desejada. 
Ao produzir uma referência a uma entidade, é definido primeiramente em qual contexto a entidade está localizada utilizando-se o grafo do domínio. Para esse fim, verifica-se em qual vértice do grafo o alvo está, percorrendo-se o grafo e identificando-se as arestas que conectam este vértice aos demais. Como resultado, é obtida a hierarquia na qual o alvo está localizado.

Por exemplo, se o alvo é um livro que está em uma sala especifica, uma parte da expressão é a instrução que leva o ouvinte até o local desejado, como em "O livro está na sala 3, no terceiro andar, do prédio A do complexo principal". Em seguida, o algoritmo deve gerar uma expressão de referência para identificar esta entidade no ambiente no qual ela está localizada, utilizando uma expressão não ambígua contendo as propriedades desta entidade, como em "O livro vermelho, sobre a mesa marrom, na sala 3, no terceiro andar, do prédio A no complexo principal".

O presente trabalho não explora contextos dinâmicos, porém dentro do universo GIVE pode haver diversos sub-contextos também potencialmente úteis para a modelagem de domínios espaciais em geral. Além disso, o trabalho proposto em Zender, Kruijff e KruijffKorbayová (2009) fornece subsídios para construção de uma hierarquia de contextos e entidades similar ao universo GIVE, que é composto de salas e corredores onde as entidades ficam dispostas.

\subsubsection{Referência geográfica utilizando relações espaciais para previsões do tempo}

Em Turner et al. (2008) é abordado o tema de geração de expressões de referência geográficas. O objetivo do algoritmo em Turner et al. (2008) é mostrar uma representação precisa das condições do tempo a partir de um mapa em um contexto no qual existam mais de 1.000 pontos (ou entidades) a serem distinguidos. Neste contexto, referenciar um ponto de forma única pode ser inviável, seja porque a expressão se tornaria excessivamente longa ou complexa, ou porque o custo computacional envolvido seria muito elevado em função do grande número de relações espaciais a considerar.

O algoritmo, chamado RoadSafe, possui uma arquitetura de módulos. Um dos quais é responsável pela análise de dados relacionada somente às propriedades espaciais. $\mathrm{O}$ algoritmo RoadSafe utiliza quatro propriedades espaciais para fazer referência ao clima de uma determinada região, que são: altitude, ponto cardeal, proximidade da costa e população. Sob uma perspectiva de GLN, é de especial interesse no algoritmo RoadSafe a motivação para uso da expressão de referência. Por exemplo, se o algoritmo precisa 
informar que choverá em uma região, a propriedade altura desta região é um fator que implica diretamente o estado físico em que esta chuva irá se precipitar. Por outro lado, se a região for inabitada, o estado físico da chuva pode ser insignificante.

Para caracterização geográfica, o algoritmo armazena as informações de latitude e longitude da região, e também as quatro propriedades espaciais citadas anteriormente. O módulo de $G E R$ poderia utilizar essas informações para, por exemplo, gerar expressões altamente específicas como "A região com latitude $x$ e longitude $y$, com alta densidade populacional, perto da costa situada ao leste tem previsão de precipitação sólida".

A proposta em Turner et al. (2008), entretanto, consiste em evitar descrições complexas como a do exemplo acima. Ao invés disso, a ideia seria fazer referência a uma pequena região na qual se encontra o ponto a ser referenciado. Nesta abordagem, não é identificada a área exata na qual se pretende fazer a previsão do tempo, porém é possível fazer referências do tipo "As regiões do Sul, próximas à zona rural, irão sofrer com quedas de temperatura abaixo de zero". A tarefa do algoritmo de GER seria assim encontrar um conjunto de propriedades para usar na expressão de referência tal que este conjunto remova o maior número possível de entidades do grupo de contexto. Em outras palavras não é necessário que o grupo de contexto fique vazio.

Em Turner et al. (2008), todas as relações espaciais são utilizadas de acordo com o objetivo da expressão. Por exemplo, a expressão "A chuva pode virar neve em alguns lugares da zona rural" não faz muito sentido para a meteorologia devido à densidade populacional não ser uma propriedade que interfira na transformação da chuva em neve. Isso poderia inclusive gerar falsas considerações ao ouvinte, e portanto é necessário que as propriedades utilizadas sejam relevantes. Para resolver este problema, o trabalho em Turner et al. (2008) faz uso da ordem de preferência de propriedades proposta em Dale e Reiter (1995). Neste caso, cada evento meteorológico possui uma lista ordenada de propriedades espaciais a serem utilizadas em cada contexto. Por exemplo, caso seja necessário gerar uma expressão que informe ao ouvinte que a chuva pode virar neve, deve ser utilizada, antes das demais, a propriedade relativa à altura da região. A expressão resultante poderia ser, por exemplo, "Hoje nas áreas com altura superior a 1.300 metros, a chuva irá se transformar em neve".

Esta lista de preferências é criada de acordo com a porcentagem de cada propriedade associada a cada evento. Para verificar quais propriedades serão utilizadas para gerar uma expressão de referência, o algoritmo de GER recebe a probabilidade de cada propriedade espacial para aquele dado evento, e com base nestes dados seleciona os atributos na ordem 
adequada.

O modelo de adaptação para grandes regiões proposto em Turner et al. (2008) referencia pequenos pontos em áreas amplas do domínio, as quais contém uma grande quantidade de informação e várias entidades próximas umas das outras. Embora não utilizado diretamente neste trabalho, um modelo deste tipo pode ser acrescentado como forma de criar uma alternativa para casos em que exista um grande número de entidades, e que seja necessário definir quais relações espaciais melhor descrevam o objeto-alvo.

\subsubsection{Gerações de expressões de referência com propriedades relacionais e a construção dos corpora $G R E 3 D$ e $G R E 3 D$ 7}

Os trabalhos em Viethen e Dale (2008) e Dale e Viethen (2009) apresentam um experimento para a coleta de dados de expressões de referências produzidas por humanos. O objetivo é ganhar um entendimento de como os seres humanos usam propriedades relacionais em expressões de referência como "A bola azul ao lado da bola amarela".

De acordo com Viethen e Dale (2008), quando descrevemos uma entidade para um ouvinte a fim de identificá-la, frequentemente o fazemos utilizando a localização de outras entidades ao seu redor. Para isso, é necessária a utilização de relações espaciais nas expressões de referência. Alguns algoritmos como Dale e Haddock (1991) e Krahmer e Theune (2002) tratam do uso de relações espaciais. No entanto, estes algoritmos utilizam estas relações como um último recurso em uma expressão de referência, ou seja, apenas quando o uso de propriedades atômicas não foi suficiente para a desambiguação do referente. De modo geral, o assunto ainda é pouco explorado nas pesquisas de $G E R$, e não há evidência concreta de se ou quando utilizar relações espaciais em expressões de referência.

O método utilizado em Viethen e Dale (2008) para coletar dados foi um experimento on-line no qual os participantes, para fins de treinamento, eram apresentados a uma cena contendo três objetos do tipo cubo ou esfera, um dos quais era apontado por uma seta. Na mesma página havia exemplos de como poderia ser feita uma expressão de referência para identificar o objeto alvo, como "pegue a bola vermelha" ou "pegue a bola sobre o cubo azul", entre outras expressões possíveis de acordo a figura apresentada. Na figura 14 é apresentado um exemplo adaptado de Dale e Viethen (2009), representando uma das cenas utilizadas.

Após este treinamento, os participantes eram instruídos a completar uma série de frases propostas, como em "Por favor, pegue o cubo...", utilizando como base para a 
resposta uma figura no mesmo modelo utilizado no treinamento.

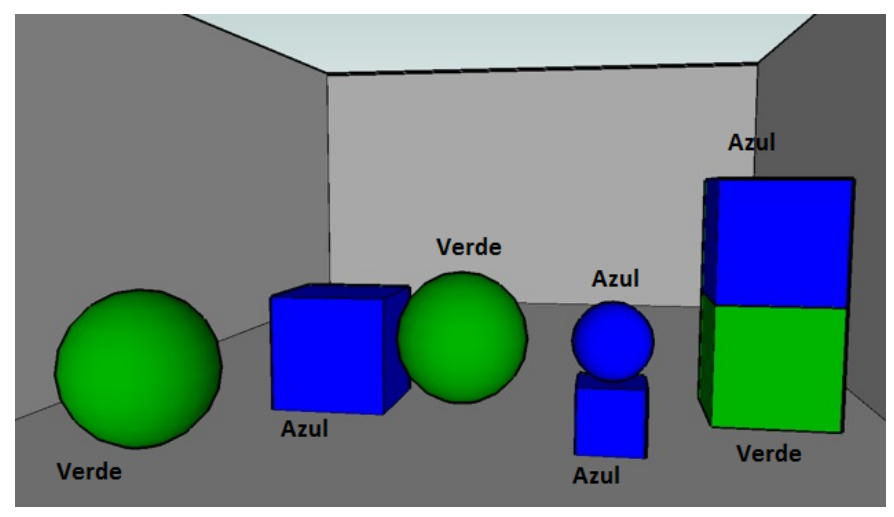

Figura 14 - Exemplo de uma cena utilizada no experimento em Dale e Viethen (2009).

Em cada cena existe sempre um ponto de referência relacionado ao objeto alvo. O ponto de referência é sempre um cubo, e além dele cada cena contém outros objetos do tipo cubo ou esfera que não necessariamente se relacionam com o objeto-alvo. Em todas as cenas, o uso de relações espaciais é opcional, ou seja, é possível referenciar o objeto-alvo de outras formas (i.e. usando atributos atômicos como cor, tamanho etc.) sem fazer uso do ponto de referência.

Os dados coletados desta forma constituem o corpus GRE3D, contendo 630 expressões de referência. Segundo Dale e Viethen (2009), 224 destas expressões (35,6\%) utilizam relações espaciais, 497 (78,9\%) utilizam cores, e 288 (45,7\%) utilizam tamanho. Dentre os 63 participantes, 9 (14,28\%) sempre utilizaram relações espaciais, enquanto 24 (30,09\%) nunca utilizaram.

O impacto da variação do cenário para a geração de expressão de referência é analisado da seguinte maneira: quando o objeto alvo está sobre o ponto de referência, a relação espacial acima_de(x) é utilizada em (58\%) de todos os casos em que relações espaciais são utilizadas no teste. Estes resultados corroboram o estudo realizado em Viethen e Dale (2008) no qual afirma-se que o uso da relação acima_de(x) é preferível à relação $a_{-} f r e n t e(x)$ e que as cores não interferem na utilização de relações espaciais, e também observado em estudos como Arts et al. (2011) e outros.

Para analisar o impacto da similaridade do objeto-alvo e do ponto de referência na utilização de relações espaciais, foi testado se o número de propriedades que o objetoalvo compartilha com qualquer outro objeto na cena implica uso destas relações. Como resultado, observou-se em Dale e Viethen (2009) que o uso de relações cai levemente quando o objeto-alvo e o ponto de referência são muito parecidos. Ou seja, quando a 
saliência visual do alvo (definida pelo número de propriedades que o alvo compartilha com as demais entidades do domínio) é menor, o uso de relações espaciais cai de (36,9\%) para (30,2\%). Este resultado não é entretanto estatisticamente significativo.

Por outro lado, para cenas em que o alvo e o ponto de referência são totalmente diferentes, ou seja, quando o objeto-alvo possui alta saliência visual, o uso de relações espaciais cresce abruptamente para $(40,2 \%)$ de todas as descrições daquela cena, contra $(28,6 \%)$ das cenas na qual o alvo e o ponto de referência são parecidos, ou seja, o objeto alvo possui baixa saliência visual. Segundo Dale e Viethen (2009), a saliência visual do ponto de referência interfere mais na inclusão de relações espaciais do que a saliência do próprio alvo.

De acordo com Viethen e Dale (2008), os fatores que podem interferir no uso de relações espaciais podem ser resumidos da seguinte forma: o tipo de relação que o alvo e o ponto de referência possuem (sendo preferível a relação acima_de $(x)$ ); a saliência visual do objeto-alvo e a saliência do ponto de referência (que indica quão diferente é o ponto de referência dos demais objetos na cena). Dependendo da saliência das entidades na cena, o uso de propriedades relacionais pode ser tão frequente quanto propriedades atômicas.

Posteriormente ao estudo envolvendo o GRE3D, em Viethen e Dale (2011) foi construída uma extensão deste corpus objetivando identificar possíveis fatores que influenciem nas decisões ao gerar uma expressão de referência. O corpus GRE3D7 foi construído em um experimento com 280 participantes. A cada participante foram apresentadas 32 cenas contendo cubos e esferas semelhantes ao utilizado em Dale e Viethen (2009). As cenas são variadas, possibilitando relações espaciais horizontais e verticais entre o objeto-alvo e o ponto de referência, como em "o cubo ao lado da esfera" ou em "a esfera sobre o cubo", e também a utilização de tamanhos e cores diversas. Um exemplo adaptado de uma cena em Viethen e Dale (2011) é apresentada na Figura 15.

Nos experimentos de coleta de dados deste corpus, o objeto-alvo a ser referenciado é sempre apontado por uma seta. O objeto-alvo e o ponto de referência principal sempre possuem características próprias determinantes, ou seja, o uso de relações espaciais nunca é necessário para a desambiguação da referência. No exemplo da Figura 15 o objeto-alvo é a única esfera vermelha de tamanho grande na cena.

As cenas são separadas de modo que sempre existam apenas dois esquemas de cores escolhidas: (Verde) e (Azul), ou (Amarelo) e (Vermelho). Cada cena possui exatamente sete objetos, sendo quatro de uma cor, e os outros três da outra. A relação entre o alvo e o ponto de referência nunca é uma relação única na cena, ou seja, se o alvo possuir uma 


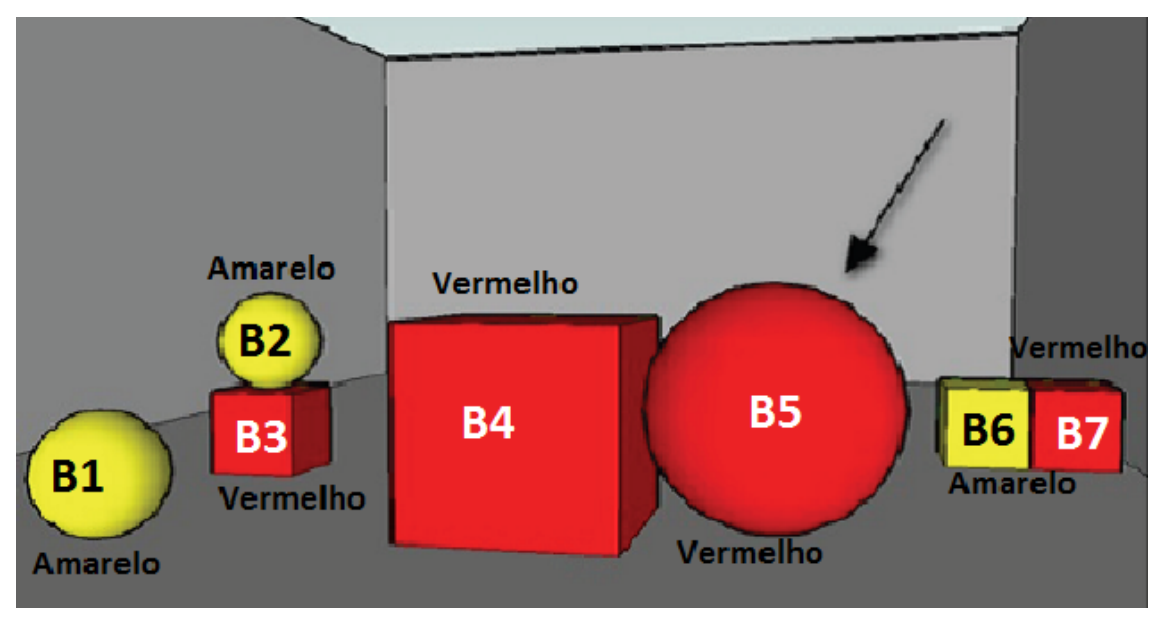

Figura 15 - Cena apresentada no corpus em Viethen e Dale (2011).

relação espacial horizontal com algum ponto de referência, outras duas entidades da cena possuem esta mesma relação entre si.

No exemplo, da Figura 15, B5 tem uma relação espacial horizontal com B4, assim como $B 7$ possui uma relação espacial horizontal com $B 6$. O ponto de referência mais próximo ao alvo é sempre um cubo, evitando-se assim falsas inferências sobre o objeto com o qual o alvo deve ser relacionado. Não existem entidades ocultas ou parcialmente visíveis nas cenas.

Com a execução do experimento, foram coletadas 4480 descrições, formando o corpus GRE3D7 de expressões de referência detalhado em Viethen e Dale (2011). Mais uma vez, o atributo cor é muito utilizado (98,7\% das descrições), inclusive em casos em que o uso de relação espacial eliminaria sua necessidade. Também de acordo com Viethen e Dale (2011), o atributo tamanho é mais utilizado principalmente nas cenas em que existe algum outro objeto do mesmo tipo que o alvo, porém com tamanho diferente.

Embora o uso da relação espacial nunca fosse determinante para a distinção do alvo, as relações espaciais foram utilizadas em $(13,40 \%)$ das descrições presentes no corpus. Dentre os participantes (43,75\%) usaram algum tipo de relação espacial, enquanto que 135 participantes $(56,25 \%)$ nunca as utilizaram. Somente seis participantes $(2,5 \%)$ usaram relações espaciais em todas as descrições que produziram.

O corpus GRE3D'7 é um recurso valioso para o estudo e desenvolvimento de algoritmos de GER capazes de utilizar propriedades espaciais. Na presente pesquisa, este corpus e os resultados descritos em Viethen e Dale (2011) são empregados como base na proposta de uma solução para o problema de GER em domínios espaciais mais complexos do tipo 
GIVE (Byron et al., 2007).

\subsubsection{Padrões de uso de relações espaciais}

Em paralelo aos estudos envolvendo o corpus GRE3D\%, é afirmado em Viethen (2010) que grande parte dos algoritmos de GER existentes não é capaz de simular o comportamento humano. Diferentes pessoas tomam diferentes decisões quando se depararam com a mesma tarefa, o que surpreendentemente é ignorado pela maioria dos algoritmos de $G E R$. Isso gera diversas questões sobre como desenvolver algoritmos que tratem deste problema, e como é possível avaliar estes algoritmos.

Segundo Viethen (2010), a geração de expressões de referência que contêm relações espaciais é um dos maiores desafios que ainda precisam ser efetivamente tratado na pesquisa em GER. Em Viethen (2010) é afirmado que, baseado nos corpora GRE3D e GRE3D\%, o uso de relações espaciais em expressões de referência depende diretamente da preferência de cada participante, e que não haveria um comportamento padrão que possa ser reproduzido por um algoritmo de GER. Apesar destas dificuldades, Viethen (2010) identifica uma série de padrões de referência potencialmente úteis. Estes padrões são resumidos a seguir

Em primeiro lugar observa-se mais uma vez que seres humanos preferem utilizar relações espaciais verticais ao invés de relações horizontais. Por exemplo, a expressão "a bola acima da caixa" é geralmente preferível à "a bola ao lado da caixa", possivelmente em virtude do menor esforço cognitivo envolvido na interpretação destas relações (Arts et al., 2011).

Em segundo lugar, e também segundo Viethen (2010), uma relação espacial entre o alvo e o ponto de referência é mais utilizada quando o ponto de referência é mais saliente que o alvo. Isso ocorre, por exemplo, quando o alvo é menor que o ponto de referência, como em "a caixa ao lado da esfera grande".

Em terceiro lugar, uma relação espacial é preferível quando há similaridade visual entre o alvo e o ponto de referência. Por exemplo, quando compartilham a mesma cor e mesmo tamanho.

Ainda segundo Viethen (2010), humanos usam relações espaciais mesmo se o alvo puder ser distinguido de todas as entidades do contexto apenas utilizando-se propriedades atômicas como tipo, tamanho ou cor. Além disso, o uso de relações espaciais também está diretamente relacionado à facilidade de descrever o alvo utilizando suas propriedades 
atômicas. Quanto maior esta dificuldade, maior a probabilidade da expressão conter uma relação espacial.

Finalmente, uma relação tem maior probabilidade de ser inclusa em uma expressão de referência se esta relação for única no contexto, pois isso diminuiria a complexidade da referência. Por exemplo, em um contexto, no qual somente uma caixa esteja à esquerda de uma esfera, o uso desta relação seria mais provável do que em um contexto onde outras entidades também possuam esta relação.

O estudo de Viethen (2010) é importante do ponto de vista do presente trabalho por oferecer a base para possíveis heurísticas aplicáveis a algoritmos que tenham como objetivo definir quando uma relação espacial deve ser utilizada.

\subsubsection{Modelos computacionais de referência espacial}

O trabalho em Kelleher e Costello (2009) propõe uma série de equações que definem as relações espaciais passíveis de referência em cenas tridimensionais. O objetivo do trabalho é definir modelos computacionais para determinar qual a relação espacial que seria mais adequada para cada situação de referência.

Em Kelleher e Costello (2009), relações espaciais como "o botão ao lado da porta" ou "o cachorro próximo ao poste" são separadas em relações dinâmicas e estáticas. As relações dinâmicas são relações que tem caráter transitório, como em "o homem que está atravessando a rua". Já as relações estáticas são imutáveis no contexto. Relações estáticas possuem dois subníveis: as relações topológicas (por exemplo, "perto", "sobre", "próximo" etc) e relações projetivas (por exemplo, "à direita de", "à esquerda de", "acima de"etc).

Segundo Kelleher e Costello (2009), relações espaciais requerem diferentes níveis de raciocínio cognitivo, e que com base nisso é possível criar uma hierarquia de tipos de relações espaciais. Esta hierarquia é ilustrada na figura 16, na qual os tipos de relações mais próximos do topo são considerados de interpretação mais difícil.

De acordo com Kelleher e Costello (2009), vários modelos de relações projetivas têm sido propostos em estudos como Yamada (1993); Olivier e Tsujii (1994); Gapp (1995); Fuhr et al. (1998);. Regier e Carlson (2001); Kelleher e Genabith (2006). Com base nestes estudos e nos resultados em Radvansky e Logan (1997) e Kelleher e Genabith (2006), a proposta de Kelleher e Costello (2009) apresenta um modelo computacional de uso de relações espaciais que procura explicar a influência de outros objetos na semântica destas proposições. 


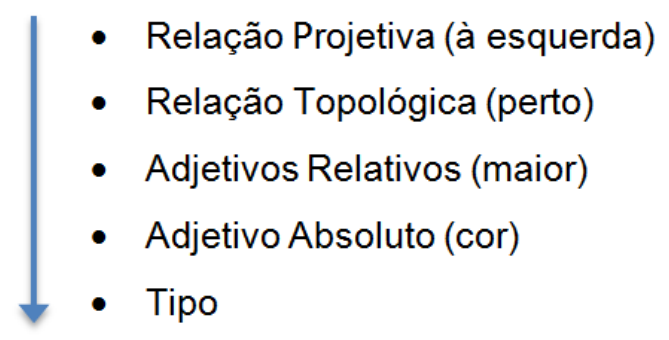

Figura 16 - Hierarquia de relações espaciais proposta em Kelleher e Costello (2009)

Em Kelleher e Costello (2009) é utilizado o conceito de modelo de campo potencial. Um campo potencial é definido como um conjunto de equações normalizadas que, para uma dado ponto de origem e um ponto de referência, calcula um valor que representa o custo de aceitar a proposição para um determinado ponto de referência. Existe uma equação diferente para construir a representação do campo potencial para cada tipo de relação espacial. Por exemplo, para relações espaciais topológicas como perto seria utilizada uma equação levando-se em conta a distância entre o alvo e um ponto de referência. Já para relações espaciais projetivas como à direita de, a equação utilizaria o ângulo de um ponto a partir da direção do ponto de referência.

O conceito de campo potencial, no entanto, não leva em conta a influência de outros objetos na cena sobre a semântica de uma relação topológica ou projetiva. O propósito dos modelos computacionais em Kelleher e Costello (2009) é assim estender este conceito pela sobreposição de campos potenciais para cada objeto. A combinação destes campos gera um campo relativo para relações topológicas ou projetivas.

O modelo topológico de Kelleher e Costello (2009) é baseado na proximidade absoluta entre cada ponto de referência e o alvo em uma cena, sobrepondo os resultados da proximidade absoluta para calcular a proximidade relativa entre estes. Para calcular a proximidade absoluta entre o ponto de referência e o alvo, independentemente da proximidade de qualquer outro ponto de referência, a cena é representada em uma matriz de pontos 2D. A partir disso, a equação de proximidade absoluta para um ponto $P$ e um ponto de referência $L$ é uma função que mede a distância entre $P$ e $L$, e a saliência de $L$. Esta equação pode ser vista na função 3.1, extraída de Kelleher e Costello (2009).

$$
\operatorname{prox}_{a b s}(L, P)=\left(1-\operatorname{dist}_{\text {normalized }}(L, P)\right) \times \operatorname{salience}(L)
$$

A função $\operatorname{dist}_{\text {normalized }}(L, P)$ representa a distância entre o alvo e o ponto de referência, podendo assumir um valor entre 0 e 1 . Quanto menor for a distância entre $L$ e $P$, maior o 
valor absoluto de proximidade obtido, ou seja, é mais aceitável afirmar que $P$ está próximo de $L$. A função de saliência pode assumir um valor entre 0 e 1 e representa a importância relativa de $L$ na cena. A função de saliência (3.2), também extraída de Kelleher e Costello (2009), pressupõe que a importância relativa de um objeto é a média entre sua saliência visual e discursiva:

$$
\operatorname{salience}(L)=\frac{\left(S_{\text {vis }}(L)+S_{\text {disc }}(L)\right)}{2}
$$

A saliência visual $\left(\left(S_{\text {vis }}(L)\right)\right.$ é calculada utilizando-se o algoritmo de Kelleher e Genabith (2004), que computa a relevância relativa de cada objeto em uma cena baseada em seu tamanho perceptível e sua centralidade em relação ao foco de atenção do espectador. A função retorna valores entre 0 e 1 . A saliência do discurso é calculada com base na teoria de Hajičová (1993), e é também representada por valores entre 0 e 1.

O cálculo de proximidade absoluta é diretamente influenciado pela saliência dos objetos. Um objeto com alta saliência, mesmo que distante do alvo, ainda pode ser utilizado como ponto de referência.

Uma vez que tenham sido definidos os campos de proximidade absoluta para os pontos de referência em uma cena, o próximo passo é a sobreposição desses campos para produzir uma medida de proximidade relativa para cada um. A proximidade relativa de um ponto de referência é a diferença entre o campo de proximidade absoluta de valor mais alto para qualquer outro ponto de referência do contexto e seu campo de proximidade absoluta, como pode ser visto na equação (3.3) extraída de Kelleher e Costello (2009):

$$
\operatorname{prox}_{r e l}(P, L)=\operatorname{prox}_{a b s}(P, L)-\max \operatorname{prox}_{a b s}\left(P, L_{x}\right)
$$

Se a proximidade absoluta de qualquer outro ponto de referência for maior do que a proximidade absoluta do ponto de referência em questão, a proximidade relativa do ponto de referência em questão será negativa. Somente quando a proximidade absoluta de todos os pontos de referência concorrentes for significativamente menor do que a proximidade absoluta do ponto de referência selecionado o ponto de referência em questão terá uma proximidade relativa elevada para o contexto em questão.

Em Kelleher e Costello (2009) também é proposto um modelo computacional para relações projetivas. Os dois principais fatores que têm impacto sobre a aplicabilidade de uma relação projetiva são o desvio angular entre o alvo e o ponto de referência, e a 
distância entre eles.

De acordo com Kelleher e Costello (2009), o vetor originário a partir do centro do ponto de referência para a posição do espectador descreve o eixo canônico da relação projetiva $a_{-} f r e n t e(x)$. Com base neste vetor, é possível produzir vetores para as relações projetiva atrás(x), à_esquerda_de(x), à_direita_de(x) etc. girando-se este vetor em um plano horizontal. O desvio angular pode ser descrito com uso da equação (3.4), também extraída de Kelleher e Costello (2009).

$$
\operatorname{angle}(\overrightarrow{L P}, \vec{c})=\cos ^{-1}\left(\frac{\overrightarrow{L P} \cdot \vec{c}}{|\overrightarrow{L P}||\vec{c}|}\right)
$$

Os parâmetros da equação (3.4) são: $L P$, que representa o vetor entre $L$ (ponto de referência) e $P$ (alvo), e $c$, que descreve o eixo canônico já discutido.

No presente trabalho os modelos computacionais propostos em Kelleher e Costello (2009) são utilizados como base para um algoritmo que decide qual relação espacial utilizar dentre um conjunto de relações possíveis entre o objeto-alvo e candidatos a ponto de referência em um determinado contexto. No entanto, como o conjunto de relações possíveis no sistema GIVE é mais limitado, alguns destes conceitos serão adaptados e/ou simplificados, além de combinados com conhecimento de domínio extraído de um corpus de instruções em mundos GIVE. 


\section{Trabalho realizado}

Este capítulo descreve uma proposta de algoritmo para geração de expressão de referência usando relações espaciais em mundos do tipo GIVE (Byron et al., 2007), a qual adapta os modelos computacionais de geração de relações espaciais de Kelleher e Costello (2009) com conhecimento de domínio. A seção 4.1 descreve a tarefa de preparação do corpus GIVE-2 (Gargett et al., 2010) utilizado para fins de treinamento e teste de vários aspectos da solução proposta, e a seção 4.2 apresenta o trabalho desenvolvido.

\subsection{Preparação de Dados}

\subsubsection{O corpus GIVE-2}

Para fins de treinamento e teste de certos aspectos da solução proposta, foi realizada uma tarefa de preparação dos dados do corpus GIVE-2 (Gargett et al., 2010). Este corpus consiste de uma coleção de instruções humanas em mundos 3D do tipo GIVE, geradas a partir de três mundos de teste.

Segundo Gargett et al. (2010), o corpus GIVE-2 foi construído por meio de uma série de experimentos envolvendo 72 participantes, sendo 30 em língua alemã e 42 em língua inglesa. Os participantes foram divididos em duplas de instrutores e jogadores. O jogador tinha acesso a uma interface GIVE tradicional, e seu objetivo era navegar o ambiente até completar um determinado jogo (i.e., encontrando o troféu).

Diferentemente de uma aplicação GIVE convencional, entretanto, neste experimento as instruções de navegação exibidas na tela do jogador não eram provenientes de um sistema de GLN. As instruções neste caso eram escritas por um instrutor, que em uma tela própria tinha acesso ao mapa do mundo que estava sendo navegado, incluindo informações sobre quais passos executar para atingir o objetivo do jogo, assim como a posição e orientação atuais do jogador. 
Cada dupla de participantes jogou três turnos (um em cada mundo de teste 1-3) alternando o papel de instrutor e jogador. O corpus contempla assim 36 jogos (15 duplas trabalhando em alemão, e 21 duplas em inglês) em cada um dos três mundos, totalizando 108 jogos completos.

Durante os experimentos em Gargett et al. (2010) foram coletadas todas as instruções fornecidas pelo instrutor e as decisões (e.g., movimentos, ações de pressionar botões etc.) tomadas pelo jogador. Este conjunto de dados multimodal forma o corpus GIVE-2, que pode ser visualizado na forma de animação com a ferramenta replay apresentada em Gargett et al. (2010). A interface desta ferramenta é ilustrada na figura 17.

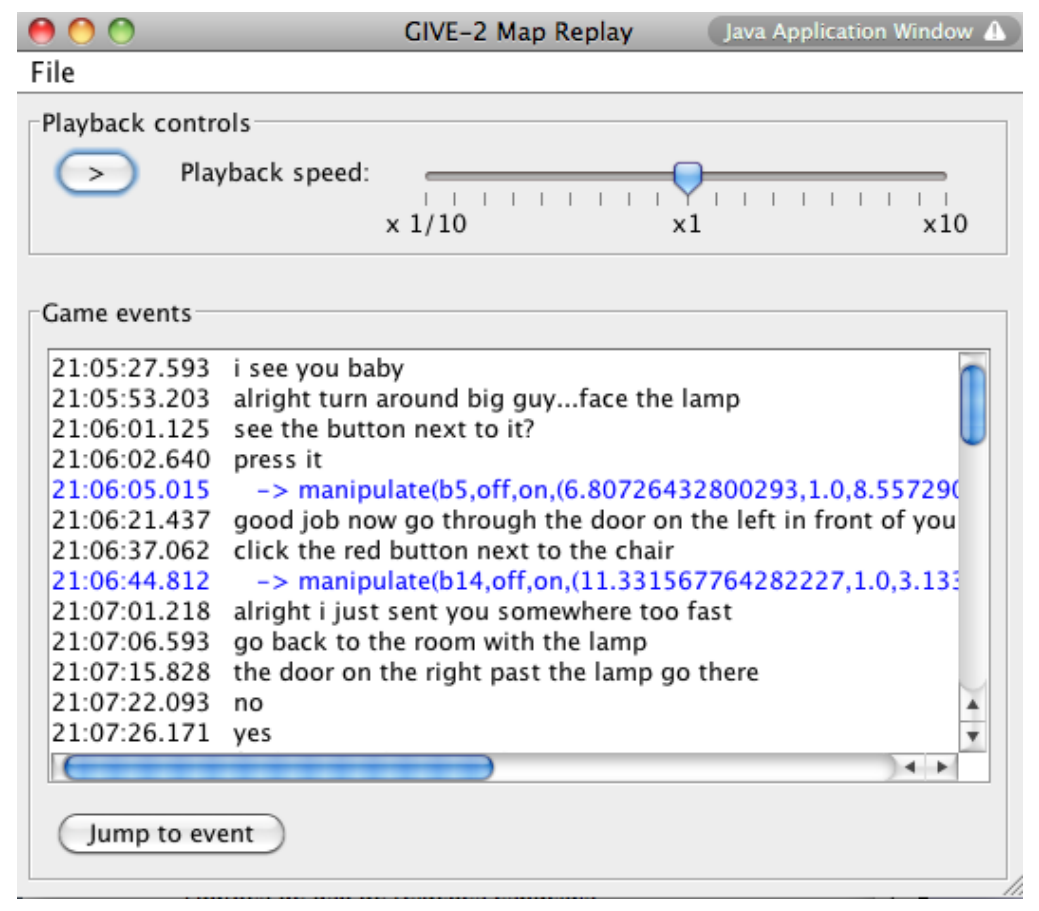

Figura 17 - Interface da ferramenta "Replay" em Gargett et al. (2010).

O corpus GIVE-2 contém apenas as instruções completas dadas pelo instrutor a cada jogador na forma textual (e.g., "aperte o botão azul"). Estas instruções ocorrem mescladas aos eventos de cada jogo e ações dos participantes na forma de uma extensa base de dados SQL representando o histórico de cada partida (ou game log). Além desta base de dados, parte da informação necessária para reproduzir cada situação de comunicação entre o instrutor e jogador é encontrada na definição de cada mundo de teste (ou giveworld) utilizado.

Para que estes dados pudessem ser utilizados no desenvolvimento e teste do algoritmo de GER da presente proposta, foi necessário assim realizar uma tarefa de extração de 
dados. Mais especificamente, foram identificados os objetos existentes em cada mundo GIVE e seus atributos referenciáveis e, para cada expressões de referência de interesse, foi necessário estimar o contexto de referência considerado (i.e., objetos e atributos específicos daquela situação). Finalmente, foi necessário identificar também os atributos presentes em cada expressão de referência coletada. Estas tarefas são detalhadas individualmente nas próximas seções.

\subsubsection{Extração de informações do domínio GIVE}

O primeiro passo da preparação de dados consistiu da extração de todos os objetos existentes no mundo GIVE pertinente a cada jogo a partir do arquivo giveworld correspondente descrito em (Gargett et al., 2010), e de informações úteis para fins de referência, como propriedades atômicas e outras explicitamente representadas. Cabe entretanto enfatizar que, no caso de propriedades relacionais, não foi realizada tentativa de extração deste tipo. Estas propriedades não são explicitamente representadas no mundo GIVE, e é portanto discutível quais podem ser realmente percebidas no contexto e utilizadas para fins de referência. O cômputo de propriedades relacionais será assim abordado como parte da solução proposta na seção 4.2 .

A tabela 5 apresenta os tipos de informação extraídas do domínio. As propriedades type e color ocorrem explicitamente em descrições de objetos referenciados no corpus GIVE-2, enquanto que as demais informações serão empregadas no cômputo de relações espaciais.

Tabela 5 - Propriedades atômicas e demais informações extraídas dos três mundos GIVE utilizados na construção do corpus GIVE-2 (Gargett et al., 2010)

\begin{tabular}{ll}
\hline Atributo & Valores possíveis \\
\hline type & button, door, alarm, picture, safe, flower, couch, lamp, chair \\
color & yellow, red, blue, green \\
orientation & up, down, right, left \\
$\mathbf{x}, \mathbf{y}, \mathbf{z}$ & $0,0-20,0$ \\
size & $1,3,4,5,6,10,14$ \\
\hline
\end{tabular}

\subsubsection{Extração de expressões de referência}

Após a extração dos objetos e informações do domínio, as instruções textuais representadas no corpus GIVE-2 foram utilizadas para extração do conjunto de expressões de 
referência de interesse e suas respectivas propriedades (que neste caso podem ser tanto atômicas quanto relacionais). As expressões aqui consideradas são aquelas que fazem referência a objetos do tipo botão, o qual é o único elemento manipulável no mundo GIVE, e por este motivo amplamente referenciado durante a navegação.

Foram extraídas todas as instruções do corpus contendo a palavra "button" (823 casos) e formas equivalentes como "this" (119 casos) e "box" (50 casos) inferidas pelo uso de verbos como "press"e "hit". Como no entanto este procedimento não foi exaustivo, é possível que uma pequena parcela de descrições menos comuns tenha ficado de fora da presente análise.

No total, foram identificadas 992 descrições de interesse, sendo 309 referências no mundo-1, 352 no mundo-2 e 331 no mundo-3. No caso da porção em alemão do corpus, as instruções foram previamente traduzidas para o inglês com uso da ferramenta Google Translate $^{1}$ de modo a facilitar sua identificação. As expressões foram então reescritas na forma de listas atributo-valor. Por exemplo, a expressão "o botão azul" foi representada como (type, button), (color, blue).

Apenas dois tipos de propriedades atômicas foram observadas nas expressões de referência coletadas: tipo e cor. O atributo type é empregado em 992 descrições (100 \%) e o atributo color é empregado em 838 descrições (84,47\%).

Das expressões coletadas, 467 (47,07\%) utilizam algum tipo de relação espacial, sendo 248 (25\%) do tipo topológica (e.g., "O botão perto da planta"), e 219 (22,07\%) do tipo projetiva (e.g., "O botão à esquerda da planta") (Kelleher e Costello, 2009). A tabela 6 sumariza os tipos de propriedades relacionais identificados.

Tabela 6 - Propriedades relacionais extraídas das descrições de objetos do tipo 'botão' existentes no corpus GIVE-2 (Gargett et al., 2010)

\begin{tabular}{lcr}
\hline Atributo & Ocorrências & $\mathbf{\%}$ \\
\hline next & 217 & $21,87 \%$ \\
left & 121 & $12,19 \%$ \\
right & 92 & $9,27 \%$ \\
over & 17 & $1,71 \%$ \\
corner & 14 & $1,41 \%$ \\
in front of & 6 & $0,60 \%$ \\
\hline
\end{tabular}

No corpus GIVE-2 há três tipos de expressões que não fazem uso de relações com

\footnotetext{
${ }^{1}$ http://translate.google.com.br/
} 
Tabela 7 - Uso de relações espaciais no corpus GIVE-2 (Gargett et al., 2010)

\begin{tabular}{ccc|ccc|ccc}
\hline \multicolumn{3}{c|}{ mundo 1 } & \multicolumn{3}{c|}{ mundo 2 } & \multicolumn{3}{c}{ mundo 3 } \\
r & sim & não & r & sim & não & r & sim & não \\
\hline b19 & 5 & 32 & $\mathrm{~b} 18$ & 32 & 6 & $\mathrm{~b} 1$ & 29 & 4 \\
b18 & 26 & 0 & $\mathrm{~b} 11$ & 1 & 6 & $\mathrm{~b} 12$ & 1 & 38 \\
b3 & 2 & 36 & $\mathrm{~b} 12$ & 26 & 10 & $\mathrm{~b} 5$ & 74 & 2 \\
b20 & 30 & 0 & $\mathrm{~b} 2$ & 0 & 47 & $\mathrm{~b} 4$ & 39 & 2 \\
b11 & 5 & 30 & $\mathrm{~b} 5$ & 19 & 17 & $\mathrm{~b} 10$ & 32 & 0 \\
b5 & 0 & 72 & $\mathrm{~b} 10$ & 5 & 75 & $\mathrm{~b} 15$ & 39 & 33 \\
b4 & 0 & 1 & $\mathrm{~b} 6$ & 6 & 39 & $\mathrm{~b} 36$ & 3 & 33 \\
b9 & 9 & 29 & $\mathrm{~b} 9$ & 26 & 0 & & & \\
b6 & 30 & 2 & $\mathrm{~b} 14$ & 31 & 6 & & & \\
\hline
\end{tabular}

outros objetos de domínio, e que por este motivo foram desconsideradas neste trabalho. Estas expressões são as que incluem relações com o jogador (e.g., 'o botão à sua frente'), propriedades relativas (e.g., "O botão mais distante da lâmpada") e envolvendo negações (e.g., "O botão que não está perto da lâmpada"). Foram identificadas 68 descrições destes tipos, correspondendo a $(6,8 \%)$ das expressões consideradas. Nestes casos é assumido um ônus para a solução proposta na seção 4.2, que nem sempre será capaz de produzir descrições idênticas às observadas no corpus.

Um breve exame das expressões coletadas é suficiente para constatar que, em uma mesma situação de referência, pessoas diferentes podem usar ou não uma relação espacial, variação esta que pode ser tomada por um indicador da complexidade da tarefa de geração considerada. A tabela 7 ilustra esta variação, representada pelo número de casos em que uma relação espacial foi ou não utilizada para cada referência do corpus.

Pelos dados da 7 é possível observar, por exemplo, casos em que todos participantes usaram a mesma estratégia de referência, como na descrição do alvo b20 no mundo 1. Por outro lado, há também casos em que a divisão é de quase (50\%), como no caso do alvo b15 no mundo 3. Casos deste último tipo ilustram algumas das dificuldades de modelagem computacional do problema de geração de relações espaciais.

\subsubsection{Conjuntos de treinamento e teste}

As informações extraídas do domínio (cf. seção 4.1.2) e expressões de referência de interesse (cf. seção 4.1.3) foram organizadas na forma de uma coleção de situações de referência para fins de treinamento e teste do presente trabalho. Cada situação consiste de um contexto formado por um conjunto de objetos e suas propriedades semânticas, um dos quais é o objeto-alvo da referência naquela situação específica, e a expressão produzida 
pelo participante humano durante a construção do corpus GIVE-2 (Gargett et al., 2010), que é representada pela sua lista de propriedades semânticas. O contexto representa um conjunto de entrada para o problema de $G E R$, e a respectiva expressão é a saída esperada.

A definição destas situações de referência coloca a questão de quais objetos levar em conta no momento da geração de uma expressão de referência, ou seja, qual o contexto a ser utilizado pelo algoritmo de GER a fim de desambiguar cada objeto-alvo. Determinar o conjunto de objetos que cada instrutor considerou em cada situação presente no corpus GIVE-2 é no entanto inviável, pois esta definição dependeria do foco de atenção dos participantes naquele momento, do grau de cuidado tomado ao produzir a expressão (muitas vezes produzida de forma preliminar e corrigida com uma instrução subsequente), do histórico do discurso e de inúmeros outros fatores baseados em conhecimento não disponibilizado pelo corpus.

De modo geral entretanto, observamos que no corpus GIVE-2 o contexto de referência tende a coincidir com o conjunto de objetos na sala onde se encontra o jogador e o objetoalvo. Em apenas um pequeno número de casos (21 instâncias) o contexto utilizado é claramente um subconjunto dos objetos na sala. Uma possível explicação para estes casos é a de que o conjunto considerado foi formado apenas pelos objetos visíveis naquele instante. Por exemplo, antes de produzir a referência em questão, alguns instrutores guiaram o jogador até uma posição em frente ao objeto-alvo, e então produziram uma descrição simples do tipo "o botão", a qual não requer que nenhum outro objeto da sala seja levado em conta.

Por simplicidade, no presente trabalho consideramos que o contexto de referência utilizado pelos instrutores nos experimentos GIVE-2 sempre é definido pelo conjunto de objetos na mesma sala onde se encontra o objeto-alvo. Este pressuposto entretanto não deve ser visto como uma afirmação (de resto imprópria, pelos motivos expostos acima) de que o contexto empregado pelos participantes tenha sido sempre exatamente este. A definição de contexto aqui pressuposta é apenas uma aproximação possível, com a qual espera-se poder gerar expressões de referência semelhantes às observadas no corpus para a maioria dos casos. Obviamente com esta simplificação assume-se mais uma vez uma margem de erro na abordagem proposta, já que não será possível reproduzir estas expressões exatamente como ocorrem no corpus.

A tarefa de preparação de dados produziu um conjunto de 992 pares de situações de referência na forma contexto-descrição. Este conjunto foi então dividido em um conjunto de treinamento $80 \%$ (794 itens) e teste 20\% (198 itens) selecionados aleatoriamente. O 
uso destes conjuntos é descrito nas seções a seguir.

O conjunto de informações extraídas a partir do corpus GIVE-2 foi representado em notação XML para facilitar sua manipulação e reuso. Para este fim, foi seguido tanto quanto possível o padrão adotado no corpus TUNA de expressões de referência (Gatt, Belz e Kow, 2009). O apêndice A apresenta exemplos desta representação para um determinado contexto, uma expressão de referência, e propriedades relacionais possíveis para aquele contexto. A disponibilização destes dados em formato XML é uma das contribuições secundárias do presente trabalho.

\subsection{A solução proposta}

A solução proposta para geração de expressões de referência envolvendo relações espaciais é composto de quatro módulos ilustrados na figura 18.

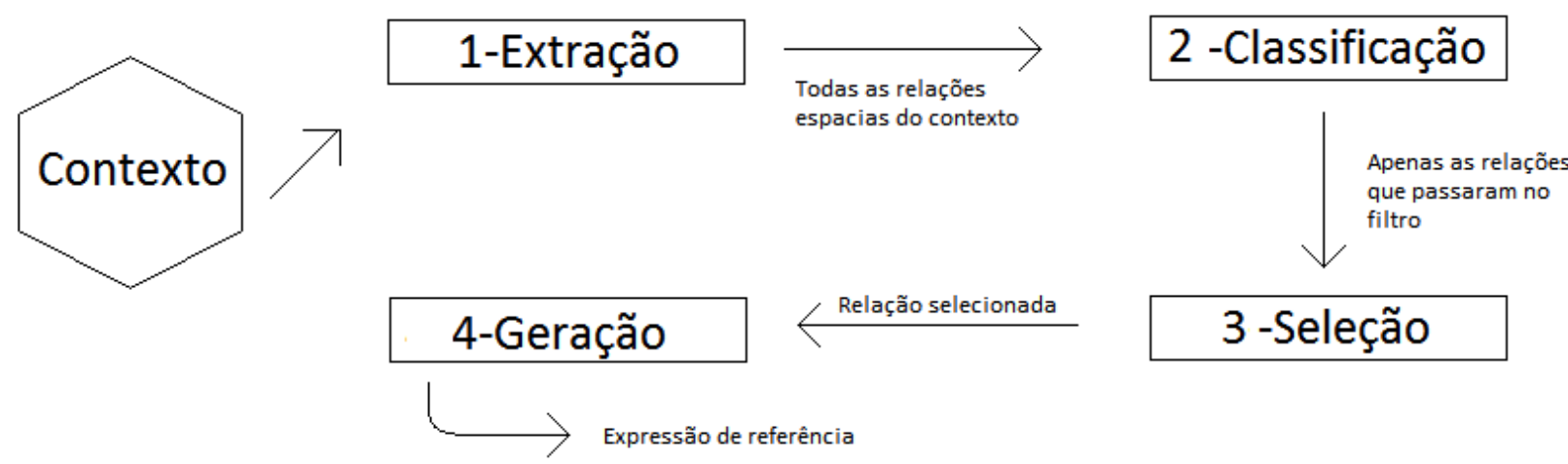

Figura 18 - Arquitetura proposta

O primeiro módulo tem a responsabilidade de extrair de uma cena GIVE os objetos e propriedades semânticas existentes. Utilizando a figura 18 como exemplo, a entrada deste módulo é o contexto (i.e., objetos e suas propriedades) da cena contendo propriedades como tipo, cor, posição, e a saída deste módulo é o conjunto de relações espaciais possíveis entre os objetos como à_direita_de $(x)$.

O segundo módulo tem a responsabilidade de escolher, para um dado objeto-alvo que se deseja descrever, os pontos de referência que devem ser considerados. Este módulo atua como um filtro de domínio, utilizando conhecimento extraído das expressões de referência do corpus para garantir que apenas as estratégias mais típicas sejam consideradas.

A entrada do módulo classificador é o conjunto de relações espaciais com à_direita_de(x) ou à_esquerda_de(y) do objeto-alvo, e a saída é o conjunto das relações consideradas válidas 
para fim de referência. Se todas relações espaciais forem suficientemente referenciadas no corpus, é possível que a saída deste módulo seja o mesmo conjunto de entrada. Por outro lado, relações espaciais pouco representativas tendem a ser descartadas, reduzindo assim o conjunto de saída.

O terceiro módulo utiliza com entrada as relações espaciais fornecidas pelo módulo anterior, e estabelece um ranking de preferência entre todas as relações válidas. A saída deste módulo é a relação considerada mais adequada segundo este ranking.

Finalmente, o quarto módulo é responsável por utilizar o conjunto das propriedades atômicas do contexto e a propriedade relacional selecionada para gerar uma expressão de referência descrevendo o objeto-alvo, como em "O botão à esquerda da cadeira". Cabe destacar entretanto que a relação espacial pode ou não ser incluída na expressão resultante, sendo esta decisão parte integrante da estratégia de referência implementada.

O funcionamento de cada um destes módulos será descrito com maior detalhe nas seções seguintes.

\subsubsection{Extração de propriedades espaciais a partir do domínio}

Como ponto de partida desta pesquisa, foi implementado um conjunto de métodos básicos para computar propriedades espaciais de diversos tipos em ambientes do tipo GIVE (Byron et al., 2007), incluindo casos já implementados em trabalhos revisados no capítulo anterior e novos casos.

Objetos em um ambiente GIVE (Byron et al., 2007) possuem apenas uma propriedade atômica básica representando seu tipo (botões, portas, cadeiras etc.) e, no caso dos botões, uma propriedade cor. O primeiro passo deste trabalho foi assim a escolha das propriedades espaciais a considerar. Conforme descrito na seção 2.2, as propriedades consideradas são: acima_de(x), abaixo_de(x), à_esquerda_de(x), à_direita_de(x), $\grave{a}_{-} f r e n t e \_d e(x)$ e $a_{-} a t r a ́ s \_d e(x)$, no qual, $x$ é o ponto de referência. As propriedades acima_de(x), abaixo_de(x), à_esquerda_de(x), à_direita_de(x) também são implementadas nos trabalhos Byron et al. (2007), Braunias et al. (2010), Schutte e Dethlefs (2010) e Akkersdijk et al. (2011).

Para extração destas relações, foi utilizada a função 3.4 proposta em Kelleher e Costello (2009), reproduzida na seção 3.3.6, que define a posição angular de um objeto em relação ao outro no plano cartesiano. De acordo com o resultado desta função é possível definir, por exemplo, se um objeto está à esquerda ou à direita de outro objeto. 
O algoritmo de extração de propriedades espaciais define uma constante de distância máxima que chamaremos de $k$. Esta constante é diferente para cada tipo de relação entre entidades. A posição física das entidades no ambiente GIVE (Byron et al., 2007) é definida pela coordenada de seu ponto central, e assim entidades maiores como sofás, portas etc. possuem um ponto central mais distante das bordas. Uma entidade está próxima de outra entidade se a diferença entre os valores para os eixos $x, y$ e $z$ é no máximo $k$ ver na seção 4.2.3. Se esta condição for verdadeira, as entidades são passíveis de possuírem uma relação espacial entre si. Caso contrário, considera-se que não há nenhuma relação espacial válida para fins de referência entre as entidades.

Conforme observado em Schutte e Dethlefs (2010) e Braunias et al. (2010), certas relações entre entidades (e.g., espaciais) podem ser transitivas. Por exemplo, suponha que existam três entidades $A, B$ e $C$ lado-a-lado em uma mesma fileira. Neste caso, poderíamos afirmar que $A$ encontra-se à esquerda de $B$ e que, transitivamente, $A$ também está à esquerda de $C$. Na implementação do presente trabalho, entretanto, considerandose o objetivo de gerar descrições livres de ambiguidade, não será computada uma relação entre $A$ e $C$ caso a entidade $C$ não esteja suficientemente próxima da entidade $A$. Assim, uma propriedade como à_esquerda_de(x) deve ser entendida como imediatamente à esquerda de $x$.

Cada entidade é um objeto que possui as propriedades cor, tipo e um mapa de objetos relacionados. Este mapa é definido por uma chave que é uma propriedade relacional como à_esquerda_de(x), na qual $x$ é um entidade relacionada. Um exemplo completo dos tipos de propriedades espaciais extraídas a partir de uma cena GIVE é ilustrado pelo contexto da Figura 19. Os rótulos em cada entidade são identificadores incluídos para fins ilustrativos, e não fazem parte do conjunto de propriedades referenciáveis destas entidades.

Para esta cena, o conjunto de propriedades computadas é sumarizado na Tabela 8. Propriedades deste tipo serão classificadas e selecionadas pelos módulos discutidos nas seções a seguir, e então podem ser utilizadas nas expressões de referência produzidas pelo algoritmo descrito na seção 4.2.4.

Tabela 8 - Propriedades computadas a partir do contexto da Figura 19

\begin{tabular}{cccl}
\hline Entidade & Tipo & Cor & Propriedades Relacionais \\
\hline b1 & botão & azul & à_esquerda_de(b2), à_direita_de(b3), à_frente_de(c1) \\
b2 & botão & azul & à_direita_de(b1), à_frente_de(c1) \\
b3 & botão & azul & à_esquerda_de(b1) \\
c1 & cadeira & & à_frente_de(b1), à_frente_de(b2) \\
\hline
\end{tabular}




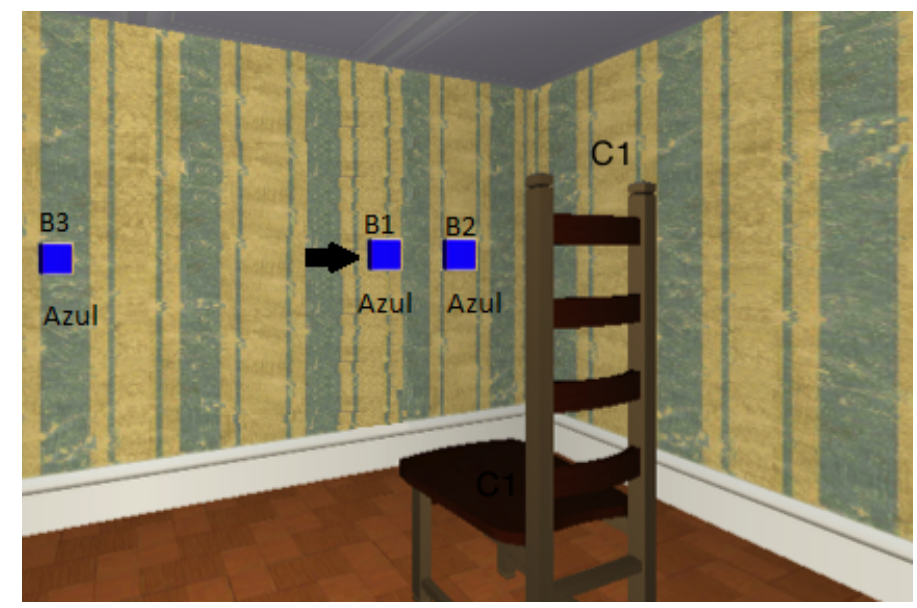

Figura 19 - Exemplo de contexto extraído do sistema GIVE.

\subsubsection{Classificação de pontos de referência}

O fato de que dois objetos mantêm uma relação espacial entre si não necessariamente significa que esta relação seja uma forma típica ou aceitável de referência a estes objetos. Por exemplo, uma expressão como "a caixa que contém um relógio"pode não ser apropriada em um contexto com várias caixas, e no qual não seja possível reconhecer a relação de forma imediata (e.g., porque um objeto oculta o outro). Em outras palavras, uma relação espacial pode ser perfeitamente válida do ponto de vista semântico, mas de uso limitado para fins de referência por questões pragmáticas variadas.

Uma forma de decidir o que constitui ou não uma relação espacial válida para fins de referência, e assim filtrar casos que não deveriam ser considerados na produção destas expressões, é pela observação de exemplos de uso real da língua. A segunda etapa da solução proposta trata assim da tarefa de determinar quais objetos de um contexto de referência mantém relações válidas - para fins de referência - com outros objetos, ou seja, filtrando casos de pouco interesse com base em conhecimento do domínio.

Como forma de manter um certo grau de independência do domínio, a implementação deste módulo faz uso de uma abordagem de aprendizado de máquina baseada no conjunto de treinamento coletado a partir do corpus GIVE-2 (Gargett et al., 2010) descrito na seção 4.1. Esta abordagem é semelhante à abordagem em Viethen (2010), mas descartando-se alguns atributos que não se aplicam ao domínio GIVE, e acrescentando-se outros potencialmente relevantes para a solução do presente problema.

A estratégia adotada consiste em construir um classificador binário use_relation capaz de determinar, para um objeto-alvo $r$ um ponto de referência candidato $o$ em um mesmo 
contexto $C$ (i.e., a sala onde se encontra o usuário), se há uma relação espacial válida para fins de referência entre os dois objetos. Os atributos de aprendizagem considerados foram extraídos da porção de treinamento do corpus GIVE-2.

Tabela $\mathbf{9}$ - Atributos de aprendizagem da classe use_relation

\begin{tabular}{cl}
\hline Atributo & Descrição \\
\hline distractors & Quantidade de objetos do mesmo tipo que $r$. \\
ambiguity & Quantidade de objetos com as mesmas propriedades atômicas de $r$. \\
landmarks & Quantidade de objetos que mantêm relações espaciais com $r$. \\
distance & Distância entre $r$ e $o$, em unidades de distância do mundo GIVE. \\
is_unique & Binário que indica se a relação $(r, o)$ é única em $C$. \\
is_saliente & Binário que indica se $o$ é mais saliente do que $r$. \\
is_similar & Binário que indica se $o$ é o do mesmo tipo e cor de $r$. \\
\hline
\end{tabular}

Os atributos distractors, ambiguity, landmarks e distance são auto explicativos. Os demais são detalhados a seguir.

A definição de is_unique é motivada pela observação feita por (Viethen e Dale, 2011) de que a relação espacial entre o alvo e o ponto de referência tem mais chance de ser inclusa em uma expressão de referência quando for única, já que assim diminui-se a complexidade de identificação do alvo. Um exemplo de aplicação deste princípio em um ambiente GIVE seria um contexto em que deseja-se descrever um botão, e este é o único objeto do tipo botão que se encontra à esquerda de uma cadeira. Neste caso, o uso da relação espacial seria altamente recomendado. O mesmo não ocorreria, entretanto, em um contexto em que outras entidades também possuam esta mesma relação (i.e., em que há outros botões à esquerda de alguma cadeira).

A definição de is_salient é baseada na observação feita por (Viethen e Dale, 2011), segundo a qual uma relação espacial entre o alvo e o ponto de referência é mais utilizada quando o ponto de referência é mais saliente que o alvo. Um exemplo de aplicação deste princípio em um ambiente GIVE seria um contexto em que deseja-se referenciar um botão (que é um objeto pequeno) próximo a uma porta (que é um objeto grande), resultando em uma expressão do tipo "o botão ao lado da porta". Para fins de implementação desta regra, a saliência das entidades é definida de acordo com seu tamanho físico, ou seja, a propriedade atômica size. Outros fatores, como a distância entre o alvo e o ponto de referência, serão considerados na próxima seção, quando será discutido um ranking de relações espaciais. Deve-se ressaltar que as entidades consideradas próximas são as entidades que se encontram na mesma sala. 
Finalmente, a definição de is_similar é também baseada em uma observação feita em Viethen e Dale (2011), segundo a qual uma relação espacial é preferível quando há similaridade visual entre o alvo e o ponto de referência. Um exemplo de aplicação deste princípio em um ambiente GIVE seria um contexto em que o alvo compartilha a mesma cor e mesmo tamanho que o ponto de referência, ou envolvendo objetos que não possuem variações de cor (e.g., sofás, cadeiras, portas, etc.), nos quais a similaridade visual fica restrita ao tipo da entidade. Observa-se entretanto que em um ambiente GIVE não existe variação de tamanho entre objetos do mesmo tipo. Isso reduz a aplicabilidade desta observação, que, para Viethen e Dale (2011) tinha um sentido original mais amplo já que naqueles experimentos havia variação de tamanho e cor.

Considerando-se a definição destes atributos, as instâncias de aprendizagem para a classe use_relation foram geradas da seguinte forma. Para cada objeto-alvo $r$ referenciado no corpus, foi computada uma lista de $n$ objetos que seriam candidatos a pontos de referência em uma possível descrição de $r$ neste contexto. Para este fim, foi utilizado o procedimento de extração de relações espaciais do domínio descrito na seção 4.2.1.

A seguir, para cada par alvo-candidato $\left(r, o_{i}\right) \operatorname{com} i=1 . . N$, foi gerada uma instância de aprendizagem, totalizando assim $n$ instâncias para cada objeto-alvo. Cada conjunto de $n$ instâncias de cada objeto-alvo $r$ foi rotulado da seguinte forma. Se a descrição de $r$ no corpus não usa uma relação espacial, então todas as $n$ instâncias são rotuladas como negativas (use_relation $=$ no), isto é, nenhum dos candidatos pode ser recomendado como ponto de referência para o objeto-alvo $r$. Por outro lado, se a descrição do objeto $r$ no corpus usou uma relação com um ponto de referência $o$, então a instância que representa o par $(r, o)$ é rotulada como positiva, e todas as outras $n$-1 instâncias como negativas.

Como resultado deste procedimento, foram geradas 3246 instâncias de aprendizagem compostas pelos atributos relacionados na tabela 9, sendo 335 positivas (use_relation = yes) e 2911 negativas (use_relation $=$ no). Para a classificação propriamente dita foi utilizado o algoritmo de indução de árvores de decisão J48 disponibilizado pelo pacote WEKA (Hall et al., 2009), utilizando-se 10 fold cross-validation e demais parâmetros default do algoritmo (confiança $\mathrm{C}=0,25$ e um mínimo de $\mathrm{M}=2$ instâncias por folha). A árvore de decisão obtida é apresentada na figura 20. 


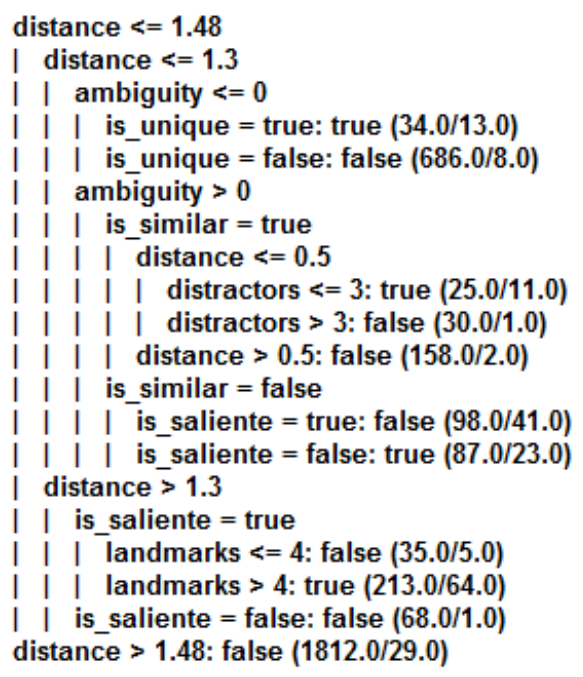

Figura 20 - Árvore de decisão induzida.

A tabela 10 apresenta a matriz confusão com base na indução do classificador da figura 20 a partir dos dados de treinamento.

Tabela 10 - Matriz de confusão para classe binária use_relation cf. figura 20.

\begin{tabular}{lcc}
\hline & yes & no \\
\hline Usa relação & 213 & 122 \\
Não usa relação & 97 & 2814 \\
\hline
\end{tabular}

A tabela 11 apresenta os resultados do treinamento de acordo com as medidas de precisão, cobertura e medida f.

Cobertura é proporção de elementos que foram classificados como $X$ sobre todos os exemplos que realmente são da classe $X$. A função de cobertura é obtida através da matriz de confusão com a fórmula 4.1, na qual TP representa o verdadeiros positivos e $F N$ os falsos negativos (Powers, 2007).

$$
\text { Cobertura }=\frac{T P}{F N+T P}
$$

Precisão é a proporção de elementos que realmente pertence à classe $X$ sobre todos os elementos que foram classificados como $X$. A função de Precisão também é obtida através da matriz de confusão com a fórmula 4.2, na qual FP é o valor de falsos positivos (Powers, 2007).

$$
\text { Precisão }=\frac{T P}{F P+T P}
$$


A medida-f é a média harmônica entre os valores de Cobertura e Precisão. O valor de Medida-f varia de 0 a 1, e quanto mais próximo de 1, melhor o desempenho do classificador (Chinchor, 1992). Como as medidas Cobertura e Precisão terão o mesmo peso no presente trabalho, o valor de $\beta$ da fórmula da Medida-f será definido como 1. Neste caso a Medida-f utilizada é definida pela fórmula 4.3 (Powers, 2007).

$$
\text { Medida }-f=\frac{2 \times \text { Cobertura } \times \text { Precisão }}{\text { Cobertura }+ \text { Precisão }}
$$

Tabela 11 - Resultados da indução do classificador

\begin{tabular}{lccc}
\hline Use_Relation & Precisão & Cobertura & Medida-f \\
\hline yes & 0,68 & 0,63 & 0,66 \\
no & 0,95 & 0,96 & 0,96 \\
média & 0,93 & 0,93 & 0,93 \\
\hline
\end{tabular}

Cabe reiterar que estes resultados são relativos apenas ao treinamento do modelo. O resultado da aplicação deste classificador aos dados de teste será tratado no capítulo 5 .

Finalmente, conforme discutido na seção 4.1.3, observamos no corpus GIVE-2 que, em uma mesma situação de referência, pessoas diferentes podem usar ou não uma relação espacial. Por este motivo, é importante destacar que o classificador proposto tem o objetivo de modelar apenas o comportamento médio dos 72 participantes do experimento GIVE-2, os quais frequentemente empregam estratégias de referência conflitantes.

O classificador ilustrado na figura 20 foi incorporado ao ambiente GIVE, e constitui o primeiro módulo a ser invocado em caso de necessidade de produção de uma descrição de um objeto-alvo $r$. Um exemplo completo de funcionamento deste módulo é apresentado a seguir, considerando-se como entrada os dados da Figura 19.

Dado o objetivo de referenciar o objeto-alvo $r$ na figura 19, o módulo classificador recebe como entrada as propriedades relacionais abaixo (extraídas pelo método discutido na seção 4.2.1), a saber:

R1: à_esquerda_de (B1, B2) d1 $=0,30$

R2: à_frente_de $(\mathrm{B} 1, \mathrm{C} 1) \mathrm{d} 5=1,25$

R3: à_direita_de (B1, B3) d1 $=1,80$

A seguir, é construída uma instância I1..I3 de teste para verificar a possibilidade de 
uso de cada uma das relações (R1..R3), conforme tabela 12 .

Tabela 12 - Instâncias utilizadas no classificador

\begin{tabular}{cccccccc}
\hline \# & distractors & landmarks & ambiguity & distance & is_unique & is_salient & is_similar \\
\hline I1 & 3 & 3 & 2 & 0,30 & true & false & true \\
I2 & 3 & 3 & 2 & 1,25 & false & true & false \\
I3 & 3 & 3 & 2 & 1,80 & true & false & true \\
\hline
\end{tabular}

As instâncias I1..I3 são submetidas à árvore de decisão da figura 20, e o resultado da classificação determina se cada uma das relações correspondentes (R1..R3) deve ou não ser recomendada para uso pelo algoritmo de GER.

Neste exemplo, os seguintes valores são obtidos para a classe use_relation: $I 1=$ True, $I 2=$ True e $I 3=$ False. Desta forma, apenas as relações $R 1$ e $R 2$ atendem aos critérios do classificador no exemplo. Estas duas relações serão então fornecidas como entrada ao próximo módulo do sistema, descrito a seguir.

\subsubsection{Seleção da relação espacial preferencial}

O terceiro módulo do sistema trata de estabelecer um ranking das relações computadas na fase anterior, e então seleciona a alternativa de melhor posição para ser considerada pelo algoritmo de GER descrito na seção 4.2.4. A seleção de uma única relação espacial preferencial é motivada pela observação de que expressões mais complexas, embora possíveis do ponto de vista linguístico, podem ser de difícil interpretação, como "o botão vermelho à esquerda da mesa e acima do botão verde", além do fato de não ocorrerem no corpus GIVE-2 (Gargett et al., 2010).

Diferentemente da questão abordada na seção anterior (concernente à decisão de usar ou não uma relação espacial, implementada na forma de um classificador binário), neste caso não é utilizada uma abordagem de aprendizagem de máquina. Esta diferença de abordagem é motivada pelo tamanho relativamente pequeno do conjunto de dados disponibilizado pelo corpus GIVE-2, em que haveria um número muito reduzido de instâncias de treinamento para cada classe (ou relação espacial) a ser apreendida.

O presente algoritmo é assim uma adaptação da proposta apresentada por Kelleher e Costello (2009) para o domínio GIVE Byron et al. (2007). A entrada do algoritmo é um conjunto de relações espaciais a serem ordenadas. Inicialmente é feito o cálculo da proximidade absoluta (função 3.1, seção 3.3.6) para todas as relações existentes, e seu 
resultado é utilizado para calcular a proximidade relativa (função 3.3, seção 3.3.6) para as mesmas relações. O algoritmo então retorna a relação com maior valor de proximidade relativa (resultado da função 3.3, seção 3.3.6).

A função proximidade absoluta foi adaptada do trabalho em Kelleher e Costello (2009) para contextos do sistema GIVE da seguinte forma. Dado um $L$ que representa o ponto de referência e um $P$ representando o alvo, o cálculo da proximidade absoluta consiste em multiplicar a função dist $t_{\text {normalized }}(L, P)$ entre $L$ e $P$ pelo valor da função salience $(L)$.

A função dist $_{\text {normalized }}(L, P)$ transforma a distância entre $L$ e $P$ em um valor entre 0 e 1. Quanto mais próximo de 0, menor a distância entre as entidades. Neste trabalho esta normalização é feita dividindo-se o valor da distância por 1,48, dado que esta é a distância máxima entre as entidades que pode ser ilustrada pela árvore de decisão ilustrada na figura 20. Já o parâmetro de entrada da função salience é a saliência de $L$, que neste trabalho é representado pelo próprio atributo size do objeto, ao contrário da abordagem em Kelleher e Costello (2009) que utiliza a saliência visual e de discurso combinadas.

A função de proximidade relativa não necessitou adaptações, mantendo-se a forma original proposta em Kelleher e Costello (2009) conforme discutido na seção 3.3.6. O procedimento combinando estas duas funções foi então implementado e também integrado ao ambiente GIVE. Um exemplo completo de seu funcionamento é descrito a seguir, ainda utilizando o contexto da Figura 19, o alvo B1 e também as relações espaciais sugeridas pelo classificador da seção 4.2.2, que são $R 1$ e $R$ 2.

R1: à_esquerda_de (B1, B2) d1 $=0,30$

R2: à_frente_de $(\mathrm{B} 1, \mathrm{C} 1) \mathrm{d} 5=1,25$

O algoritmo recebe como entrada todas as relações selecionadas do alvo $B 1$ (que são $R 1$ a $R 2)$ com os valores de suas respectivas distâncias, e calcula as proximidades absolutas de $R 1(P A 1)$ e R2(PA2) utilizando-se a função 3.1 modificada, resultando em $P A 1=0,79$ e $P A 2=0,77$.

PA1 e PA2 são então utilizados para calcular os valores das proximidades relativas de $R 1$ (PR1) e R2(PR2), utilizando-se a função 3.3, resultando em $P R 1=0$ e PR2 = -0,02. Como o maior valor de proximidade relativa entre $R 1$ e $R 2$ é o de $R 1$, a saída do algoritmo é a relação $R 1$, que será então fornecida como entrada para o algoritmo de $G E R$ discutido na seção a seguir. 


\subsubsection{Geração de expressões de referência com uso de relações espaciais}

O último módulo da solução proposta é o algoritmo de $G E R$ propriamente dito. Este módulo recebe como entrada as relações espaciais produzidas pelos módulos anteriores e as propriedades atômicas dos objetos do contexto, e produz como saída um conjunto de propriedades semânticas a serem realizadas, por exemplo como uma descrição definida. Este algoritmo é uma versão modificada do algoritmo Incremental proposto por Dale e Reiter (1995) para manipular propriedades relacionais (e não apenas atômicas), e que foi também integrado ao sistema GIVE (Byron et al., 2007).

O algoritmo original foi adaptado para considerar tanto propriedades atômicas (e.g., tipo, cor) como relacionais (tais como acima_de(x), abaixo_de(x), etc.) Estas propriedades são consideradas para inclusão em uma expressão de referência de acordo com a frequência com que elas aparecem no conjunto de treinamento descrito na tabela 13.

Tabela 13 - Frequência de atributos observados no conjunto de treinamento.

\begin{tabular}{lcr}
\hline Atributo & Quantidade & $\mathbf{\%}$ \\
\hline tipo & 1189 & $51,00 \%$ \\
cor & 758 & $32,51 \%$ \\
próximo & 210 & $9,0 \%$ \\
esquerda & 92 & $3,94 \%$ \\
direita & 63 & $2,70 \%$ \\
acima & 5 & $0,21 \%$ \\
canto & 9 & $0,38 \%$ \\
em frente & 5 & $0,21 \%$ \\
\hline
\end{tabular}

Das frequências observadas na tabela 13 obtemos a seguinte lista de preferência a ser usada como parâmetro P do algoritmo:

$\mathrm{P}=$ tipo, cor, $\grave{a}_{-} e s q u e r d a_{-} d e(x), \grave{a}_{-} d i r e i t a_{-} d e(x), \operatorname{acima}_{-} d e(x), \grave{a}_{-} f r e n t e_{-} d e(x)$, abaixo_$_{-}(x)$ e $a_{-}$atrás_de $(x)$

A política de seleção de propriedades segue as mesmas diretrizes do algoritmo Incremental de Dale e Reiter (1995), ou seja, as propriedades são avaliadas na ordem P e incluídas na expressão resultante desde que eliminem ao menos uma entidade do contexto.

O uso de propriedades relacionais pode no entanto apresentar o problema de recursividade infinita (Dale e Haddock, 1991), como em "o botão verde à direita do botão azul, que 
está à esquerda do botão verde...". No presente trabalho, entretanto, a solução adotada para este problema consiste em descrever de forma independente cada entidade citada na expressão, e manter uma lista das entidades que já foram utilizadas como referência de modo a evitar que sejam referenciadas duas vezes.

Esta solução é diferente da adotada por Dale e Haddock (1991), que buscam produzir uma descrição que seja livre de ambiguidade apenas do ponto de vista global, como em "o livro sobre a mesa" em um contexto com vários livros e mesas, mas apenas uma mesa sustentando um livro, permitindo assim que duas referências individualmente ambíguas (livro e mesa) possam ser combinadas em uma descrição livre de ambiguidade da entidadealvo.

Ao descrever de forma individual e livre de ambiguidade cada um dos objetos da relação, há obviamente o risco de inclusão de certas propriedades redundantes, como em "o livro sobre a mesa, à esquerda" em um contexto em que somente a mesa esquerda sustentava um livro, e portanto não haveria (em princípio) motivo real para referenciar a posição desta. Esta medida foi no entanto adotada com base no estudo em Paraboni, Deemter e Masthoff (2007), que sugere que a desambiguação mútua de entidades tal como proposta por Dale e Haddock (1991) pode produzir descrições de difícil resolução (e.g., que exigem um esforço de busca considerável por parte do ouvinte) em domínios espaciais do tipo tratado no presente trabalho.

A seguir são apresentados exemplos de saídas do algoritmo para cada um dos botões do contexto da Figura 19, considerando-se as propriedades da Tabela 14 e a ordem de preferência $\mathrm{P}$ acima, observando-se que cada descrição é composta de uma série de listas de propriedades (cláusulas Ref-) que podem referenciar outros objetos.

Tabela 14 - Exemplos de descrições para os objetos da figura 19

\begin{tabular}{|c|c|c|}
\hline $\mathbf{r}$ & Propriedades selecionadas & Exemplo de realização possível \\
\hline b1 & $\begin{array}{l}\text { Ref-b1 }=[(\text { tipo, botão) } \\
\left(\grave{a}_{-} \text {esquerda_de(b2)] }\right.\end{array}$ & O botão à esquerda do botão \\
\hline b2 & $\begin{array}{l}\text { Ref-b2 }=[(\text { tipo, botão) } \\
\left(\grave{a}_{-} \text {direita_de }(b 1)\right]\end{array}$ & O botão à direita do botão \\
\hline b3 & Ref-b3 $=[($ tipo, botão $)]$ & O botão \\
\hline & Ref-c1 $=[($ tipo, cadeira $)]$ & A cadeira \\
\hline
\end{tabular}

O algoritmo aqui apresentado, e uma ampla gama de alternativas, foi avaliado de forma intrínseca conforme será discutido no próximo capítulo. 


\section{Avaliação}

Na avaliação do trabalho desenvolvido, considerou-se inicialmente a possibilidade de avaliação extrínseca, baseada no uso real do algoritmo de $G E R$ proposto em uma aplicação do tipo GIVE. O procedimento neste caso seria semelhante ao adotado por (Paraboni e Deemter, 2013), medindo-se o desempenho de um usuário na tarefa de navegação ao reagir a uma série de instruções contendo expressões de referência produzidas pelo algoritmo proposto, ou por algum sistema de baseline usado como termo de comparação.

Uma análise dos diferentes tipos de expressões produzidas, e das limitações do ambiente GIVE, nos leva entretanto à conclusão de que este tipo de avaliação não é factível. No ambiente GIVE, as únicas métricas de avaliação possíveis são aquelas baseadas na distância percorrida pelo usuário até aproximar-se do objeto-alvo, ou baseadas no tempo transcorrido entre a produção da descrição e a seleção do objeto referenciado. Estas métricas, entretanto, não nos permitiriam capturar de forma significativa a possível diferença entre alternativas como "pressione o botão vermelho"e "pressione o botão ao lado do botão amarelo", que são saídas típicas de um algoritmo do tipo proposto. Em outras palavras, diferenças como esta exigiriam recursos de medição mais sofisticados, como técnicas de eye-tracking (Engelhardt, Xiang e Ferreira, 2008) ou uso de imagens cerebrais (Engelhardt, Demiral e Ferreira, 2011), as quais estão fora do escopo deste trabalho.

Além da inadequação para o tipo de avaliação aqui exigido, medidas de tempo e distância em ambientes GIVE são também altamente sujeitas a ruído. Por exemplo, o usuário pode ter dificuldades de manipulação da interface, ou pode interromper a navegação para considerar uma decisão com mais cautela, dentre muitas outras possibilidades que tornam as métricas de tempo e distância ainda menos confiáveis (embora naturalmente não inviabilize avaliação de outros aspectos de um sistema deste tipo, como o caso da geração de instruções de navegação abordada na série de desafios GIVE (Byron et al., 2009; Koller et al., 2010; Striegnitz et al., 2011)).

Em razão destas dificuldades, diversos aspectos do trabalho proposto no capítulo 
anterior foram assim avaliados de forma intrínseca com base no conjunto de teste extraído do corpus GIVE-2 (Gargett et al., 2010). Esta avaliação é detalhada nas próximas seções.

\subsection{Procedimento}

A avaliação da proposta foi realizada de forma intrínseca, tomando-se por base o conjunto de teste extraído do corpus GIVE-2 conforme detalhado na seção 4.2. Este conjunto é composto de 198 expressões inéditas, as quais não foram consideradas no treinamento do classificador empregado na seleção de pontos de referência (seção 4.2.2), e também não foram consideradas no cômputo das frequências de utilização dos atributos pelo algoritmo de GER (seção 4.2.4).

A avaliação da extração e classificação de pontos de referência (módulos 1 e 2 da proposta) é implementada de forma direta pelo teste do classificador previamente treinado 20]. Não há assim maiores detalhes a acrescentar quanto a este procedimento, cujos resultados são discutidos na seção 5.2. Na presente seção tratamos especificamente do procedimento de avaliação dos módulos 3 e 4 da proposta (a seleção de relação espacial e a tarefa de geração de expressões de referência propriamente dita).

A avaliação realizada teve dois objetivos: verificar se a proposta apresentada realmente possui desempenho global superior a certas alternativas de baseline, e identificar quais os aspectos da solução que mais contribuem para o resultado observado. Para este fim, foram investigadas quatro questões de interesse: a política de seleção de relações espaciais utilizada, a estratégia de ordenação da lista de propriedades consideradas pelo algoritmo, a prioridade atribuída à relação espacial nesta lista, e o tratamento de propriedades espaciais redundantes.

Com relação à política de seleção de relações espaciais, o algoritmo proposto utiliza uma estratégia aqui denominada Proposta, que consiste em utilizar o ranking de relações espaciais descrito na seção 4.2.3. Além desta, serão consideradas também duas outras possibilidades: uma alternativa Aleatória que seleciona uma relação espacial ao acaso, e uma alternativa MaisFreq que seleciona a relação espacial mais frequente de acordo com a frequência observada no conjunto de treinamento.

O algoritmo proposto utiliza uma estratégia de ordenação da lista preferencial de propriedades a serem consideradas (o parâmetro $P$ do algoritmo) aqui denominada PorFreq, que ordena a lista $P$ de acordo com a frequência das propriedades extraída do conjunto de treinamento. Esta estratégia será comparada com duas alternativas: uma estratégia 
de ordenação Aleatória e uma estratégia Gulosa. A estratégia Gulosa ordena a lista $P$ de acordo com o poder discriminatório das propriedades (do maior para o menor). Caso dois atributos eliminem a mesma quantidade de elementos, o empate será resolvido também de maneira aleatória. O propósito da estratégia Aleatória é ilustrar a complexidade da tarefa de GER em questão, e a estratégia Gulosa avalia o argumento apresentado por (Dale e Reiter, 1995), segundo o qual descrições breves são preferíveis por serem consistentes com a máxima de brevidade de H. P. Grice (Grice, 1975).

No algoritmo proposto, a prioridade da relação espacial (ou seja, sua posição dentro da lista P) é estipulada pela política de ordenação empregada (i.e., baseada em frequência). Entretanto, além desta possibilidade - aqui denominada Padrão - serão consideradas duas alternativas: atribuir prioridade Máx, ou seja, considerar a relação espacial na posição inicial da lista, ou atribuir prioridade Mín, isto é, na última posição da lista de preferência. A comparação de prioridades máxima e mínima testam as posições conflitantes de (Viethen e Dale, 2011) - que sugerem que relações espaciais são comuns mesmo quando não têm poder discriminatório - e de (Dale e Haddock, 1991) - segundo a qual uma relação espacial só deve ser utilizada em último caso, ou seja, quando não houver mais propriedades atômicas passíveis de seleção.

Finalmente, no algoritmo proposto uma relação espacial só é selecionada quando desempenha um papel discriminatório na descrição. Além deste papel, aqui denominado Discr, será considerada também o papel redundante, aqui denominado Redund das relações espaciais. Neste caso, a relação espacial será incluída na descrição mesmo que não elimine nenhum objeto do contexto ${ }^{1}$.

A avaliação destas alternativas leva ao enunciado de $(3 * 3 * 3 * 2=54)$ estratégias de GER, cuja relação completa é apresentada na tabela 22 do apêndice B. A tabela 15 sumariza as variações que serão consideradas para fins de avaliação, onde as opções correspondentes à proposta original aparecem em destaque. ${ }^{2}$

Tabela 15 - Variações consideradas para fins de avaliação

\begin{tabular}{cccc}
\hline Seleção & Ordenação & Prioridade & Papel \\
\hline MaisFreq & Gulosa & Máx & Redund \\
Proposta & PorFreq & Padrão & Discr \\
Aleatória & Aleatória & Mín & \\
\hline
\end{tabular}

\footnotetext{
${ }^{1}$ Isso no entanto não significa que a descrição sempre contenha uma relação espacial: o algoritmo ainda deve considerar a posição relativa da propriedade espacial na ordem de preferência P.

${ }^{2} \mathrm{Um}$ subconjunto destes resultados, envolvendo um número reduzido de alternativas de teste, foi apresentado em (Silva e Paraboni, 2013).
} 
As 54 estratégias foram implementadas e executadas individualmente, tomando-se como entrada as 198 situações de referência constantes no corpus de teste. Como resultado, foram obtidos 54 conjuntos de expressões, aqui denominados conjuntos Sistema 1..54.

A avaliação propriamente dita consistiu em comparar cada conjunto de expressões Sistema 1..54 com o conjunto de expressões existentes no corpus, aqui denominado conjunto Referência utilizando-se quatro métricas: acurácia de seleção (Sel), acurácia global (Acc), Dice (Dice, 1945) e MASI (Passonneau, 2006).

Seja $A$ o conjunto que contém as propriedades selecionadas por cada um dos sistemas propostos, e $B$ o conjunto de propriedades existentes na expressão de referência da instância de teste. As métricas de avaliação são calculadas como segue.

A Acurácia de Seleção (Sel) indica se a relação sugerida pelo módulo de ranking de relações espaciais existe no conjunto $B$, assumindo o valor 1 (acertou) ou 0 (não acertou). Esta medida será usada de forma limitada para avaliar se o tipo de relação espacial escolhido pela abordagem proposta é o correto, e será calculado apenas para os casos em que o algoritmo tenha efetivamente selecionado uma relação espacial. Casos em que o algoritmo não selecionou nenhuma relação, porém a descrição Referência utilizava uma, serão avaliados pelos próprio teste do classificador, representado pelos resultados de precisão, cobertura e medida-f.

A Acurácia Global (Acc) indica se os conjuntos $A$ e $B$ são exatamente iguais, assumindo o valor de 1 (iguais) ou 0 (desiguais). Esta medida será utilizada para verificar se há coincidência total entre a expressão gerada (i.e., o uso adequado de relação espacial, que é o foco principal deste trabalho, e demais características da implementação do algoritmo de GER usado como base).

Cabe observar entretanto que, assim como em diversos outros estudos que usam a métrica de acurácia global para avaliação de artefatos de $G L N$ como algoritmos de GER (Lucena, Pereira e Paraboni, 2010) ou módulos de realização superficial (Santos, Pereira e Paraboni, 2008; Pereira e Paraboni, 2008; Novais e Paraboni, 2012), está métrica tende a apresentar uma granularidade inadequada para fins de avaliação. Por este motivo, a acurácia global deve ser interpretada como sendo de caráter ilustrativo, i.e., em complemento às métricas de granularidade mais fina que permitem uma avaliação mais detalhada do fenômeno estudado.

Os coeficientes Dice (Dice, 1945) e MASI (Passonneau, 2006) medem o grau de seme- 
lhança (ou sobreposição) entre dois conjunto. No caso do coeficiente Dice, cada elemento do conjunto $A$ é comparado com os demais elementos do conjunto $B$, considerando-se apenas os elementos iguais. O coeficiente varia de 0 a 1 , sendo que 1 indica que os conjuntos são idênticos, e 0 indicando total desigualdade.

$$
D I C E=\frac{2 \times|(A \cap B)|}{|A|+|B|}
$$

O coeficiente MASI (Passonneau, 2006) também assume valores entre 0 a 1 . Neste caso, entretanto, MASI atribui maior peso ao caso em que um conjunto é subconjunto de outro. Sua fórmula é observada na equação 5.2 .

$$
M A S I=\delta \times \frac{A \cap B}{A \cup B}
$$

A forma que $\delta$ para dois conjuntos $A$ e $B$ é calculada da seguinte maneira. Se a intersecção de $A$ e $B$ for $0 \delta$ é 0 , se $A$ for $0 \delta$ é 1 , se $A$ for subconjunto de $B \delta$ é $\frac{2}{3}$, caso contrário $\delta$ é $\frac{1}{3}$.

\subsection{Resultados}

Os 198 itens de teste apresentaram um total de 86 expressões contendo relações espaciais $(43,43 \%)$. Destas, 36 itens $(18,18 \%)$ faziam referência ao próprio ouvinte receptor da expressão, como em 'pressione o botão ao seu lado'. Conforme discutido na seção 4.2, estes casos não foram cobertos pela presente proposta e acarretam assim uma margem de erro a todas as implementações avaliadas.

\subsubsection{Módulos de extração e classificação}

Antes de discutir a avaliação do sistema proposto e das demais alternativas, será discutida a avaliação do classificador responsável pela seleção de possíveis pontos de referência (conforme discutido na seção 4.2.1) aplicado aos dados de teste. Estes módulos são fixos para todas as versões do sistema consideradas nesta avaliação, e portanto seu desempenho não se reflete na análise que se segue.

A matriz de confusão obtida pelas etapas de extração e classificação de pontos de referência é sumarizada na tabela 16 . 
Tabela 16 - Matriz confusão do classificador descrito no algoritmo na seção 4.2.2 para os dados do conjunto de teste.

\begin{tabular}{lcc}
\hline & yes & no \\
\hline Usa Relação & 13 & 4 \\
Não Usa Relação & 9 & 172 \\
\hline
\end{tabular}

O resultado obtido pelas etapas de extração e classificação de pontos de referência é sumarizado na tabela 17.

Tabela 17 - Resultados da classificação do conjunto de teste.

\begin{tabular}{cccc}
\hline Use_Relation & Precisão & Cobertura & Medida-f \\
\hline yes & 0,59 & 0,77 & 0,67 \\
no & 0,98 & 0,95 & 0,96 \\
Média & 0,94 & 0,93 & 0,94 \\
\hline
\end{tabular}

\subsubsection{Módulos de seleção e $G E R$}

O resultado completo da avaliação das 54 estratégias de GER consideradas é sumarizado no apêndice B. Na tabela 18 são resumidos apenas as 10 estratégias de maior coeficiente Dice. Nesta tabela foram também agregadas as alternativas que produziram saídas idênticas para todas as expressões de teste. O sistema proposto (representado pelas alternativas \#21/23, que são idênticas) é destacado.

Tabela 18 - Resultados resumidos (10 maiores coeficientes Dice)

\begin{tabular}{ccccccccc}
\hline$\#$ & Seleção & Ordenação & Prioridade & Papel & Sel & Acc & Dice & MASI \\
\hline $\mathbf{2 1 / 2 3}$ & Proposta & PorFreq & Mín,Padrão & Discr & $\mathbf{0 . 1 4}$ & $\mathbf{0 . 3 7}$ & $\mathbf{0 . 7 3}$ & $\mathbf{0 . 5 1}$ \\
$3 / 5$ & MaisFreq & PorFreq & Mín, Padrão & Discr & 0,00 & 0,34 & 0,73 & 0,49 \\
$39 / 41$ & Aleatória & PorFreq & Mín, Padrão & Discr & 0,00 & 0,34 & 0,73 & 0,49 \\
33 & Proposta & Aleatória & Mín & Discr & 0,14 & 0,31 & 0,68 & 0,46 \\
51 & Aleatória & Aleatória & Mín & Discr & 0,00 & 0,21 & 0,64 & 0,38 \\
15 & MaisFreq & Aleatória & Mín & Discr & 0,00 & 0,20 & 0,62 & 0,36 \\
$22 / 24$ & Proposta & PorFreq & Mín, Padrão & Redund & 0,23 & 0,04 & 0,60 & 0,26 \\
$40 / 42$ & Aleatória & PorFreq & Mín, Padrão & Redund & 0,00 & 0,00 & 0,59 & 0,22 \\
$4 / 6$ & MaisFreq & PorFreq & Mín, Padrão & Redund & 0,00 & 0,00 & 0,58 & 0,22 \\
34 & Proposta & Aleatória & Mín & Redund & 0,23 & 0,03 & 0,54 & 0,21 \\
\hline
\end{tabular}

$\mathrm{Na}$ discussão que se segue, foram realizadas diversas comparações entre os resultados das 54 estratégias de GER tomando-se por base os coeficientes Dice calculados e os valores de acurácia sobre todas as 198 expressões geradas em cada teste. A análise de valores de Seleção, que se aplica apenas aos 86 casos em que foi efetivamente utilizada uma relação espacial, será discutida posteriormente. Não foi realizada nenhuma análise específica sobre 
os coeficientes MASI uma vez que estes possuem forte correlação com coeficientes Dice (Gatt, Belz e Kow, 2008) . No caso de análises envolvendo coeficientes Dice, foi utilizado o teste de Wilcoxon (Ott e Longnecker, 2010). Para valores de acurácia e Seleção foi utilizado o teste de Qui-quadrado (Ott e Longnecker, 2010).

Para identificar os algoritmos de melhor desempenho global deste conjunto, comparamos a alternativa de maior coeficiente Dice (ou seja, o algoritmo \#21/23) com os subsequentes $\{\# 3 / 5, \# 39 / 41, \# 33, \# 51, \# 15, \# 22 / 24, \# 40 / 42, \# 4 / 6$ e \#34 $\}$. Foram assim identificados os seguintes conjuntos de algoritmos significativamente distintos: em primeiro lugar, o conjunto $C 1=\{\# 21 / 23, \# 3 / 5, \# 39 / 41\}$, seguido pelo conjunto $C 2=$ $\{\# 33, \# 51, \# 15, \# 22 / 24, \# 40 / 42, \# 4 / 6\}$ e finalmente $C 3=\{\# 34\}$. Os coeficientes Dice do conjunto $C 1$ são significativamente superiores aos do conjunto $C 2$ (W=1464, $\mathrm{Z}=4,02$ e $\mathrm{p}<0,0001)$, que são significativamente superiores a $C 3(\mathrm{~W}=1481, \mathrm{Z}=3,76$ e $\mathrm{p}<0,0002)$.

Já de acordo com o coeficiente da Acurácia, foram identificados os seguintes conjuntos de algoritmos significativamente distintos: em primeiro lugar, o conjunto $C 1=$ $\{\# 21 / 23, \# 3 / 5, \# 39 / 41, \# 33\}$, seguido pelo conjunto $C 2=\{\# 51, \# 15\}$ e então $C 3=$ $\left\{\# 22 / 24, \# 40 / 42, \# 4 / 6\right.$ \#34\}. Os coeficientes $\chi^{2}$ da Acurácia do conjunto $C 1$ são significativamente superiores aos do conjunto $C 2\left(\chi^{2}=11,838\right.$, df $\left.=1, \mathrm{p}<0,0003\right)$, que são significativamente superiores a $C 3\left(\chi^{2}=22,782\right.$, df $\left.=1, \mathrm{p}<0,0001\right)$.

\subsubsection{Comparação entre pares de algoritmos}

Além de identificar o grupo de algoritmos de melhor desempenho como sendo o do grupo ao qual pertence o algoritmo proposto (\#23), procurou-se também estabelecer quais das características deste algoritmo tiveram impacto no resultado (i.e., a política de seleção da relação espacial, a estratégia de ordenação da lista de preferência $\mathrm{P}$, a posição da relação espacial em $\mathrm{P}$, e a questão do uso de relações espaciais redundantes). Para este fim, comparamos o algoritmo \#23 (que é a alternativa de melhor desempenho segundo Dice=0,7311, Acc=0,37 e Sel=0,14) com suas contrapartidas em que apenas um fator foi alterado de cada vez. Por exemplo, sendo a estratégia de ordenação adotada pelo algoritmo \#23 baseada em frequência, este algoritmo foi então comparado com os algoritmos \#29 e \#35, que são idênticos a este, porém utilizando as outras estratégias possíveis de ordenação.

Os resultados estatisticamente significativos das comparações realizadas entre o algoritmo \#23 e suas contrapartidas são destacados em negrito na tabela 19. Todos os testes de $\chi^{2}$ consideram a distribuição com $\mathrm{df}=1$ graus de liberdade. Esta informação, que é 
fixa para todos os testes, foi omitida da tabela para facilitar sua visualização.

Tabela 19 - Comparação do algoritmo \#23 (seleção proposta, ordenação por frequência, prioridade padrão e papel discriminatório) com suas contrapartidas.

\begin{tabular}{lrrrrrrr}
\hline & \multicolumn{3}{c}{ Dice } & \multicolumn{2}{c}{ Acurácia global (Acc) } & \multicolumn{2}{c}{ Seleção (Sel) } \\
Pares de algoritmos & $\mathbf{W}$ & $\mathbf{Z}$ & $\mathbf{p}$ & $\boldsymbol{\chi}^{\mathbf{2}}$ & $\mathbf{p}$ & $\boldsymbol{\chi}^{\mathbf{2}}$ & $\mathbf{p}$ \\
\hline \#23 x \#05 Sel. MaisFreq & 193 & 1,09 & 0,2757 & 0,28 & 0,5992 & 30,89 & $<\mathbf{0 , 0 0 0 1}$ \\
\#23 x \#41 Sel. Aleatória & 158 & 0,89 & 0,3735 & 0,28 & 0,5992 & 30,89 & $<\mathbf{0 , 0 0 0 1}$ \\
\#23 x \#29 Ord. Gulosa & 18336 & 11,98 & $<\mathbf{0 , 0 0 0 1}$ & 87,06 & $<\mathbf{0 , 0 0 0 1}$ & 6,68 & $\mathbf{0 , 0 0 9 7}$ \\
\#23 x \#35 Ord. Aleatória & 8515 & 9,89 & $<\mathbf{0 , 0 0 0 1}$ & 41,61 & $<\mathbf{0 , 0 0 0 1}$ & 6,68 & $\mathbf{0 , 0 0 9 7}$ \\
\#23 x \#19 Prior.Máx & 15931 & 11,57 & $\mathbf{< 0 , 0 0 0 1}$ & 80,60 & $<\mathbf{0 , 0 0 0 1}$ & 6,68 & $\mathbf{0 , 0 0 9 7}$ \\
\#23 x \#24 Papel Redund. & 10721 & 8,41 & $\mathbf{< 0 , 0 0 0 1}$ & 63,57 & $<\mathbf{0 , 0 0 0 1}$ & 6,68 & $\mathbf{0 , 0 0 9 7}$ \\
\hline
\end{tabular}

\subsubsection{Comparação entre grupos de algoritmos}

Dadas as diferenças observadas entre o algoritmo de melhor desempenho (\#23) e suas contrapartidas, é pertinente questionar se estas observações dizem respeito apenas ao par de algoritmos em questão, ou se são generalizáveis para todos os algoritmos daquela mesma categoria. Por exemplo, segundo a análise de coeficientes Dice, a estratégia de ordenação adotada pelo algoritmo \#23 (baseada em frequência) é superior às estratégias de \#35 (i.e., ordenação aleatória) e de \#29 (gulosa). Resta então investigar se esta vantagem representa uma superioridade média de todos os algoritmos de que utilizam ordenação baseada em frequência sobre todos os algoritmos que utilizam uma determinada ordenação alternativa.

Foi realizada assim uma série de comparações entre os valores médios de Dice, Acc e Sel para as diversas classes de algoritmos considerados. A tabela 20 resume estas comparações, destacando em negrito as diferenças estatisticamente significativas que foram observadas. Novamente, as distribuições de $\chi^{2}$ possuem $\mathrm{df}=1$ graus de liberdade.

Tabela 20 - Comparação dos valores médios de Dice a Acurácia por grupo de algoritmos

\begin{tabular}{lrrrrrrr}
\hline & \multicolumn{3}{c}{ Dice médio } & \multicolumn{2}{c}{ Acc média } & \multicolumn{2}{c}{ Sel média } \\
Grupos de algoritmos & W & $\mathbf{Z}$ & $\mathbf{p}$ & $\boldsymbol{\chi}^{\mathbf{2}}$ & $\mathbf{p}$ & $\boldsymbol{\chi}^{\mathbf{2}}$ & $\mathbf{p}$ \\
\hline Seleção (Proposta X MaisFreq) & 81 & 1,75 & 0,0801 & 0,17 & 0,6794 & 19,09 & $<\mathbf{0 , 0 0 0 1}$ \\
Seleção (Proposta x Aleatória) & 59 & 1,27 & 0,2041 & 0,17 & 0,6794 & 19,09 & $<\mathbf{0 , 0 0 0 1}$ \\
Ordenação (PorFreq x Gulosa) & 129 & 2,80 & $\mathbf{0 , 0 0 5 1}$ & 23,46 & $<\mathbf{0 , 0 0 0 1}$ & 0 & 1 \\
Ordenação (PorFreq x Aleatória) & 153 & 3,61 & $\mathbf{0 , 0 0 0 3}$ & 3,70 & 0,0545 & 0 & 1 \\
Prioridade (Padrão X Máx) & 103 & 2,23 & $\mathbf{0 , 0 2 5 7}$ & 14,65 & $<\mathbf{0 , 0 0 0 1}$ & 0 & 1 \\
Prioridade (Padrão x Mín) & 21 & 0 & 1 & 0,28 & 0,6000 & 0 & 1 \\
Papel (Redund x Discr) & 217 & 3,76 & $<\mathbf{0 , 0 0 0 2}$ & 19,56 & $<\mathbf{0 , 0 0 0 1}$ & 0,08 & 0,7733 \\
\hline
\end{tabular}




\subsubsection{Comparação com algoritmo sem classificador}

Finalmente, procuramos também avaliar a influência do módulo classificador sobre os resultados obtidos pela solução proposta (\#23). Para este fim, repetimos o procedimento de avaliação deste algoritmo, porém desta vez sem uso do módulo classificador. As relações espaciais extraídas do domínio (módulo 1 do sistema) foram assim fornecidas diretamente ao algoritmo de seleção (módulo 3) sem passar pelo filtro treinado a partir do corpus GIVE-2 (Gargett et al., 2010). O resultado deste algoritmo, aqui denominado algoritmo \#55, é sumarizado na tabela 21.

Tabela 21 - Resultado da avaliação sem classificador (algoritmo \#55)

\begin{tabular}{ccccccccc}
\hline \# & Seleção & Ordenação & Prioridade & Papel & Seleção & Acurácia & Dice & MASI \\
\hline $\mathbf{5 5}$ & Proposta & PorFreq & Padrão & Discr & 0,00 & 0,44 & 0,74 & 0,58 \\
\hline
\end{tabular}

Não foram observadas diferenças significativas em coeficientes Dice e Acc entre o algoritmo \#23 original e sua contrapartida sem classificador (\#55). Entretanto, o uso do classificador aumenta significativamente a acurácia de seleção (Sel) $\left(\chi^{2}=30,86\right.$, df =1, $\mathrm{p}<0,0001)$.

\subsection{Discussão}

De acordo com as tabelas 19 e 20 das seções anteriores, é possível constatar que o algoritmo proposto (\#23) possui o melhor desempenho sob vários pontos de vista, tanto na comparação com as suas contrapartidas como na média geral dos algoritmos de características semelhantes. Estes pontos são discutidos a seguir.

Com relação à política de seleção da relação espacial, a alternativa Proposta mostrou-se significativamente superior às estratégias de seleção do atributo mais frequente MaisFreq e Aleatória de acordo com a acurácia de seleção (Sel), mas não de acordo com coeficientes Dice e de acurácia global (Acc). O mesmo ocorre no caso da comparação do conjunto de algoritmos que utilizam a mesma estratégia de seleção MaisFreq com os demais conjuntos, em que não houve diferença estatisticamente significativa em coeficientes Dice ou Acc mas apenas em Sel.

Embora cada uma das três políticas de seleção esteja efetivamente selecionando relações espaciais distintas, e embora o algoritmo proposto tenha um número de acertos na seleção do atributo espacial (Sel) significativamente superior às suas contrapartidas tanto na comparação entre pares como entre grupos, este maior número de acertos não se refletiu nos 
coeficientes Dice e Acc. Esta divergência entre métricas entretanto se explica pelo fato de a propriedade espacial ser apenas uma dentre as várias propriedades que são selecionadas para compor a expressão resultante, as quais são consideradas de forma conjunta (i.e., indistinta) no cálculo de Dice e Acc. Por este motivo, os valores finais destas métricas acabam sendo muito próximos entre si, independentemente do uso ou não da relação espacial correta.

Com relação à estratégia de ordenação da lista de propriedades $P$, o algoritmo proposto ordena $P$ com base na frequência observada nos dados de treinamento (PorFreq). Esta alternativa é estatisticamente superior às estratégias de ordenação Gulosa e Aleatória tanto com base em coeficientes Dice bem como Acc. Além disso, a acurácia média do conjunto de algoritmos que utilizam a estratégia de ordenação PorFreq é significativamente superior à acurácia média das estratégias Gulosa e Aleatória. Estes resultados confirmam nossa proposta original de que a ordenação baseada em frequência apresenta resultados satisfatórios, e corrobora resultados obtidos para o problema de GER no domínio TUNA (Gatt, Belz e Kow, 2008) discutidos em (Lucena, Pereira e Paraboni, 2010), dentre vários outros.

Com relação à prioridade atribuída à relação espacial, o algoritmo proposto utiliza a prioridade Padrão, i.e., mantendo a posição da relação espacial em $P$ tal qual ditada pela estratégia de ordenação. De acordo com os resultados obtidos, não há diferença significativa entre esta prioridade e a prioridade mínima (Mín) . Já a diferença entre a prioridade Padrão e a de prioridade máxima Máx é significativa tanto em termos de coeficientes Dice quanto Acc. Além disso, a comparação entre o conjunto de algoritmos que utilizam prioridade Padrão e os demais conjuntos indica que a prioridade Padrão ou Mín são iguais, e significativamente superiores à prioridade (Máx). Estas observações confirmam nossa proposta de uso da relação espacial com base na sua frequência de uso relativo. O uso de relações espaciais em domínios do tipo GIVE não é apenas um último recurso de referência, como se observa em Dale e Haddock (1991), e tampouco é um fenômeno predominante como proposto em Viethen e Dale (2011).

O algoritmo proposto utiliza relações espaciais apenas de forma discriminatória ( Discr). Esta estratégia revelou-se significativamente superior ao uso redundante (Redund) destas relações tanto em termos de coeficiente Dice quanto em termos de coeficiente Acc. O mesmo resultado foi observado na comparação entre o conjunto de algoritmos que não utilizam redundância com o conjunto que utiliza. Estes resultados comprovam que, no domínio GIVE, relações espaciais tendem a ser utilizadas apenas quando auxiliam na 
desambiguação do referente. Por outro lado, estes resultados contrastam estudos como aqueles realizados por (Paraboni, Deemter e Masthoff, 2007), em que o uso de relações espaciais redundantes faz-se recomendável ou mesmo necessário para a correta identificação do referente em domínios de maior complexidade estrutural do que a observada em mundos GIVE.

Finalmente, além da redução substancial no número de candidatos a serem considerados pelo módulo de seleção, o uso do classificador baseado em dados do corpus aumentou de forma significativa a acurácia de seleção. Esta vantagem pode vir a ser ainda maior em domínios mais complexos (e.g., com maior número de candidatos a considerar), e/ou em aplicações de tempo real nas quais estas propriedades tenham de ser computadas de forma dinâmica.

\subsection{Análise de Erros}

Dentro das 198 expressões de referência gerada pelo algoritmo proposto, 125 delas $(63,13 \%)$ não utilizaram exatamente o mesmo conjunto de propriedades da expressão do corpus, ou seja, possuem o valor 0 para o coeficiente Acc. Estes erros são em partes causados pelo uso indevido de relações espaciais, e também por outras decisões incorretas do algoritmo de GER tomado por base para esta implementação (e.g., no uso de propriedades atômicas). Nesta seção discutimos a análise destes erros, ressaltando que pode haver mais de uma causa possível para um mesmo erro.

Em primeiro lugar, no conjunto de expressões que utilizam relações espaciais, 36 casos $(28,8 \%)$ utilizam como ponto de referência o próprio jogador, como em 'o botão ao seu lado'. A utilização de relação espacial com o jogador não é feita pelo algoritmo proposto, e constitui assim uma margem de erro inerente ao trabalho desenvolvido.

Foram observados 23 casos $(18,40 \%)$ de situações em que a expressão de referência do corpus contêm relação espacial e a expressão de referência do algoritmo proposto não. Este erro é explicado pela decisão humana em não utilizar a relação espacial na expressão de referência, mesmo sendo esta necessária para a desambiguação do alvo. Acreditamos não haver uma solução computacional simples para casos deste tipo.

Em 4 casos (3,20\%), observa-se que o contexto utilizado para a expressão do corpus foi reduzido, possibilitando a geração de expressões que utilizavam apenas a propriedade atômica type. Este tipo de erro ocorreu porque o contexto utilizado pelo algoritmo proposto foi sempre o conjunto de todos os objetos da sala, e não apenas os objetos no campo 
de visão do ouvinte. Por outro lado, observa-se também que há 16 casos (12,80\%) em que a expressão de referência do corpus utiliza a propriedade atômica cor de maneira redundante, recurso este que não é implementado pelo algoritmo Incremental tomado por base.

A escolha incorreta do objeto usado como ponto de referência foi observada em 20 expressões (16\% dos casos). Este erro é ocasionado por imprecisão do classificador, pois nenhum dos pontos de referência utilizados na expressão do corpus estavam disponíveis para o algoritmo Incremental após o filtro do classificador ser aplicado. É possível portanto que um maior volume de dados de treinamento venha a minimizar este tipo de erro.

Observamos também 20 casos (16\%) em que a expressão de referência do corpus possui relação espacial, mas o algoritmo proposto não a utilizou. Isso ocorre em parte porque a lista de preferência $P$ utilizada pelo algoritmo ditar uma seleção de propriedades diferentes (ou seja, a seleção de atributos feita pelo algoritmo Incremental não corresponde exatamente ao processo humano), e em parte em virtude do uso redundante de relações espaciais (o qual não é favorecido pela solução proposta).

Finalmente, há 6 casos $(4,80 \%$ ) em que a expressão do corpus utilizou uma relação espacial de maneira topológica (Next). Isso acontece porque o algoritmo proposto utiliza as relações espaciais apenas de maneira projetiva. 


\section{Conclusões}

Este trabalho apresentou uma pesquisa em nível de mestrado acadêmico na área de GLN enfocando o problema da geração expressões de referência utilizando relações espaciais em ambientes interativos tridimensionais do tipo GIVE (Byron et al., 2007). O trabalho resultou na proposta de um algoritmo de GER que determina se e quando utilizar atributos espaciais em uma expressão de referência para fins de identificação de um objeto-alvo.

O algoritmo proposto combina conhecimento linguístico extraído dos corpora GRE3DY (Viethen, 2010) e GIVE-2 (Gargett et al., 2010) e os modelos computacionais em (Kelleher e Costello, 2009), e foi integrado a um sistema de GLN para ambientes interativos tridimensionais do tipo GIVE.

O trabalho foi avaliado de forma intrínseca sob diversos aspectos, envolvendo o teste de 55 variações da proposta cobrindo quatro questões de interesse: a política de seleção de relações espaciais utilizada, a estratégia de ordenação da lista de propriedades consideradas pelo algoritmo, a prioridade atribuída à relação espacial nesta lista, e o tratamento de propriedades espaciais redundantes.

Os resultados obtidos sugerem que o algoritmo proposto possui o melhor desempenho sob vários pontos de vista. O uso do classificador aumentou de forma significativa a acurácia de seleção de atributos espaciais, e a ordenação de propriedades baseada em frequência apresentou-se superior às alternativas consideradas, inclusive à estratégia gulosa. Além disso, pelo menos no caso do domínio GIVE, o uso de relação espacial não é apenas um último recurso de referência. As relações espaciais são comuns nesse domínio, e tendem a ser utilizadas de forma discriminatória para fins de desambiguação do referente.

\subsection{Contribuições}

O trabalho realizado oferece as seguintes contribuições: 
- Um modelo de geração de expressões de referência envolvendo o uso de relações espaciais em ambientes GIVE. Este modelo contempla diversas contribuições teóricas para a pesquisa em $G E R$, incluindo contribuições direcionadas a questões sobre as maneiras possíveis de usar relações espaciais, a melhor ordem para um algoritmo do tipo incremental considerar as propriedades disponíveis, a prioridade a ser atribuída à relação espacial, e o papel das propriedades espaciais redundantes.

- Uma extensão do algoritmo Incremental que faz uso de propriedades relacionais.

- Uma implementação completa do algoritmo e modelo de $G E R$ integrado ao ambiente GIVE.

- Um subconjunto do corpus GIVE-2 (Gargett et al., 2010) contendo expressões de referência de objetos do tipo botão, anotadas semanticamente e representadas em formato $X M L$.

Uma versão preliminar do algoritmo proposto e de resultados parciais da avaliação realizada são discutidos em (Silva e Paraboni, 2013).

\subsection{Limitações}

Uma limitação importante do presente trabalho é o fato de que foi validada apenas no domínio GIVE. Da mesma forma que encontramos diferenças significativas no uso de relações espaciais entre os corpora GRE3D7 e GIVE, é provável que os princípios aqui discutidos tenham de ser adaptados a outras domínios. Acreditamos, entretanto, que a combinação de modelos de referência espacial com conhecimento de corpus possa de certa forma facilitar esta adaptação, embora obviamente este trabalho não apresente evidência para embasar esta afirmação.

Em virtude do tipo de corpus disponível, a avaliação contemplou exclusivamente o caso de referência a objetos do tipo botão. Não é entretanto óbvio se um algoritmo de GER deveria ter exatamente este mesmo comportamento em situações de referência a outros tipos de objetos. Além disso, ao limitarmos o estudo dos tipos de referência espacial as referências mais comuns (acima, abaixo, esquerda, direita etc.) uma série de questões permanecem em aberto, como o tratamento de relações espaciais diagonais, descrições topológicas, negações etc.

Ainda com relação ao tipo de expressão gerada, cabe observar que foi adotado o princípio geral de que o contexto de referência é definido como o conjunto de objetos 
presentes na mesma sala onde se encontra o objeto-alvo. Na prática entretanto, esta simplificação possui exceções importantes, como alguns casos verificados no próprio corpus GIVE-2. Um algoritmo mais sofisticado deveria assim considerar apenas os objetos no foco de atenção no momento da referência.

Outra limitação do presente trabalho é o tamanho reduzido do corpus GIVE-2 usado para treinamento e teste da solução proposta. Este problema é agravado também pelo desbalanceamento de dados, com incidência relativamente baixa de uso de relações espaciais. Embora os resultados possam ser considerados satisfatórios para os propósitos desta pesquisa, seria desejável validar o modelo proposto com base em um conjunto de dados mais extenso.

\subsection{Trabalhos futuros}

A pesquisa realizada oferece uma série de oportunidades de melhoria e extensões. Como trabalho futuro, contemplamos em primeiro lugar a necessidade de validar o modelo proposto em outros tipos de domínio espacial (i.e., que não sejam do tipo GIVE), tarefa esta que requer a coleta e anotação de corpora especializado.

Além disso, o algoritmo proposto pode ser estendido de modo a oferecer suporte a mais tipos de atributos espaciais infrequentes no corpus GIVE-2, incluindo a geração de referências ao próprio ouvinte (e.g., "ao seu lado").

Finalmente, como este trabalho restringiu-se a enfocar a tarefa de seleção de conteúdo semântico de expressões de referência, coloca-se ainda a necessidade de tratar também a realização superficial destas expressões, a qual também apresenta uma série de desafios computacionais não triviais. 


\section{APÊENICE A - Exemplo de representação XML do corpus GIVE-2}

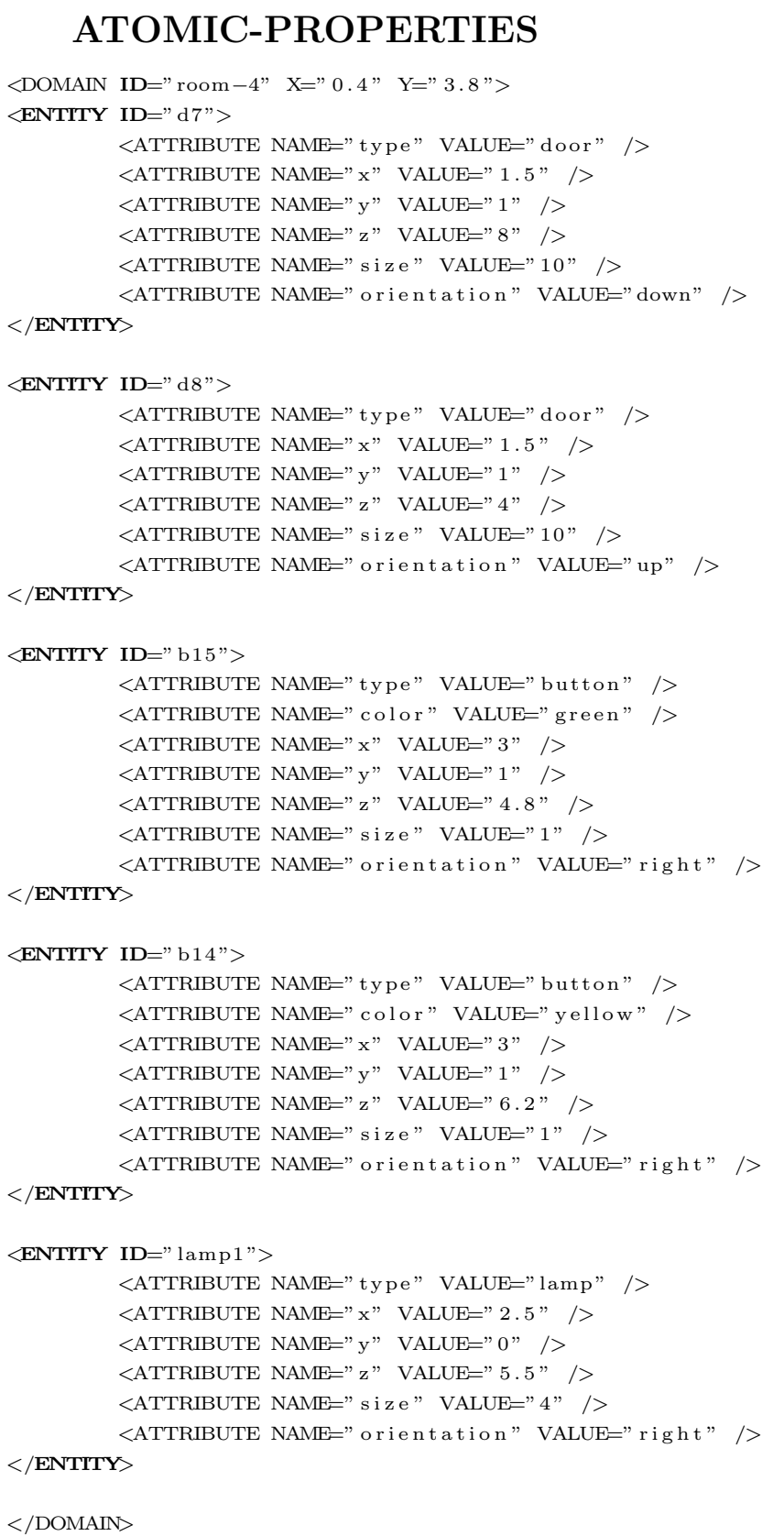




\section{Expressão de Referência}

$<$ EXPRESSION WORLD_ID=" 3" PLAYER_ID=" 26 "

LANGUAGE_ID="EN" TARGET_ID=" b15">

$<$ ENTITY ID=" b15">

$<$ ATTRIBUTE NAME-" ty pe" VALUE="button" />

$</$ ENTITY $>$

$<$ ATTRIBUTE NAME=" color" VALUE=" green" $/>$

$<$ RELATIONSHIP $>$

<RELATION TARGET=" b15" LANDMARK="lamp1">

$<$ ATTRIBUTE NAME=" relation" VALUE=" next" $/>$

$</$ RELATION $>$

$<$ ENTITY ID="lamp1" $>$

$</$ ENTITY $>$

$<$ ATTRIBUTE NAME=" type" VALUE="lamp" />

$</$ EXPRESSION $>$

$</$ RELATIONSHIP $>$

\section{Propriedades Relacionais}

$<$ DOMAIN ID=" room -1 " $>$

$<$ RELATION TARGET=" b15" LANDMARK=" lamp1" $>$

$<$ ATTRIBUTE NAME=" position" VALUE="slightlyleft" />

$</$ RELATION $>$

$<$ ATTRIBUTE NAME=" distan ce" VALUE=" $1.32 " />$

$<$ RELATION TARGET=" b14" LANDMARK="lamp1">

$<$ ATTRIBUTE NAME=" position" VALUE="slightlyright" $/>$ $<$ ATTRIBUTE NAME=" distan ce" VALUE=" $1.32 " />$

$</$ RELATION $>$

$<$ RELATION TARGET=" lamp1" LANDMARK=" b15">

<ATTRIBUTE NAME=" position" VALUE="slightlyright" $/>$ $</$ RELATION $>$

$<$ ATTRIBUTE NAME=" distan ce" VALUE=" $1.32 " />$

$<$ RELATION TARGET="lamp1" LANDMARK=" b14">

$<$ ATTRIBUTE NAME=" position" VALUE="leftaround" $/>$

$<$ ATTRIBUTE NAME=" distance" VALUE=" $1.32 " />$

$</$ RELATION $>$

$</$ DOMAIN $>$ 


\section{APÊNDICE B - Resultado da avaliação intrínseca}

A tabela 22 apresenta os resultados detalhados da avaliação das 54 alternativas consideradas. O sistema proposto (\#23) aparece em destaque.

Tabela 22 - Resultados

\begin{tabular}{|c|c|c|c|c|c|c|c|c|}
\hline \# & Seleção & Ordenação & Prioridade & Papel & Seleção & Acurácia & Dice & MASI \\
\hline 1 & MaisFreq & PorFreq & Máx & Discr & 0,00 & 0,00 & 0,24 & 0,07 \\
\hline 2 & MaisFreq & PorFreq & Máx & Redund & 0,00 & 0,00 & 0,24 & 0,07 \\
\hline 3 & MaisFreq & PorFreq & Mín & Discr & 0,00 & 0,34 & 0,73 & 0,49 \\
\hline 4 & MaisFreq & PorFreq & Mín & Redund & 0,00 & 0,00 & 0,58 & 0,22 \\
\hline 5 & MaisFreq & PorFreq & Padrão & Discr & 0,00 & 0,34 & 0,73 & 0,49 \\
\hline 6 & MaisFreq & PorFreq & Padrão & Redund & 0,00 & 0,00 & 0,58 & 0,22 \\
\hline 7 & MaisFreq & Gulosa & Máx & Discr & 0,00 & 0,00 & 0,43 & 0,18 \\
\hline 8 & MaisFreq & Gulosa & Máx & Redund & 0,00 & 0,00 & 0,31 & 0,07 \\
\hline 9 & MaisFreq & Gulosa & Mín & Discr & 0,00 & 0,00 & 0,28 & 0,11 \\
\hline 10 & MaisFreq & Gulosa & Mín & Redund & 0,00 & 0,00 & 0,21 & 0,05 \\
\hline 11 & MaisFreq & Gulosa & Padrão & Discr & 0,00 & 0,00 & 0,28 & 0,11 \\
\hline 12 & MaisFreq & Gulosa & Padrão & Redund & 0,00 & 0,00 & 0,21 & 0,05 \\
\hline 13 & MaisFreq & Aleatória & Máx & Discr & 0,00 & 0,00 & 0,23 & 0,07 \\
\hline 14 & MaisFreq & Aleatória & Máx & Redund & 0,00 & 0,00 & 0,23 & 0,07 \\
\hline 15 & MaisFreq & Aleatória & Mín & Discr & 0,00 & 0,20 & 0,62 & 0,36 \\
\hline 16 & MaisFreq & Aleatória & Mín & Redund & 0,00 & 0,00 & 0,45 & 0,15 \\
\hline 17 & MaisFreq & Aleatória & Padrão & Discr & 0,00 & 0,14 & 0,36 & 0,21 \\
\hline 18 & MaisFreq & Aleatória & Padrão & Redund & 0,00 & 0,00 & 0,43 & 0,15 \\
\hline 19 & Proposta & PorFreq & Máx & Discr & 0,23 & 0,01 & 0,16 & 0,06 \\
\hline 20 & Proposta & PorFreq & Máx & Redund & 0,23 & 0,01 & 0,16 & 0,06 \\
\hline 21 & Proposta & PorFreq & Mín & Discr & 0,14 & 0,37 & 0,73 & 0,51 \\
\hline 22 & Proposta & PorFreq & Mín & Redund & 0,23 & 0,04 & 0,60 & 0,26 \\
\hline 23 & Proposta & PorFreq & Padrão & Discr & 0,14 & 0,37 & 0,73 & 0,51 \\
\hline 24 & Proposta & PorFreq & Padrão & Redund & 0,23 & 0,04 & 0,60 & 0,26 \\
\hline 25 & Proposta & Gulosa & Máx & Discr & 0,14 & 0,00 & 0,40 & 0,18 \\
\hline 26 & Proposta & Gulosa & Máx & Redund & 0,23 & 0,00 & 0,30 & 0,08 \\
\hline 27 & Proposta & Gulosa & Mín & Discr & 0,23 & 0,00 & 0,13 & 0,04 \\
\hline 28 & Proposta & Gulosa & Mín & Redund & 0,23 & 0,00 & 0,13 & 0,04 \\
\hline 29 & Proposta & Gulosa & Padrão & Discr & 0,23 & 0,00 & 0,13 & 0,04 \\
\hline 30 & Proposta & Gulosa & Padrão & Redund & 0,23 & 0,00 & 0,13 & 0,04 \\
\hline 31 & Proposta & Aleatória & Máx & Discr & 0,23 & 0,00 & 0,14 & 0,05 \\
\hline 32 & Proposta & Aleatória & Máx & Redund & 0,23 & 0,01 & 0,15 & 0,06 \\
\hline 33 & Proposta & Aleatória & Mín & Discr & 0,14 & 0,31 & 0,68 & 0,46 \\
\hline 34 & Proposta & Aleatória & Mín & Redund & 0,23 & 0,03 & 0,54 & 0,21 \\
\hline 35 & Proposta & Aleatória & Padrão & Discr & 0,23 & 0,09 & 0,48 & 0,24 \\
\hline 36 & Proposta & Aleatória & Padrão & Redund & 0,23 & 0,02 & 0,35 & 0,12 \\
\hline 37 & Aleatória & PorFreq & Máx & Discr & 0,00 & 0,00 & 0,28 & 0,08 \\
\hline 38 & Aleatória & PorFreq & Máx & Redund & 0,00 & 0,00 & 0,28 & 0,08 \\
\hline 39 & Aleatória & PorFreq & Mín & Discr & 0,00 & 0,34 & 0,73 & 0,49 \\
\hline 40 & Aleatória & PorFreq & Mín & Redund & 0,00 & 0,00 & 0,58 & 0,22 \\
\hline 41 & Aleatória & PorFreq & Padrão & Discr & 0,00 & 0,34 & 0,73 & 0,49 \\
\hline 42 & Aleatória & PorFreq & Padrão & Redund & 0,00 & 0,00 & 0,58 & 0,22 \\
\hline 43 & Aleatória & Gulosa & Máx & Discr & 0,00 & 0,00 & 0,41 & 0,18 \\
\hline 44 & Aleatória & Gulosa & Máx & Redund & 0,00 & 0,00 & 0,30 & 0,07 \\
\hline 45 & Aleatória & Gulosa & Mín & Discr & 0,00 & 0,00 & 0,34 & 0,14 \\
\hline 46 & Aleatória & Gulosa & Mín & Redund & 0,00 & 0,00 & 0,25 & 0,06 \\
\hline 47 & Aleatória & Gulosa & Padrão & Discr & 0,00 & 0,00 & 0,34 & 0,14 \\
\hline 48 & Aleatória & Gulosa & Padrão & Redund & 0,00 & 0,00 & 0,25 & 0,06 \\
\hline 49 & Aleatória & Aleatória & Máx & Discr & 0,00 & 0,00 & 0,28 & 0,08 \\
\hline 50 & Aleatória & Aleatória & Máx & Redund & 0,00 & 0,00 & 0,25 & 0,06 \\
\hline 51 & Aleatória & Aleatória & Mín & Discr & 0,00 & 0,21 & 0,64 & 0,38 \\
\hline 52 & Aleatória & Aleatória & Mín & Redund & 0,00 & 0,00 & 0,40 & 0,12 \\
\hline 53 & Aleatória & Aleatória & Padrão & Discr & 0,00 & 0,08 & 0,37 & 0,16 \\
\hline 54 & Aleatória & Aleatória & Padrão & Redund & 0,00 & 0,00 & 0,34 & 0,10 \\
\hline 55 & Proposta & PorFreq & Padrão & Discr & 0,00 & 0,44 & 0.74 & 0,58 \\
\hline
\end{tabular}




\section{Referências}

AKKERSDIJK, S. et al. The Thumbs Up! Twente system for GIVE 2.5. In: Proceedings of the Generation Challenges Session at the 13nd European Workshop on Natural Language Generation, Nancy, France. Nancy, France: Association for Computational Linguistics, 2011. p. 312-317.

ALUÍSIO, S. M. et al. Towards Brazilian Portuguese automatic text simplification systems. In: Proceedings of the eighth ACM symposium on Document engineering. New York, NY, USA: ACM, 2008. (DocEng '08), p. 240-248. ISBN 978-1-60558-081-4. Disponível em: <http://doi.acm.org/10.1145/1410140.1410191>.

APPELT, D. E. Planning english referring expressions. Artif. Intell., Elsevier Science Publishers Ltd., Essex, UK, v. 26, n. 1, p. 1-33, abr. 1985. ISSN 0004-3702. Disponível em: <http://dx.doi.org/10.1016/0004-3702(85)90011-6>.

ARECES, C.; FIGUEIRA, S.; GORÍN, D. Using Logic in the Generation of Referring Expressions. In: POGODALLA, S.; PROST, J. (Ed.). Proceedings of the 6th International Conference on Logical Aspects of Computational Linguistics (LACL 2011). Montpelier: Springer, 2011. (Lecture Notes in Computer Science, v. 6736), p. 17-32.

ARTS, A. et al. Overspecification facilitates object identification. Journal of Pragmatics, v. 43, p. $361-374,2011$.

AZIZ, W. F.; PARDO, T. A. S.; PARABONI, I. An Experiment in Spanish-Portuguese Statistical Machine Translation. Advances in Artificial Intelligence-SBIA 2008, Springer-Verlag, LNAI 5249, p. 248-257, 2008.

AZIZ, W. F.; PARDO, T. A. S.; PARABONI, I. Statistical phrase-based machine translation: Experiments with Brazilian Portuguese. In: Anais do VII Encontro Nacional de Inteligência Artificial. Bento Gonçalves: SBC, 2009. p. 769-778.

BELZ, A.; GATT, A. The attribute selection for GER challenge: Overview and evaluation results. In: Proceedings of $U C N L G+M T$ : Language Generation and Machine Translation. Denmark: Association for Computational Linguistics, 2007. p. 75-83.

BRAUNIAS, J. et al. The GIVE-2 Challenge: Saarland GLN System. 2010.

BRYANT, D. J.; TVERSKY, B.; FRANKLIN, N. Internal and External Spatial Frameworks for Representing Describes Scenes. Journal of Memory and Language, v. 31, p. 74-98, 1992.

BYRON, D. et al. Generating Instructions in Virtual Environments (GIVE): A challenge and evaluation testbed for NLG. In: Proceedings of Workshop on Shared Tasks and Comparative Evaluation in Natural Language Generation. Arlington: Association for Computational Linguistics, 2007. 
BYRON, D. et al. GIVE Generating Instructions in Virtual Environments. In: Proceeding ENLG'09 Proceedings of the 12nd European Workshop on Natural Language Generation. Stroudsburg, PA, USA: Association for Computational Linguistics, 2009.

CHINCHOR, N. MUC-4 evaluation metrics. In: Proceedings of the 4 th conference on Message understanding. Stroudsburg, PA, USA: Association for Computational Linguistics, 1992. (MUC4 '92), p. 22-29. ISBN 1-55860-273-9. Disponível em: $<$ http://dx.doi.org/10.3115/1072064.1072067>.

CUEVAS, R. R. M.; PARABONI, I. A Machine Learning Approach to Portuguese Pronoun Resolution. Advances in Artificial Intelligence-IBERAMIA 2008, SpringerVerlag, LNAI 5290, p. 262-271, 2008.

DALE, R.; HADDOCK, N. J. Content determination in the generation of referring expressions. Computational Intelligence, v. 7, p. 252-265, 1991.

DALE, R.; REITER, E. Computational Interpretations of the Gricean Maxims in the Generation of Referring Expressions. Cognitive Science, Lawrence Erlbaum Associates, Inc., v. 19, n. 2, p. 233-263, 1995. Disponível em: <http://dx.doi.org/10.1207/s15516709cog1902_3>.

DALE, R.; VIETHEN, J. Referring expression generation through attribute-based heuristics. In: Proceedings of the 12th European Workshop on Natural Language Generation. Stroudsburg, PA, USA: Association for Computational Linguistics, 2009. (ENLG '09), p. 58-65.

DICE, L. R. Measures of the Amount of Ecologic Association Between Species. Ecology, v. 26 , n. 3 , p. 297-302, jul. 1945 .

ENGELHARDT, P. E.; DEMIRAL, S. B.; FERREIRA, F. Over-specified referring expressions impair comprehension: An ERP study. Brain and Cognition, 2011.

ENGELHARDT, P. E.; XIANG, M.; FERREIRA, F. Anticipatory eye movements mediated by word order constraints. In: Proceedings of the 30th annual conference of the cognitive science society. Washington, DC, USA: Cognitive Science Society, Inc, 2008. p. 951-957.

FILHO, P. P. B.; PARDO, T. A. S. Summarizing Scientific Texts: Experiments with Extractive Summarizers. In: Proceedings of the Seventh International Conference on Intelligent Systems Design and Applications. Washington, DC, USA: IEEE Computer Society, 2007. (ISDA '07), p. 520-524. ISBN 0-7695-2976-3. Disponível em: $<$ http://dl.acm.org/citation.cfm?id=1317534.1318288>.

FUHR, T. et al. A three-dimensional spatial model for the interpretation of image data. In: In P. Olivier and K. P. Gapp, editors, Representation and Processing of Spatial Expressions. London: Taylor \& Francis, 1998. p. 103-118.

GAPP, K. Angle, distance, shape, and their relationship to projective relations: VITRA. Saarbrücken, Alemanha: Univ. des Saarlandes, FB 14, Informatik IV, 1995. (Bericht). 
GARDENT, C. Generating minimal definite descriptions. In: Proceedings of the 40th Annual Meeting on Association for Computational Linguistics. Stroudsburg, PA, USA: Association for Computational Linguistics, 2002. (ACL '02), p. 96-103. Disponível em: $<$ http://dx.doi.org/10.3115/1073083.1073101>.

GARGETT, A. et al. The GIVE-2 Corpus of Giving Instructions in Virtual Environments. In: CHAIR), N. C. C. et al. (Ed.). Proceedings of the Seventh International Conference on Language Resources and Evaluation (LREC'10). Valletta, Malta: European Language Resources Association (ELRA), 2010. ISBN 2-9517408-6-7.

GATT, A.; BELZ, A.; KOW, E. The TUNA Challenge 2008: Overview and Evaluation Results. In: WHITE, M.; NAKATSU, C.; MCDONALD, D. (Ed.). INLG. Stroudsburg, PA, USA: The Association for Computer Linguistics, 2008.

GATT, A.; BELZ, A.; KOW, E. The TUNA-REG Challenge 2009: Overview and Evaluation Results. In: Proceedings of the 12th European Workshop on Natural Language Generation (ENLG 2009). Athens, Greece: Association for Computational Linguistics, 2009. p. 174-182. Disponível em: <http://www.aclweb.org/anthology/W09-0629>.

GRICE, H. P. Logic and conversation. In: COLE, P.; MORGAN, J. L. (Ed.). Syntax and semantics. New York: Academic Press, 1975. v. 3.

HAJIČOVÁ, E. Issues of Sentence Structure and Discourse Patterns. Prague, Czech Republic: Charles University, 1993.

HALL, M. et al. The WEKA data mining software: an update. In: . New York, NY, USA: ACM, 2009. v. 11, n. 1, p. 10-18. ISSN 1931-0145. Disponível em: <http://doi.acm.org/10.1145/1656274.1656278>.

HORACEK, H. An algorithm for generating referential descriptions with flexible interfaces. In: Proceedings of the eighth conference on European chapter of the Association for Computational Linguistics. Stroudsburg, PA, USA: Association for Computational Linguistics, 1997. (EACL '97), p. 206-213. Disponível em: <http://dx.doi.org/10.3115/979617.979644>.

KELLEHER, J.; GENABITH, J. V. Visual Salience and Reference Resolution in Simulated 3-D Environments. Artif. Intell. Rev., Kluwer Academic Publishers, Norwell, MA, USA, v. 21, p. 253-267, June 2004. ISSN 0269-2821.

KELLEHER, J.; GENABITH, J. V. A Computational Model of the Referential Semantics of Projective Prepositions. In: SAINT-DIZIER, P. (Ed.). Syntax and Semantics of Prepositions. Netherlands: Springer, 2006. p. 211-228.

KELLEHER, J. D.; COSTELLO, F. J. Applying computational models of spatial prepositions to visually situated dialog. Computational Linguistics, MIT Press, Cambridge, MA, USA, v. 35, n. 2, p. 271-306, jun. 2009. ISSN 0891-2017.

KELLEHER, J. D.; KRUIJFF, G.-J. M. Incremental generation of spatial referring expressions in situated dialog. In: Proceedings of the 21st International Conference on Computational Linguistics and the 44th annual meeting of the Association for Computational Linguistics. Stroudsburg, PA, USA: Association 
for Computational Linguistics, 2006. (ACL-44), p. 1041-1048. Disponível em: <http://dx.doi.org/10.3115/1220175.1220306>.

KOLLER, A. et al. Report on the second NLG challenge on generating instructions in virtual environments (GIVE-2). In: Proceedings of the 6th International Natural Language Generation Conference. Stroudsburg, PA, USA: Association for Computational Linguistics, 2010. (INLG '10), p. 243-250. Disponível em: $<$ http://dl.acm.org/citation.cfm?id=1873738.1873776>.

KRAHMER, E.; DEEMTER, K. van. Computational generation of referring expressions: A survey. Computational Linguistics, Cambridge, MA, USA, v. 38, n. 1, p. 173-218, 2012 .

KRAHMER, E.; ERK, S. van; VERLEG, A. Graph-Based Generation of Referring Expressions. Computational Linguistics, v. 29, n. 1, p. 53-72, 2003.

KRAHMER, E.; THEUNE, M. Efficient Context-Sensitive Generation of Referring Expressions. In: DEEMTER, K. van; KIBBLE, R. (Ed.). Information Sharing: Reference and Presupposition in Language Generation and Interpretation. Stanford, CA: CSLI Publications, 2002. p. 223-264.

LAWLER, E. L.; WOOD, D. E. Branch-And-Bound Methods: A Survey. Operations Research, INFORMS, v. 14, n. 4, p. 699-719, 1966. ISSN 0030364X. Disponível em: $<$ http://dx.doi.org/10.2307/168733>.

LUCENA, D. J. de; PEREIRA, D. B.; PARABONI, I. From semantic properties to surface text: The generation of domain object descriptions. Inteligencia Artificial. Revista Iberoamericana de Inteligencia Artificial, Asociacion Espanhola para la Inteligencia Artificial, n. 45, p. 48-58, 2010.

NOVAIS, E. M. de; PARABONI, I. Portuguese text generation using factored language models. Journal of the Brazilian Computer Society, Springer-Verlag, v. 19, p. 135-146, 2012. Disponível em: <http://dx.doi.org/10.1007/s13173-012-0095-1>.

OLIVIER, P.; TSUJII, J.-I. Quantitative perceptual representation of prepositional semantics. Artificial Intelligence Review, Kluwer Academic Publishers, v. 8, n. 2-3, p. $147-$ 158, 1994. ISSN 0269-2821. Disponível em: <http://dx.doi.org/10.1007/BF00849071>.

OTT, L.; LONGNECKER, M. An Introduction to Statistical Methods And Data Analysis. Brooks/Cole Cengage Learning, 2010. (Available 2010 Titles Enhanced Web Assign Series). ISBN 9780495017585. Disponível em: $<$ http://books.google.com.br/books?id=ka9ClH2fZc4C $>$.

PARABONI, I. Uma arquitetura para a resolução de referências pronominais possessivas no processamento de textos em língua portuguesa. Dissertação (Mestrado) - PUCRS, Porto Alegre, 1997.

PARABONI, I. An algorithm for generating document-deictic references. In: Procs. of workshop Coherence in Generated Multimedia, associated with First Int. Conf. on Natural Language Generation (INLG-2000). Israel: Mitzpe Ramon, 2000. p. 27-31. 
PARABONI, I. Generating references in hierarchical domains: the case of Document Deixis. Tese (Doutorado) — University of Brighton, 2003.

PARABONI, I.; DEEMTER, K. van. Issues for the Generation of Document Deixis. In: Procs. of workshop on Deixis, Demonstration and Deictic Belief in Multimedia Contexts, in association with the 11th European Summers School in Logic, Language and Information (esslli99). The Netherlands: Utrecht, 1999. p. 44-48.

PARABONI, I.; DEEMTER, K. van. Generating easy references: the case of document deixis. In: . New York, USA: Information Technology Research Institute, 2002. p. $113-119$.

PARABONI, I.; DEEMTER, K. van. Towards the generation of document-deictic references. In: Information sharing: reference and presupposition in language generation and interpretation. Stanford, USA: CSLI Publications, 2002. p. 329-352.

PARABONI, I.; DEEMTER, K. van. Reference and the Facilitation of Search in Spatial Domains. Language and Cognitive Processes, 2013. Disponível em: $<$ http://dx.doi.org/10.1080/01690965.2013.805796>.

PARABONI, I.; DEEMTER, K. van; MASTHOFF, J. Generating Referring Expressions: Making Referents Easy to Identify. Computational Linguistics, MIT Press, Cambridge, MA, USA, v. 33, p. 229-254, jun. 2007. ISSN 0891-2017. Disponível em: $<$ http://dx.doi.org/10.1162/coli.2007.33.2.229>.

PARABONI, I.; MASTHOFF, J.; DEEMTER, K. van. Overspecified reference in hierarchical domains: measuring the benefits for readers. In: Proceedings of the fourth international natural language generation conference (INLG-2006). Sydney, Australia: Association for Computational Linguistics, 2006. p. 55-62. Disponível em: <http://www.aclweb.org/anthology/W/W06/W06-1409>.

PASSONNEAU, R. Measuring agreement on set-valued items (MASI) for semantic and pragmatic annotation. In: In Proceedings of the International Conference on Language Resources and Evaluation (LREC. Genoa, Italy: ELRA, 2006.

PEREIRA, D. B.; PARABONI, I. A Language Modelling Tool for Statistical NLP. In: 5th Workshop on Information and Human Language Technology (TIL-2007). Anais do XXVII Congresso da SBC. Rio de Janeiro: Sociedade Brasileira de Computação, 2007. p. $1679-1688$.

PEREIRA, D. B.; PARABONI, I. Statistical surface realisation of portuguese referring expressions. Advances in Natural Language Processing, Springer-Verlag, LNAI 5221, p. 383-392, 2008.

POWERS, D. M. W. Evaluation: From Precision, Recall and F-Factor to ROC, Informedness, Markedness $\&$ Correlation. Adelaide, Australia: [S.N], 2007.

RADVANSKY, L. A. C.; LOGAN, G. The influence of reference frame selection on spatial template construction. Journal of Memory and Language, p. 411-437, 1997.

REGIER, T.; CARLSON, L. Grounding spatial language in perception: An empirical and computational investigation. Journal of Experimental Psychology: Genera, p. 273-298, 2001. 
REITER, E.; DALE, R. Building natural language generation systems. New York, NY, USA: Cambridge University Press, 2000. ISBN 0-521-62036-8.

SANTOS, F. M. V. dos; PEREIRA, D. B.; PARABONI, I. Rule-based vs. probabilistic surface realisation of definite description. In: Companion Proceedings of the XIV Brazilian Symposium on Multimedia and the Web. Vila Velha: ACM, 2008. p. 372-374.

SCHUTTE, N.; DETHLEFS, N. The DUBLIN-BREMEN System For the GIVE-2 Challenge. In: In Online Proceedings of the GIVE-2 Challenge. 2010.

SILVA, D. dos S.; PARABONI, I. Geração de expressões de referência usando relações espaciais. In: Proceedings of STIL-2013. Fortaleza, Brasil: Brazilian Conference on Intelligent Systems, 2013.

STRIEGNITZ, K. et al. Report on the Second Second Challenge on Generating Instructions in Virtual Environments (GIVE-2.5). In: Proceedings of the Generation Challenges Session at the 13th European Workshop on Natural Language Generation, Nancy, France. Nancy, France: Association for Computational Linguistics, 2011. p. 270-279. ISBN not assigned.

TURNER, R. et al. Using spatial reference frames to generate grounded textual summaries of georeferenced data. In: Proceedings of the Fifth International Natural Language Generation Conference. Stroudsburg, PA, USA: Association for Computational Linguistics, 2008. (INLG '08), p. 16-24.

VARGES, S. Overgenerating Referring Expressions Involving Relations and Booleans. In: Natural Language Generation. Berlin Heidelberg: Springer, 2004, (Lecture Notes in Computer Science, v. 3123). p. 171-181.

VIETHEN, H. The Generation of Natural Descriptions: Corpus-based Investigations of Referring Expressions in Visual Domains. Tese (Doutorado) - Macquarie University, 2010.

VIETHEN, J.; DALE, R. The use of spatial relations in referring expression generation. In: Proceedings of the Fifth International Natural Language Generation Conference. Stroudsburg, PA, USA: Association for Computational Linguistics, 2008. (INLG '08), p. 59-67.

VIETHEN, J.; DALE, R. GRE3D7: A Corpus of Distinguishing Descriptions for Objects in Visual Scenes. In: Proceedings of the UCNLG+Eval: Language Generation and Evaluation Workshop. Edinburgh, Scotland: Association for Computational Linguistics, 2011. p. $12-22$.

WALKER, M. A. Centering, Anaphora Resolution, and Discourse Structure. In: Centering Theory in Discourse. Oxford, England: Oxford University Press, 1998. p. 401-435.

YAMADA, A. Studies in Spatial Descriptions Understanding Based on Geometric Constraints Satisfaction. Tese (Doutorado) — University of Kyoto, Kyoto, Japan, 1993. 
ZENDER, H.; KRUIJFF, G.-J. M.; KRUIJFF-KORBAYOVá, I. Situated resolution and generation of spatial referring expressions for robotic assistants. In: Proceedings of the 21st international jont conference on Artifical intelligence. San Francisco, CA, USA: Morgan Kaufmann Publishers Inc., 2009. (IJCAI'09), p. 1604-1609. 